\title{
BUBBLY TURBULENCE WITH HEAT TRANSFER
}

Biljana Gvozdić 
Graduation committee

Prof. Dr. Ir. J. W. M. Hilgenkamp (chairman) University of Twente Prof. Dr. D. Lohse (supervisor) University of Twente Prof. Dr. C. Sun (supervisor) Tsinghua University, University of Twente Assistant Prof. Dr. S. G. Huisman (co-supervisor) University of Twente Prof. Dr. Ir. T. H. van der Meer University of Twente Prof. Dr. S. R. A. Kersten University of Twente

Prof. Dr. Ir. A. W. Vreman

Prof. Dr. Ir. N. G. Deen Eindhoven University of Technology Eindhoven University of Technology

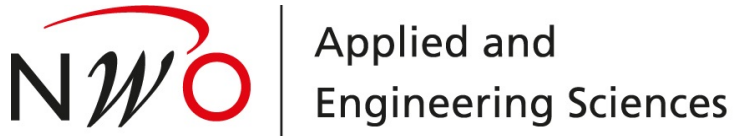

The work in this thesis was carried out at the Physics of Fluids group of the Faculty of Science and Technology of the University of Twente. It is part of the industrial partnership programme: Heat, Mass Transport and Phase Transition in Dense Bubbly Flows of the Dutch organisation for Scientific Research (NWO) and the industrial partners AkzoNobel, DSM, SABIC, Shell and Tata Steel.

Dutch Title:

Warmtetransport in turbulente stromingen met bellen

Cover design: Loreto Oyarte Galvez and Biljana Gvozdić.

Copyright (C) 2018 by Biljana Gvozdić, Enschede, The Netherlands. All rights reserved. No part of this book may be reproduced, stored in a retrieval system, or transmitted in any form or by any means, without the written permission of the author.

Printed by IPSKAMP printing

DOI: $10.3990 / 1.9789036546812$

ISBN: 978-90-365-4681-2

URL: https://doi.org/10.3990/1.9789036546812 


\title{
BUBBLY TURBULENCE WITH HEAT TRANSFER
}

\section{DISSERTATION}

\author{
to obtain \\ the degree of doctor at the University of Twente, \\ on the authority of the rector magnificus, \\ Prof. Dr. T. T. M. Palstra, \\ on account of the decision of the graduation committee, \\ to be publicly defended, \\ on Thursday the 20th of December 2018 at 16:45
}

by

Biljana Gvozdić

Born on $13^{\text {th }}$ October 1990

in Inđija, Serbia 
This dissertation has been approved by the supervisors:

\author{
Prof. Dr. Detlef Lohse \\ Prof. Dr. Chao Sun
}

and the co-supervisor:

Assistant Prof. Dr. Sander G. Huisman 


\section{Contents}

1 Introduction 1

1.1 Heat transfer . . . . . . . . . . . . . . . . . . . . 2

1.2 Canonical systems for natural convection $\ldots \ldots \ldots \ldots$

1.3 Heat transport enhancement . . . . . . . . . . . . . 4

1.4 Outline of the thesis $\ldots \ldots \ldots \ldots \ldots \ldots$

2 Heat transport in homogeneous bubbly flows 9

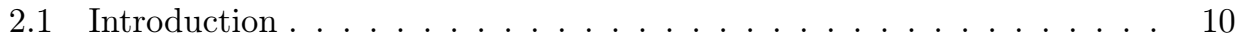

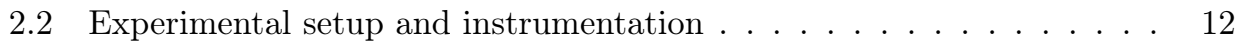

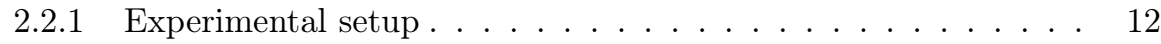

2.2 .2 Single phase vertical convection . . . . . . . . . . . . 14

2.2.3 Instrumentation for the gas phase characterization . . . . . . 14

2.2.4 Instrumentation for the heat flux and temperature measurements 17

2.3 Global heat transport enhancement . . . . . . . . . . . . . . . . 19

2.4 Local characterisation of the heat transport . . . . . . . . . . 22

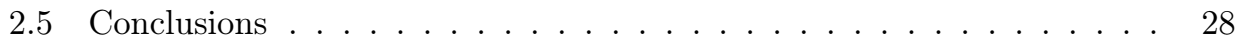

3 Heat transport in inhomogeneous bubbly flows 31

3.1 Introduction . . . . . . . . . . . . . . . . . 32

3.2 Experimental setup and instrumentation . . . . . . . . . . . 34

3.2 .1 Experimental setup . . . . . . . . . . . . . . . . . . 34

3.2.2 Instrumentation for the gas phase characterisation . . . . . . 36

3.2.3 Instrumentation for the liquid phase velocity measurements . . 37

3.2.4 Instrumentation for the heat flux measurements . . . . . . . . 38

3.3 Results . . . . . . . . . . . . . . . . . . . . 38

3.3.1 Global heat transfer enhancement . . . . . . . . . . 38

3.3.2 Local liquid velocity measurements . . . . . . . . . . . . . 43

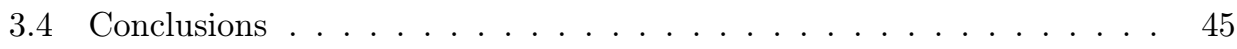


4 Twente Mass and Heat Transfer Water Tunnel 47

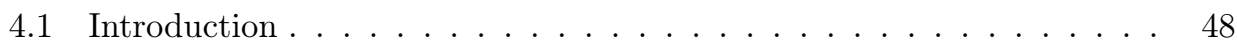

4.2 System description . . . . . . . . . . . . . . . . . . 49

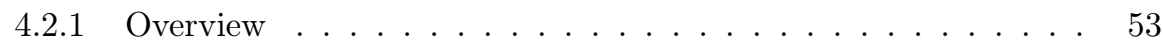

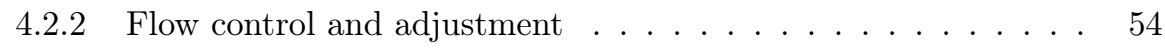

4.2 .3 Temperature control and heat injection $\ldots \ldots \ldots \ldots . \ldots 54$

4.2.4 Local temperature measurements . . . . . . . . . . . . 57

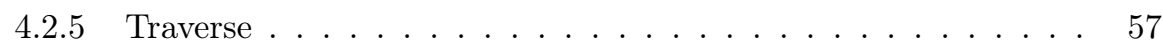

4.2 .6 Bubble injection and gas volume fraction $\ldots \ldots \ldots \ldots$

4.2 .7 Active turbulent grid . . . . . . . . . . . . . . . . . . . 59

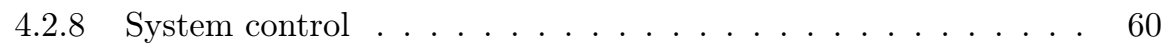

4.3 Measurements . . . . . . . . . . . . . . . . . . . . . 61

4.3.1 Velocity profile measurements . . . . . . . . . . . 6 61

4.3.2 Local temperature measurements . . . . . . . . . . . . 65

4.3.3 Dispersion of a passive scalar in a turbulent bubbly flow . . . 65

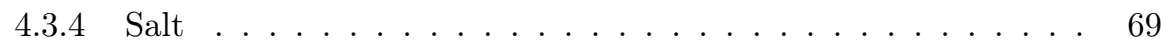

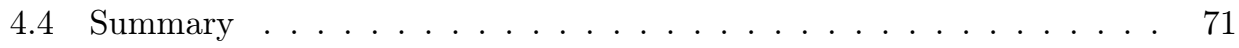

5 Summary and outlook $\quad 73$

$\begin{array}{lr}\text { Samenvatting } & 84\end{array}$

$\begin{array}{lr}\text { Acknowledgments } & 89\end{array}$ 
Chapter 1

\section{Introduction}




\subsection{Heat transfer}

Heat transfer is a non-mechanical way of energy transfer driven by the temperature differences. It is one of the fundamental ways of transport observed in nature, daily activities and industrial applications. For example, warm-blooded animals have a finely tuned biological system to regulate their body temperature by adjusting the rate of internal reactions to produce heat and varying the diameter of blood vessels and blood flow rate as needed. The water cycle, which is one of the fundamental processes relevant for sustaining plant and animal life, relies on thermal energy exchange between water and its environment. Electric cooking involves heat transfer in many stages; for example, boiling starts from warming up the water in a vessel where the heat produced via Joule heating is transferred from the heating elements to the vessel and then to the water. In order to ensure comfort, our homes, offices and vehicles employ a wide variety of devices to exchange thermal energy with the environment [1]. Controlled heat transport is important for functioning of computers, where fans or refrigerants cooling the electrical circuitry ensure error-free operation [2].

Given the importance of heat transport in a wide range of phenomena, it is crucial to understand its fundamentals which can eventually lead to optimal control. The first attempts at actively generating and controlling heat was performed by early humans $\mathcal{O}\left(10^{5}\right)$ years ago when they discovered fire and used it for cooking and keeping warm. Understanding and controlling heat transport is still an active area of research in science and industrial applications and is driven by continuous advancements in experimental, theoretical and computational techniques.

Heat transport can be fundamentally classified into three different modes: (i) conduction: transport of heat across a temperature gradient in a stationary medium, (ii) convection: heat transport by a moving fluid across temperature gradients and (iii) radiation: heat transport in the form of electromagnetic waves in the absence of a medium, for example in vacuum. Figure 1.1 shows some of the several examples where all these processes can work in tandem. In this thesis, we focus on understanding convective heat transport and the influence of bubble injection on the net transport. Additionally, we design and build an experimental facility which is referred to as the Twente Mass and Heat Transfer Water Tunnel (TMHT) with a mean streamwise velocity in the presence of bubble injection where incident turbulence is generated using an active grid. 

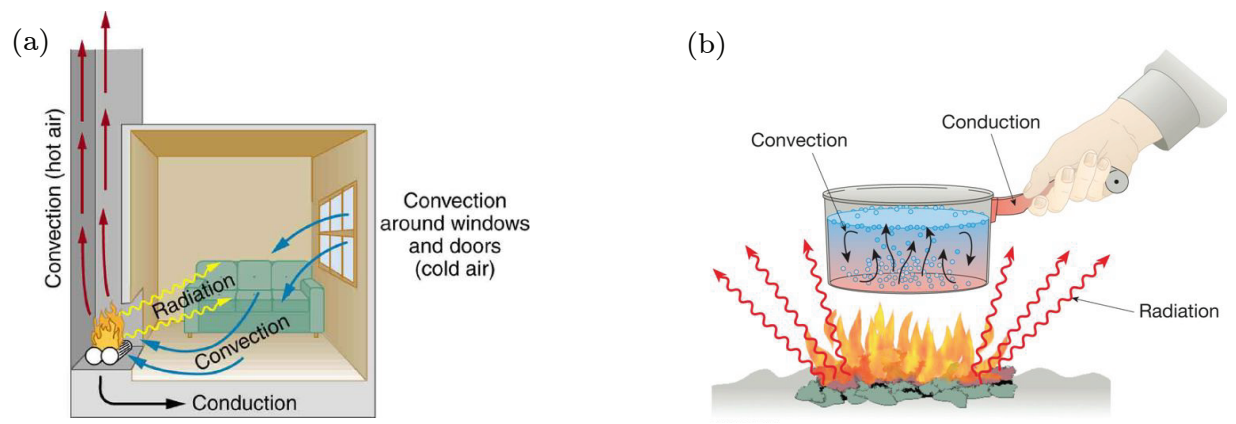

Figure 1.1: Common everyday examples of heat transfer occurring in the house (a) or when heating up water in a vessel (b). (Source for images: (a) cnx.org, (b) www.simscale.com)

\subsection{Canonical systems for natural convection}

As mentioned earlier, convection is a fundamental mode of heat transport driven by the motion of a fluid. A form of convection which is widely observed in many systems is natural convection, where the flow is not driven by any external source (e.g. motor, fan, etc.), but by density differences in the fluid which are in turn generated by temperature gradients. Natural convection is relevant across a wide range of scales. To cite a couple of examples, in the atmosphere, natural convection is observed in the form of air rising above land or water heated by sunlight. At a much smaller length scale, heat generated by computer chips can be transported with the help of natural convection. The onset of natural convection can be determined by the non-dimensional number called the Rayleigh number defined as:

$$
R a=\frac{g \beta \Delta T L^{3}}{\nu \kappa}
$$

$\Delta T$ is the characteristic temperature difference, $L$ is the characteristic length scale, $g$ is the acceleration due to gravity, $\beta, \kappa$ and $\nu$ are the coefficients of thermal expansion, thermal diffusivity and kinematic viscosity of the fluid, respectively.

The simplest system that can be formulated to study and understand natural convection is the Rayleigh-Bènard (RB) flow [3, 4]. In RB flow, the fluid is heated from below and cooled from the top. Below a critical Rayleigh number, conduction is the only mode for heat transport. Beyond the critical $R a$, the system destabilises and the flow is driven by convection. The temperature differences between the bottom and top of the fluid result in a density gradient which leads to a heavier fluid resting on a 
(a)

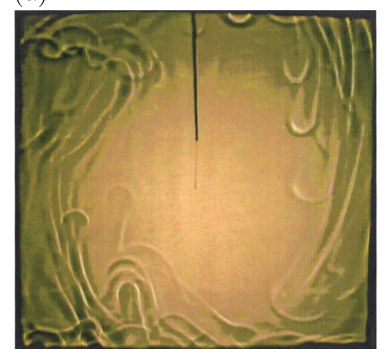

(b)

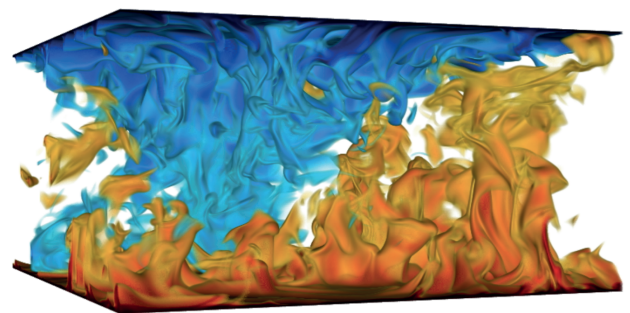

Figure 1.2: Experimental and numerical snapshots of the flow to visualise the spatial distribution of small scale plumes and the large-scale circulation. (a) A shadowgraph snapshot of the mid-plane in a cylindrical apparatus at $R a=7 \times 10^{8}$. Figure adopted from [5]. (b) Snapshot of the three-dimensional temperature field in a numerical simulation at $R a=10^{8}$; red corresponds to a warmer fluid, while blue corresponds to a colder fluid. Figure adopted from [6].

lighter fluid. The increased gravitational pull on the fluid on the top in comparison to the fluid below results in an unstable system. A characteristic feature of convection in such a system is the large-scale circulation (LSC) and thermal plumes which are the main source of heat transport. These plumes carry heat from the hot wall to the cold wall and the collective effect of these plumes generates a large scale coherent roll in the system. Figure 1.2 shows visualisations of these plumes in experiments and numerical simulations.

While the hot and cold walls in classical RB flow are horizontal, one can also observe convective flows when the walls are vertical. This is typically referred to as vertical natural convection (VNC) and is the system used in this thesis to study convection.

\subsection{Heat transport enhancement}

The overall heat transport in natural convection is governed by the geometry, Rayleigh number and Prandtl number of the fluid [7] and the focal point of fundamental research in convective flows has been to understand the relation between them. There are many practical applications where enhancing the heat transport between a solid wall and a fluid is highly desirable. Heat exchangers, which are widely used as thermal systems for domestic, industrial and commercial purposes, require 
enhancement of heat transport for the purpose of reducing the weight and the size or improving the performance. Enhancement of heat transport in chemical reactors is crucial since the yield of chemical reactions can be limited by the heat transport in the reactor, or could lead to unwanted local heat build-up, which can be inefficient and even dangerous. So a natural question is: how can we enhance the heat transport in a convective flow for a given geometry and fluid? While one can easily enhance heat transport by simply increasing the temperature difference, in many cases we are highly constrained by the range of temperature differences that can be practically attained. In RB flow, a variety of heat transfer enhancement mechanisms have been explored in the past which include tuning of the boundary conditions to aid the formation of large scale rolls or coherent structures [8], or introducing wall roughness elements [9-12]. Understanding and developing novel techniques for heat transfer enhancement in natural convection has been of great interest for both fundamental research and industrial applications.

Techniques for enhancement of heat transport in practical applications can be broadly classified as active or passive [13, 14]. Active methods require supply of additional external power either to the heated surface or to the working fluid. Examples of active methods are: inducing motion of the heat transfer surface, coupling of the electric [15, 16] (resp. magnetic [17, 18]) field with the flow field of a dielectric (resp. ferro-fluid) fluid or pulsation of the working fluid [19]. These are promising techniques to enhance heat transfer since a reasonably good control of the flow modification is possible. However, these techniques include additional effort to design and develop a compact and efficient heat exchanger. Passive methods do not require additional supply of energy. These techniques thus involve surface modification (artificial roughness [20], extended surfaces [21-23]) or insertion of swirl devices in the flow (twisted tape [24], coiled wires [25], conical ring [26], winglets [27]). Passive methods are more often present in industrial applications, since they are easier to employ in already existing devices, cheaper, reliable and of simpler design. The disadvantage in passive methods is that it leads to an increased pressure drop which can be detrimental in certain applications and thus more power is needed for driving the fluid.

Another effective way of enhancing heat transport which does not require insertion of additional mechanical parts nor the deformation of the heated surface is the injection of bubbles into the continuous phase. Due to their buoyancy, bubbles rise at a higher velocity than that of the liquid phase, thus inducing perturbation therein. The turbulence induced by bubbles in such a way is commonly called pseudo-turbulence [28-31]. Rising bubbles mix warm and cold parcels of the flow and possibly disturb 
thermal boundary layers, which leads to enhanced mixing and heat and mass transfer [32-34]. Such a technique can be applied in both heat exchangers [35, 36] and chemical reactors $[37,38]$. Bubbly turbulence has led to many application oriented studies where the focus was to formulate empirical correlations for the net heat and mass transfer coefficients [38]. A detailed understanding of the underlying physics is still lacking. Significant research has also been devoted to understanding multiphase convective flows. In particular, boiling in Rayleigh-Bénard flow has been examined both numerically [39-42] and experimentally [43, 44]. However, while in boiling RB it is not straight-forward to control the volume fraction and the size of the bubbles, in vertical natural convection one can inject bubbles of a given size at a constant volume fraction through capillaries at the bottom of the setup. Such a configuration also resembles bubble columns present in the chemical processing industry and it is the focal point of this thesis. What is the effect on the overall heat transport with varying volume fractions of the bubbles? What is the influence of spatial distribution of bubbles on the local and global flow statistics? What are different flow regimes that can be observed in such systems and what is their origin? These are some of the questions explored in this thesis.

\subsection{Outline of the thesis}

This thesis is organised as follows. In $\S 2$, we study the effect of homogeneous bubble injection on heat transfer in a system with vertical natural convection. Experimental measurements were performed with and without the injection of $\sim 2.5 \mathrm{~mm}$ diameter bubbles in a rectangular water column heated from one side and cooled from the other. We characterize the global heat flux and the local temperature fluctuations induced by bubble injection.

In $\S 3$ we study the heat transport in inhomogeneous bubbly flow using the same experimental setup as in $\S 2$ with millimetric bubbles introduced only through one half of the injection section (close to the hot wall or close to the cold wall). Inhomogeneous injection leads to an effective shear generated by bubbles rising on one side of the setup, which eventually leads a variety of flow regimes not observable in the case of homogeneous injection. We characterise the global heat transport while varying two parameters: the gas volume fraction $\alpha=0.4 \%-5.1 \%$, and the Rayleigh number $R a_{H}=4 \times 10^{9}-2.2 \times 10^{10}$. Using imaging and Laser Doppler Anemometry (LDA) we capture the different flow regimes which occur with increasing gas flow rates. We compare our results with the findings for heat transport in homogeneous bubbly flow from $\S 2$. 
In $\S 4$ we present the newly built experimental setup Twente Mass and Heat Transfer Water Tunnel. The new vertical water tunnel with global temperature control, bubble injection and local heat/mass injection offers the possibility to accurately study heat and mass transfer in turbulent multiphase flow. We present the flow characterisation, preliminary temperature measurements and the measurements with addition of salt and the dye injection. We conclude the thesis in $\S 5$ with a summary and an outlook on future work. 


\section{Chapter 2}

\section{Heat transport in homogeneous bubbly flows}

Based on: Biljana Gvozdić, Elise Alméras, Varghese Mathai, Xiaojue Zhu, Dennis P. M. van Gils, Roberto Verzicco, Sander G. Huisman, Chao Sun, Detlef Lohse , 'Experimental investigation of heat transport in homogeneous bubbly flows' Journal of Fluid Mechanics, Vol. 845, 226-244, 2018. 


\subsection{Introduction}

In this chapter we experimentally study the effect of homogeneous injection of millimetric bubbles on the heat transfer globally and locally. We focus on understanding the difference in the liquid temperature fluctuations and the global heat flux between the cases with and without bubble injection. As discussed in $\S 1$, injection of bubbles in the flow enhances the heat transport considerably [37]. In general, the bubbles can be injected in a quiescent liquid phase ("pseudo-turbulent" flow [28-31]) or in an already turbulent liquid phase (turbulent bubbly flow [45-49]). The motion of injected bubbles induces mixing of warm and cold parcels of the liquid phase, which in industrial applications can lead to $\mathcal{O}\left(10^{2}\right)$ times increase in heat transfer coefficient when compared to flows without bubbles [37]. Therefore there is a practical benefit for a better understanding of the heat transport in bubbly flows as this enables better design and optimization of the industrial processes. As a result, the effect of bubbles on heat transfer has been subject of several experimental and numerical studies in the past.

The bubbles can be injected in a system with natural or forced convection. Early studies which focused on forced convective heat transfer in bubbly flows [50-52] showed that the bubbles modify the temperature profile and that higher void fractions close to the heated wall lead to an enhanced heat transfer. In a more recent numerical study on forced convective heat transfer in turbulent bubbly flow in vertical channels, Dabiri and Tryggvason (2015) [53] showed that both, nearly spherical and deformable bubbles improve the heat transfer rate. They found that a $3 \%$ volume fraction of bubbles increases the Nusselt number by $60 \%$.

Studies on natural convection in bubbly flows have been performed mostly by introducing micro-bubbles [54,55] and sub-millimeter-bubbles [56] close to the heated wall. Among these, the micro-bubbles (mean bubble diameter $d_{b u b}=0.04 \mathrm{~mm}$ ) showed higher heat transfer enhancement as compared to sub-millimeter-bubbles $\left(d_{b u b}=0.5 \mathrm{~mm}\right)[56]$. The authors stated that this occurred because the micro-bubbles form large bubble swarms which rise close to the wall and enhance mixing in the direction of the temperature gradient, while sub-millimeter bubbles, owing to their weak wake and low bubble number density, resulted in limited mixing. In contrast, in case of bubbles with diameter of a few millimeters, the wake of individual bubbles and vortex shedding behind the bubbles play a significant role in the heat transfer enhancement [56]. Tokuhiro and Lykoudi (1994) [32] experimentally studied the effects of $2-4 \mathrm{~mm}$ diameter inhomogeneously injected nitrogen-bubbles on laminar and turbulent natural convection heat transfer from a vertical heated 
plate in mercury. They reported a twofold increase in the heat transfer coefficient as compared to the case without bubbles. Similarly, Deen and Kuipers (2013) [33] showed in their numerical study that a few high Reynolds number bubbles rising in quiescent liquid could increase the local heat transfer between the liquid and a hot wall.

In systems with natural convection bubbles can be introduced through boiling as well. Some of the studies on this subject have been performed for Rayleigh-Bénard convection. The Rayleigh-Bénard system consists of a flow confined between two horizontal parallel plates, where the bottom plate is heated and the top one is cooled $[3,4]$. In case of boiling it has been found that bubbles strongly affect velocity and temperature fields depending on the Jakob number which is defined as a ratio of latent heat to sensible heat [39-41]. Numerical studies performed by Lakkaraju et al. (2013) [42] found that depending on the number of the bubbles and superheat the heat transfer can be enhanced up to around 6 times. In an attempt to control the bubble nucleation process, Guzman et al. (2016a,b) [43, 44] performed an experimental study where they varied the geometry of the nucleation sites of the bubbles and found that the heat transfer could be enhanced up to $50 \%$.

To summarize, previous studies (performed in systems with natural convection) mostly focused either on heat transfer in inhomogeneous bubbly flow, where bubbles of different sizes were introduced close to the hot wall, and where the thermal stability of the used setups remained unclear, or the studies were performed in a well-defined Rayleigh-Bénard system, but in this case the bubbles mainly consisted of vapour where bubble volume fraction and the bubble size varied spatially and temporally due to evaporation and condensation.

In this study on heat transfer in bubbly flow we choose a different approach. Firstly, we use a rectangular water column heated from one side and cooled from the other (see figure 2.1) which resembles the classical vertical natural convection system. Secondly, at the bottom of the setup we homogeneously inject millimetric-bubbles, so that in the bubbly case pseudo-turbulent flow is present, the dynamics of which is adequately characterized and broadly studied in the past. We characterise the global heat transfer in both the single- and two-phase flow cases with the goal of understanding how the imposed temperature difference (characterised by the the Rayleigh number $R a_{H}$ ) influences the heat flux (characterised by the Nusselt number $\overline{N u}$ ) for various gas volume fractions $\alpha$, in order to try to better understand the mechanism of heat transport enhancement. The characterization of the global heat transfer is based on the calculation of the dimensionless temperature difference, the 
Rayleigh number:

$$
R a_{H}=\frac{g \beta\left(\overline{T_{h}}-\overline{T_{c}}\right) H^{3}}{\nu \kappa} ;
$$

and the dimensionless heat transfer rate, the Nusselt number:

$$
\overline{N u}=\frac{Q / A}{\chi\left(\overline{T_{h}}-\overline{T_{c}}\right) / L} .
$$

Here, $Q$ is the measured power supplied to the heaters, $\overline{T_{h}}$ and $\overline{T_{c}}$ are the mean temperatures of the hot and cold walls, respectively, $L$ is the length of the setup, $A$ is the surface of the sidewall, $\beta$ is the thermal expansion coefficient, $g$ the gravitational acceleration, $\kappa$ the thermal diffusivity, and $\chi$ the thermal conductivity of water. In this study we choose the height to be the characteristic length scale for $R a_{H}$ since the boundary layer regime is present (see Section 3.3.1), where the velocity is predominately in the vertical direction. Note that in this study the Prandtl number is nearly constant, $\operatorname{Pr} \equiv \frac{\nu}{\kappa}=6.5 \pm 0.3$.

Furthermore, we perform temperature profile measurements with and without bubble injection, by traversing a small thermistor along the length of the setup at the mid-height. In this way we obtain information on the statistics of the temperature fluctuations and on the power spectrum of the temperature fluctuations in a homogeneous bubbly flow.

\subsection{Experimental setup and instrumentation}

\subsubsection{Experimental setup}

The experiments were performed in a rectangular bubble column $(600 \times 230 \times$ $60 \mathrm{~mm}^{3}$ ), shown in figure 3.1. Air bubbles of about $2.5 \mathrm{~mm}$ diameter were injected into quiescent demineralized water using 180 capillaries (inner diameter $0.21 \mathrm{~mm}$ ) uniformly distributed over the bottom of the column. The gas volume fraction was varied from $0.5 \%$ to $5 \%$ by controlling the inlet gas flow rate via a digital mass flow controller (Bronkhorst F-111AC-50K-AAD-22-V). The two main sidewalls of the setup $\left(600 \times 230 \mathrm{~mm}^{2}\right)$ were made of $1 \mathrm{~cm}$ thick glass and two (heated resp. cooled) sidewalls $\left(600 \times 60 \mathrm{~mm}^{2}\right)$ of $1.3 \mathrm{~cm}$ thick brass.

As mentioned previously, our setup resembles one for vertical natural convection since one brass sidewall is heated and the other is cooled in order to generate a horizontal temperature gradient in the setup. More precisely, heating was provided by placing three etched-foil heaters on the outer side of the hot wall. Heaters were 


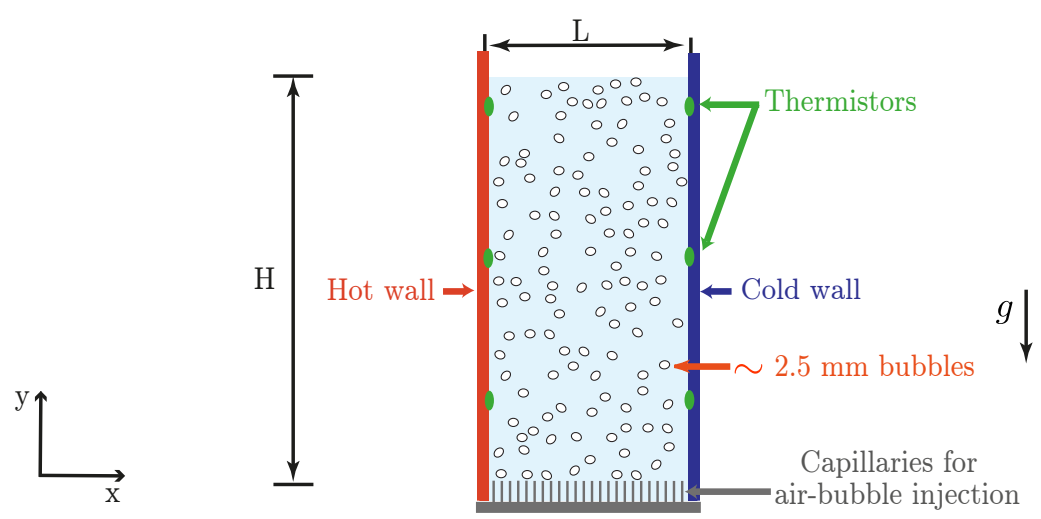

Figure 2.1: Rectangular bubbly column heated from one sidewall and cooled from the other $(H=500 \mathrm{~mm}, L=230 \mathrm{~mm})$. Bubbles of about $2.5 \mathrm{~mm}$ diameter were injected through 180 capillaries placed at the bottom of the setup (inner diameter $0.21 \mathrm{~mm}$ ).

connected in parallel to a digitally controlled power supply (Keysight N8741A), providing altogether up to $300 \mathrm{~W}$. The other brass wall was cooled by a water circulating bath (Polytemp PD15R-30). The temperature of the heated and the cooled walls was monitored by three thermistors which were glued on different heights of the cold and warm walls, namely at $125 \mathrm{~mm}, 315 \mathrm{~mm}$, and $505 \mathrm{~mm}$. Temperature regulation of both the cold and warm walls was achieved by PID (Proportional-Integral-Derivative) control so that the mean temperature of the walls was maintained constant over time. In order to limit the heat losses, the setup was wrapped in several layers of insulating blanket and foam. Moreover, an aluminium plate with heaters attached to it was placed on the outer side of the hot wall and maintained at the same temperature as the hot wall to act as a temperature shield.

Heat losses were estimated to be not more than $7 \%$ by calculating convective heat transport rate from all outer surfaces of the setup with the assumption that these surfaces are at maximum $25^{\circ} \mathrm{C}$. On the other hand, we measured the power needed to maintain the temperature of the bulk constant $\left(T_{\text {bulk }}=25^{\circ} \mathrm{C}\right)$ over 4 hours. Power supplied to the heaters in that way is not more that $3 \%$ of the total power needed when running the actual experiments in which the bulk temperature is also 25 degrees. We therefore expect the actual heat losses to be in the range of $3 \%$ to $7 \%$ which enables us to study precisely the heat transport driven by a horizontal temperature gradient in a bubbly flow. 


\subsubsection{Single phase vertical convection}

The single-phase heat transport will be used as a reference for the heat transport enhancement by bubble injection. In a single-phase system a variety of flow regimes can be observed depending on the height $H$, the length $L$, and the Rayleigh number $R a_{H}$ of the system [57]. For the parameter range studied here $(H / L=2.4$ and $R a_{H}=4.0 \times 10^{9}-1.2 \times 10^{11}$ ) we expect the system to be in a boundary layer dominant regime. In this regime the boundary layers which distinctly form along the heated and cooled sidewalls control the heat transfer, while the bulk of the fluid is relatively stagnant. Furthermore, previous studies on single-phase vertical convection describe the dependence of Nusselt number on the Rayleigh number in the power law form $N u \sim R a^{\beta}$ at fixed $P r$, with exponent $\beta$ ranging between $1 / 4$ and $1 / 3$ (see $[58,59]$ and references within). We find that for the range of $R a_{H}$ studied here the effective scaling exponent is $\beta \approx 0.33 \pm 0.02$, which lies within the expected range as can be seen on the compensated plot in figure 2.2 .

For the single phase flow we benchmark the heat transfer against direct numerical simulations (DNS). For this purpose an in-house second order finite difference code $[60,61]$ was used to solve the three-dimensional Boussinesq equations for the single phase vertical convection. The code has been extensively validated and used for Rayleigh-Bénard flow [60,61], in which the only difference is the direction of the buoyancy force. The computational box has the same size as has been employed in the experiments. The no-slip boundary conditions are adopted for the velocity at all solid boundaries. At the top and bottom walls, the heat-insulating conditions are employed, and at the left and right plates, constant temperatures are prescribed. The resolution of the simulations is fine enough to guarantee that the results are grid-independent. Figure 2.2 shows good agreement between numerical and experimental results, within the range of uncertainty. As the experimental setup was not completely insulated at the top and due to unavoidable heat losses to the outside, the experimentally obtained $\overline{N u}$ are slightly higher.

\subsubsection{Instrumentation for the gas phase characterization}

The homogeneity of the bubble swarm was verified by measuring the gas volume fraction $\alpha$ at different locations within the flow by means of a single optical fiber probe. In the absence of a temperature gradient, we observe that $\alpha$ is nearly uniform along the length $L$ and height $H$ of the setup (see figure 2.3 (a)). We also note that no large-scale clustering is present, since the cumulative distribution function $F(\Delta t)$ of the time between consecutive bubbles $\Delta t$ is Poissonian (see figure 2.3 (b) and [28] 


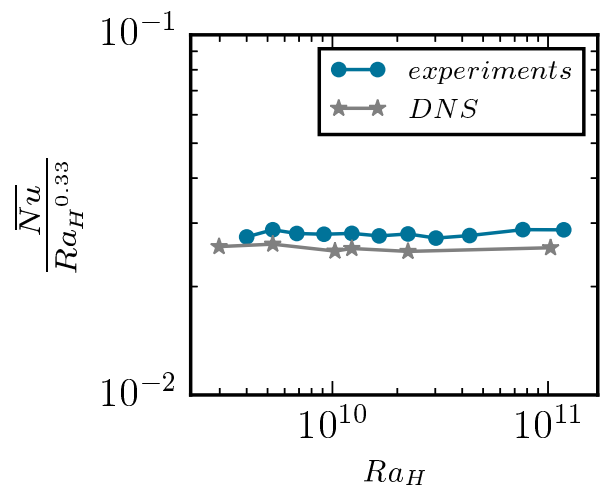

Figure 2.2: Compensated form of the dependence of Nusselt number $\overline{N u}$ on the Rayleigh number $R a_{H}$ for single phase case

(a)

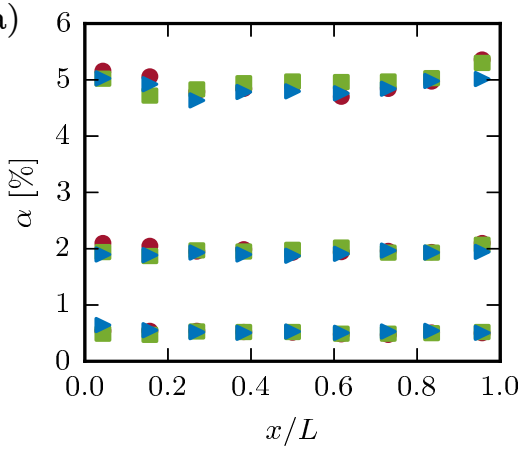

(b)

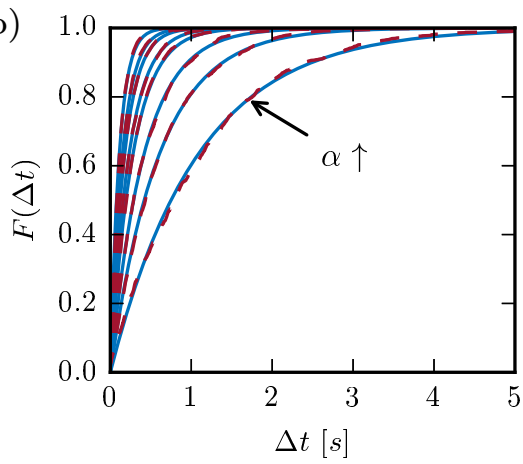

Figure 2.3: (a) Gas volume fraction $\alpha$ at different measurement positions in the experimental setup: $>H=125 \mathrm{~mm},-H=315 \mathrm{~mm},-H=505 \mathrm{~mm}$; (b) Cumulative distribution function of the time interval between consecutive bubbles in the center of the setup for $\alpha=0.3 \%, 0.5 \%, 0.9 \%, 1.5 \%, 2 \%, 3.0 \%, 3.9 \%$ and $6.0 \%$, respectively. 


\begin{tabular}{|c|c|c|}
\hline $\begin{array}{l}\text { this study } \\
+\quad \text { Almeras (2014) }\end{array}$ & $\square$ & $\begin{array}{l}\text { Riboux et al. (2010), } d_{e q}=2.1 \mathrm{~mm} \\
\text { Riboux et al. }(2010), d_{e q}=2.5 \mathrm{~mm}\end{array}$ \\
\hline
\end{tabular}
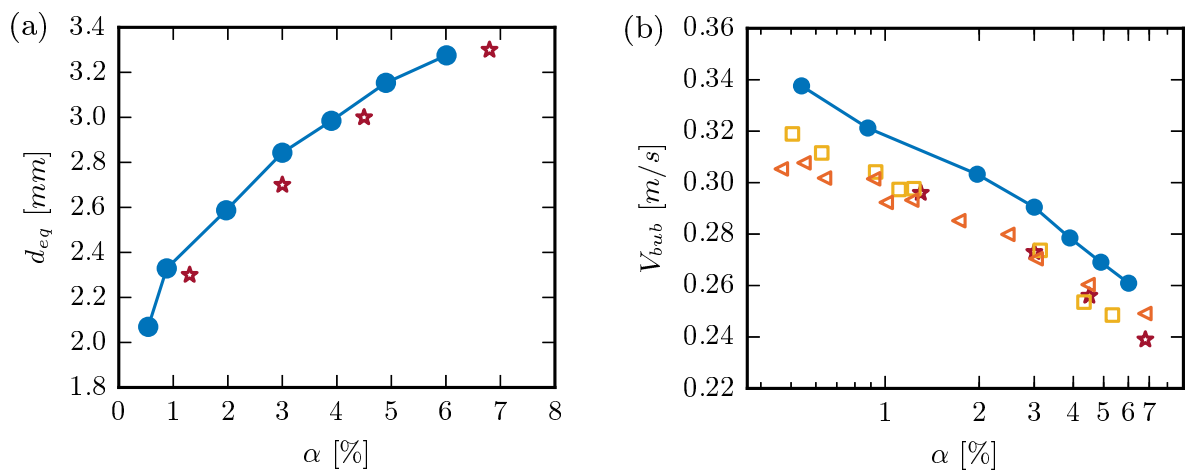

Figure 2.4: (a) Mean bubble diameter $d_{e q}$ and (b) bubble rise velocity $V_{b u b}$ for the studied gas volume fractions $\alpha$, in comparison to different experimental studies.

for more details). In presence of the heating, the homogeneity of the swarm was comparable to that without heating, with not more than $2 \%$ variation. The bubble swarm thus remained homogeneous even with heating, indicating that the bubbly flow was not destabilised by the temperature gradient. We further characterised the gas phase by measuring the bubble diameter and the bubble rising velocity with an in-house dual optical fiber probe [62]. Bubble diameter $d_{e q}$ and bubble rise velocity $V_{b}$ lie in the ranges $[2.1,3.4] \mathrm{mm}$ and $[0.24,0.34] \mathrm{m} / \mathrm{s}$, respectively (see figure 2.4 (a) $\&(\mathrm{~b}))$, resulting in a bubble Reynolds number $R e_{b}=V_{b} d_{e q} / \nu \approx 600$. The bubble rise velocity follows the same trend as previously observed by Riboux et al. (2010) [29], namely it evolves roughly as $V_{b u b} \propto \alpha^{-0.1}$. These values of bubble diameter (resp. bubble velocities) fall within the expected range for this configuration of needle injection (resp. bubble diameter). Once compared to those found by Riboux et al. (2010) [29] and Alméras et al. (2014) [63], we find up to $6 \%$ variation which is acceptable since it can be attributed to slightly different bubble injection section and water quality. 


\subsubsection{Instrumentation for the heat flux and temperature measurements}

In the present study, we performed global and local characterisations of the heat transfer. In order to obtain $\overline{N u}$ and $R a_{H}$, we measured the hot and cold wall temperatures, and the heat input to the system $Q$. To this end, resistances of the thermistors placed on the hot and cold walls were read out every 4.2 seconds using a digital multimeter (Keysight 34970A). The temperature is then converted from the resistances based on the calibrations of the individual thermistors. The total heater power input was measured as $Q=\sum Q_{i}=Q_{i}=I_{i} \cdot V_{i}$, where $I_{i}$ and $V_{i}$ are the current and voltage across each heater, respectively. The experimental measurements were performed after steady state was achieved in which the mean wall temperatures fluctuated less that $\pm 0.01 \mathrm{~K}$ (resp. $\pm 0.1 \mathrm{~K}$ ) for lowest $R a_{H}$ and $\pm 0.4 \mathrm{~K}$ (resp. \pm 0.5 $\mathrm{K})$ for highest $R a_{H}$, for single-phase (resp. two-phase) case. Time averaging of the instantaneous power supplied to each heater $Q_{i}$ was then performed over a total time period of 6 hours for single-phase cases, and 3 hours for two-phase cases.

For a better understanding of the heat transfer, we performed local measurements of the liquid temperature fluctuations: $T^{\prime}=T-\langle T\rangle$, where $T^{\prime}$ - temperature fluctuations, $T$ - measured instantaneous temperature and $\langle T\rangle$ - time averaged temperature at the measurement point. For each operating condition, temperature fluctuations were recorded for at least $180 \mathrm{~min}$ (resp. $360 \mathrm{~min}$ ) in two-phase (resp. single-phase) case once the flow was stable, which yields satisfactory statistical convergence. We used a NTC miniature thermistor manufactured by TE connectivity (Measurement Specialties G22K7MCD419) with a tip diameter of $0.38 \mathrm{~mm}$, and a response time of $30 \mathrm{~ms}$ in water. The thermistor was connected as one arm of a Wheatstone bridge so that very small variations of the thermistors' resistance could be measured. For noise reduction we used a Lock-In amplifier (SR830). The function of the Lock-In amplifier is to firstly supply voltage to the bridge and then filter out noise at frequencies which are different from that of the signal range. This ensured milli-Kelvin resolution of the temperature fluctuations. In order to measure the temperature with this resolution reliably, the thermistors were calibrated in a circulating bath with $5 \mathrm{mK}$ stability. A typical obtained signals in single - phase and two-phase are presented in the figure $2.5 \mathrm{a}$ ) and b), respectively. It is interesting to note that the temperature fluctuations are up to 200 times stronger in the two-phase case and this will be discussed in Section 2.4.

The local temperature measurement technique used here is well established for single - phase flow [64]; however, until now it has never been used for temperature fluctuations measurements in bubbly flows. Since the presence of bubbles may perturb 

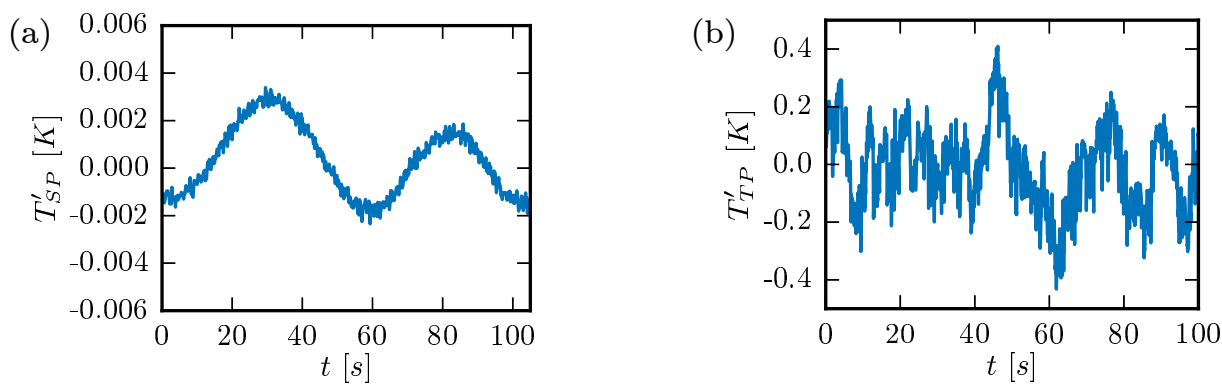

(c)

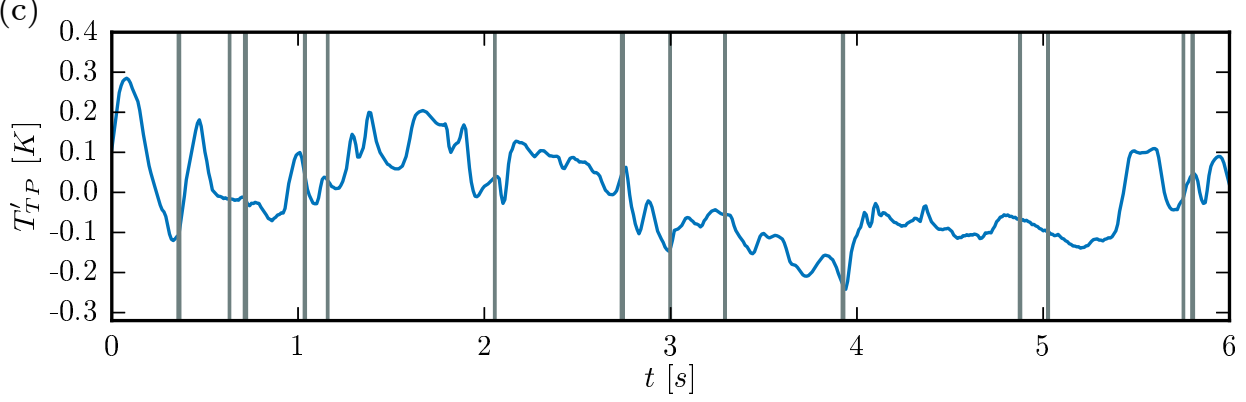

Figure 2.5: Signal of the temperature fluctuations at $L=11.5 \mathrm{~cm}$ for $R a_{H}=2.2 \times 10^{10}$ in (a) single-phase flow $T_{S P}^{\prime}$ (observed frequency of around $10^{-2} \mathrm{~Hz}$ corresponds to large scale circulation frequency, which is addressed in Section 2.4), (b) two-phase flow $\alpha=0.9 \% T_{T P}^{\prime}$, and (c) enlarged simultaneously obtained temperature fluctuations and optical fiber signal where each gray vertical line is a passage of a single bubble. 


\begin{tabular}{r||r|r|r|r|r|r|}
$\alpha[\%]$ & 0.5 & 0.9 & 2.0 & 3.1 & 3.9 & 5.0 \\
$t_{2 b}[\mathrm{~ms}]$ & 590 & 400 & 222 & 167 & 143 & 123 \\
$t_{\text {int }}[\mathrm{ms}]$ & 6.2 & 7.2 & 8.5 & 9.8 & 10.7 & 11.7
\end{tabular}

Table 2.1: Measured mean time between bubble passages $t_{2 b}$ and estimated time of bubble-thermistor contact $t_{\text {int }}$ for the studied gas volume fractions $\alpha$.

the local measurements by interacting directly with the probe [31, 45], it is necessary to validate the technique for two-phase flow. For this purpose we made an in-house probe in which an optical fiber and the thermistor were positioned $\sim 1 \mathrm{~mm}$ apart in the horizontal plane and with the thermistor placed $\sim 1 \mathrm{~mm}$ below the fiber tip. Figure $2.5 \mathrm{c}$ ) shows typical thermistor (blue line) and optical fiber (vertical gray lines) signals simultaneously obtained. The optical fiber allows us to detect the presence of the bubble at the probe tip; it was thus possible to remove parts of the temperature signal corresponding to bubble-probe collisions [31], and to compare the statistical properties of this truncated temperature signal with the original signal. The difference in the statistics (mean, standard deviation, kurtosis, skewness) obtained from the original and the truncated signal was minor $(\approx 0.05 \%)$. This suggests that the short durations of the bubble-thermistor contact $\left(t_{i n t}=d_{e q} / V_{b u b}=7.2 \mathrm{~ms}\right.$ for $\alpha=0.9 \%)$ were filtered out due to the longer response time of the thermistor $\left(t_{r} \sim 30\right.$ $\mathrm{ms})$. Nevertheless, the thermistor response time is sufficiently short to measure the temperature fluctuations between two bubble passages. From table 2.1 we see that $t_{2 b}$ is sufficiently long when compared to $t_{r}$ even for higher gas volume fractions. Furthermore, the estimated time of the bubble-thermistor contact remains much shorter than $t_{r}$ for $\alpha$ up to $5 \%$ (see table 2.1). The present measurement technique is thus suitable for measurements of the temperature fluctuations in the liquid phase not only for $\alpha=0.9 \%$, but also for higher gas volume fractions.

\subsection{Global heat transport enhancement}

Let us now discuss the heat transport in the presence of a homogeneous bubble swarm for gas volume fraction $\alpha$ ranging from $0.5 \%$ to $5 \%$, and the Rayleigh number ranging from $4.0 \times 10^{9}$ to utmost $3.6 \times 10^{10}$ (see Figure 3.5). For the whole range of $\alpha$ and $R a_{H}$, adding bubbles considerably increases the heat transport, since the Nusselt number is about an order of magnitude higher as compared to single-phase flow (see 


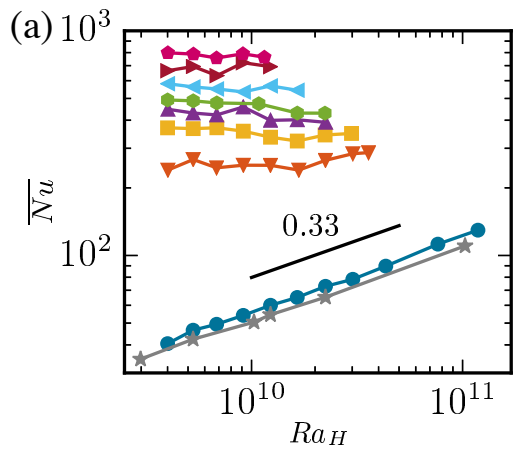

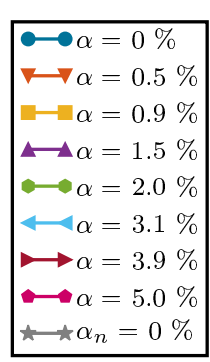

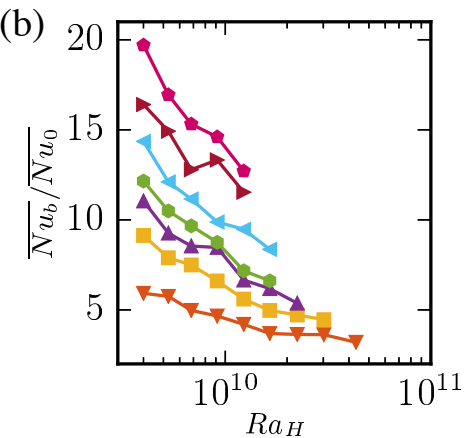

Figure 2.6: (a) Dependence of Nusselt number $\overline{N u}$ on the Rayleigh $R a_{H}$ number for different gas volume fractions ( $\alpha$ - experimental data, $\alpha_{n}$ - numerical simulations) the size of the symbol corresponds to the error-bar, (b) Heat transfer enhancement, $\overline{N u}_{0}$ - Nusselt number in single-phase case, $\overline{N u}_{b}$ - Nusselt in bubbly flow.

figure $3.5(\mathrm{a})$ ). In order to better quantify the heat transport enhancement due to bubble injection, we show in figure 3.5 (b) the ratio of the Nusselt number in the bubbly flow $\overline{N u_{b}}$ to the Nusselt number in the single-phase $\overline{N u_{0}}$ as a function of $R a_{H}$ for different $\alpha$. We find that heat transfer is enhanced up to 20 times due to bubble injection, and that the enhancement increases with increasing $\alpha$ and decreasing $R a_{H}$. Note that the decreasing trend of $\overline{N u_{b}} / \overline{N u_{0}}$ with $R a_{H}$ occurs because the single-phase heat flux $\overline{N u_{0}}$ increases with $R a_{H}$.

Figure 3.5 (a) also shows that for a fixed $\alpha \geq 0.5 \% \overline{N u}$ remains nearly constant with increasing $R a_{H}$. This indicates that the boundary layers developing along the walls are not limiting the heat transport anymore in the two-phase case. Together with the observation that the heating does not induce a gradient in the gas volume fraction profile (see Figure 2.7), this further implies that the temperature behaves as a passive scalar in bubbly flow. In order to understand the mechanism of the heat transport in bubbly flow we compare the findings of our study to those of Alméras et al. (2015) [65], who showed that the transport of a passive scalar at high Péclet number $\left(P e=V_{b u b} d_{e q} / D \approx 10^{6}\right.$, with $V_{b u b}$ as the bubble velocity and $d_{e q}$ as the bubble diameter and $D$ as molecular diffusivity) by a homogeneous bubble swarm is a diffusive process. In the case of a diffusive process, the turbulent heat flux can be modeled as $\overline{u_{i}^{\prime} T^{\prime}}=-D_{i i} \nabla \bar{T}$, introducing the effective diffusivity $D_{i i}$. If we take the heat transport to be a diffusive process in our study, the Nusselt number can be interpreted as the ratio between the effective diffusivity induced by the bubble swarm $D_{i i}$ and the thermal diffusivity $\chi$. Thus, from our measurements we can estimate the 


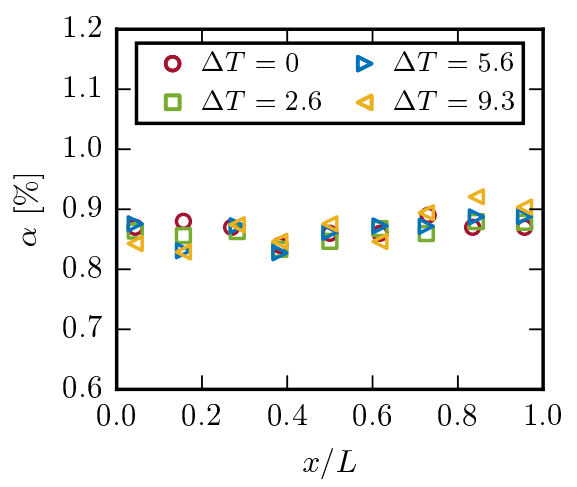

Figure 2.7: The profile of the gas volume fraction for $\alpha=0.9 \%$ at half height for different imposed temperature differences between hot and cold wall $\Delta T$.

effective diffusivity induced by a bubble swarm for a gas volume fraction ranging from $0.5 \%$ to $5 \%$. Note that since the temperature gradient is imposed in the horizontal direction, we assume that the measured effective diffusivity is mainly in the horizontal direction. Figure 3.6 (a) shows the Nusselt number $\langle\overline{N u}\rangle$ averaged over the full range of Rayleigh number for a constant gas volume fraction as a function of $\alpha$. We clearly see that the averaged Nusselt number evolves as $\alpha^{0.45 \pm 0.025}$. Even if we subtract the single-phase Nusselt number (which might be thought of as the contribution of natural convection to the total heat transfer) from the one in bubbly flow the scaling remains unchanged (see figure $3.6(\mathrm{~b})$ ). This trend is in a good agreement with the model of effective diffusivity proposed by Alméras et al. (2015) [65]. In fact, the authors showed that at low gas volume fraction, the diffusion coefficient can be written as: $D_{i i} \propto u^{\prime} \Lambda$, where $u^{\prime}$ is the standard deviation of the velocity fluctuations, and $\Lambda$ is the integral Lagrangian length scale $\left(\Lambda \simeq d_{b u b} / C_{d 0}, C_{d 0}=4 d_{b u b} g / 3 V_{0}^{2}\right.$, here $C_{d 0}$ is the drag coefficient and $V_{0}$ is the rise velocity of a single bubble [29]). In the expression for the diffusion coefficient only the $u^{\prime}$ depends on the gas volume fraction and this dependence is given by $u^{\prime} \sim V_{0} \alpha^{0.4}$ [28]. In the present study, we expect to have a similar liquid agitation since bubble rising velocity and diameter are comparable. This yields the same evolution of the effective diffusivity $D_{i i}$ with the gas volume fraction $\alpha$ namely, $D_{i i} \propto \alpha^{0.45}$, extending the model proposed by Alméras et al. (2015) [65] to lower Péclet number ( $P e \approx 5000$ in this study). We also must stress here that the influence of the Péclet number on the effective diffusivity can be significant. In fact, numerical simulation performed by Loisy (2016) [66], at $\alpha=2.4 \%$ and $R e_{b}=30$ show that the effective diffusivity normalised by the molecular/thermal diffusivity varies 

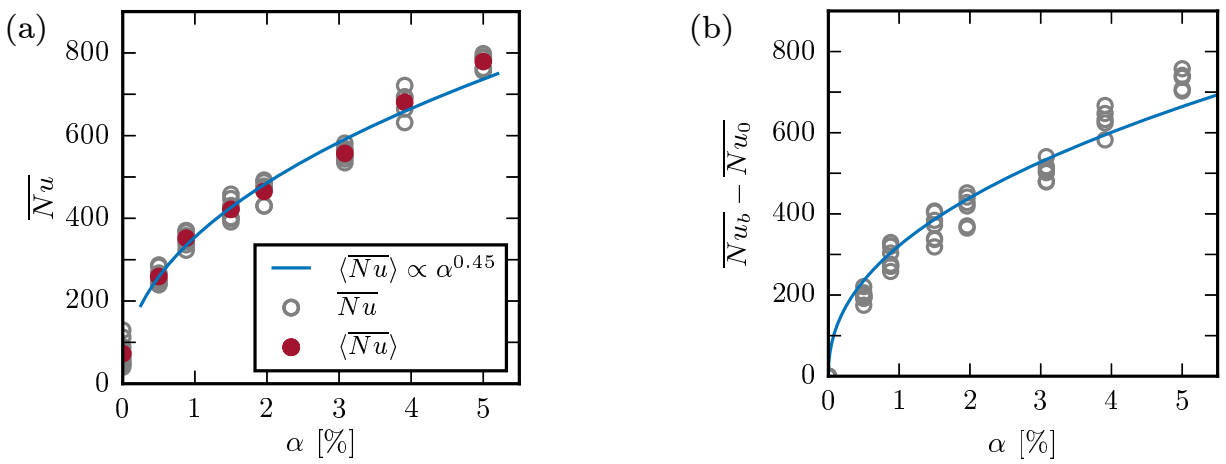

Figure 2.8: (a) Dependence of Nusselt number $\overline{N u}$ on gas volume fraction $\alpha$ (shallow gray circles present all the experimental measurements, red circles are values of Nusselt number averaged over the studied range of $R a_{H}$ for each gas volume fraction); (b) The scaling of the difference between Nusselt number in bubbly flow $\overline{N u}_{b}$ and Nusselt in single-phase case $\overline{N u}_{0}$ as a function of $\alpha$, blue curve corresponds to $\overline{N u_{b}}-\overline{N u_{0}} \propto \alpha^{0.45}$.

linearly with the Péclet number (for $P e$ ranging from $10^{3}$ to $10^{6}$ ). Consequently, since the Péclet number varies by three decades between the present study and the one of Alméras et al. (2015) [65], no quantitative comparison of the effective diffusivity can be performed. Therefore, further studies on the effect of the Péclet number on the effective diffusivity at high Reynolds number should be performed.

\subsection{Local characterisation of the heat transport}

In order to gain further insight into the heat transport enhancement, we performed local liquid temperature measurements by traversing the thermistor along the length of the setup at mid-height for three Rayleigh numbers $\left(R a_{H}=5.2 \times 10^{9}, R a_{H}=\right.$ $1.6 \times 10^{10}$, and $R a_{H}=2.2 \times 10^{10}$ ), and for $\alpha=0 \%$ and $\alpha=0.9 \%$. Figure 2.9 (a) shows the normalised temperature profiles. For the single-phase cases, as expected from the range of $R a_{H}$ and the $H / L$ in our study, a flat temperature profile along the length is observed in the bulk at mid-height $[58,59,64,67-70]$. After normalisation, the single-phase temperature profiles for all three Rayleigh numbers overlap. However, due to present heat losses to the outside at the top of the setup since the setup is open on the top, the temperature profiles do not collapse at $\frac{\langle T\rangle-T_{c}}{T_{h}-T c}=0.5$ but at $\frac{\langle T\rangle-T_{c}}{T_{h}-T c}=0.4$. This has to be taken into account when comparing numerical data with the data obtained experimentally. Therefore, after shifting the numerically 
obtained temperature profiles good agreement is found between the two. The spatial temperature gradient in the single-phase case is located in the thermal boundary layer whose thickness $\delta_{t}$ is estimated from the numerical data to be $\mathcal{O}(1 \mathrm{~mm})$. In figure 2.10 we show the boundary layer thickness in the single phase case as a function of $R a_{H}$. Note that our flow configuration is different from the one present in classical Rayleigh-Bénard setup. Here the thermal boundary layer is defined as wall distance to the intercept of $\bar{T}=T_{h}+d \bar{T} /\left.d x\right|_{w} x$ and $\bar{T}=T_{h}-\Delta T / 2$ and the kinetic boundary layer is given as an intercept of $\bar{u}=d \bar{u} /\left.d x\right|_{w} x$ and $\bar{u}=\bar{u}_{\text {max }}$ (see e.g. [58] for more details). The thickness of the thermal boundary layer based on the experimentally obtained Nusselt number is comparable to the one obtained numerically (see Figure $2.10)$.

As seen in figure 2.9 (a), the mean temperature profiles in the case of bubbly flow is completely different from that of single phase flow. In the bulk, two known mixing mechanisms contribute to the distortion of the flat temperature profile that was observed in the single-phase case: (i) capture and transport by the bubble wakes [71], and (ii) dispersion by the bubble-induced turbulence which is the dominant one as shown by Alméras et al. (2015) [65]. Near the heated and cooled walls, we visually observed the bubbles bouncing along the walls. This presumably disturbs the thermal boundary layers; however, this cannot be measured due to insufficient experimental resolution.

Figures 2.9 (b) and 2.5 (a) and 2.5 (b) show that the temperature fluctuations induced by bubbles are even two orders of magnitudes higher than in the single-phase case $\left(T^{\prime}=T-\langle T\rangle\right.$, where $T^{\prime}$ is the temperature fluctuations, $T$ is the measured instantaneous temperature and $\langle T\rangle$ is the time averaged temperature at the measurement point). The normalised standard deviations of the fluctuations in both single-phase and two-phase are higher closer to the cold and hot walls than in the center of the setup. This is possibly due to the temperature probe seeing more hot and cold plumes closer to the heated and cold walls, a well known phenomenon from Rayleigh-Bénard flow [3]. Here slight asymmetry of the temperature profiles and the profiles of normalised standard deviation close to the walls must be attributed to the difference in the nature of heating and cooling of the sidewalls (see asymmetry also in figure $2.9(\mathrm{a})$ ). Figures 2.5 (a) and (b) also demonstrate that the time scales of fluctuations in single-phase and two-phase are different, along with much more intense temperature fluctuations for the bubbly flow.

To explore this in better detail, we now present the power spectrum of the temperature fluctuations ("thermal power spectrum") for both cases. Figure 2.11 (a) shows this power spectrum of temperature fluctuations at mid-height in the centre of 
(a)

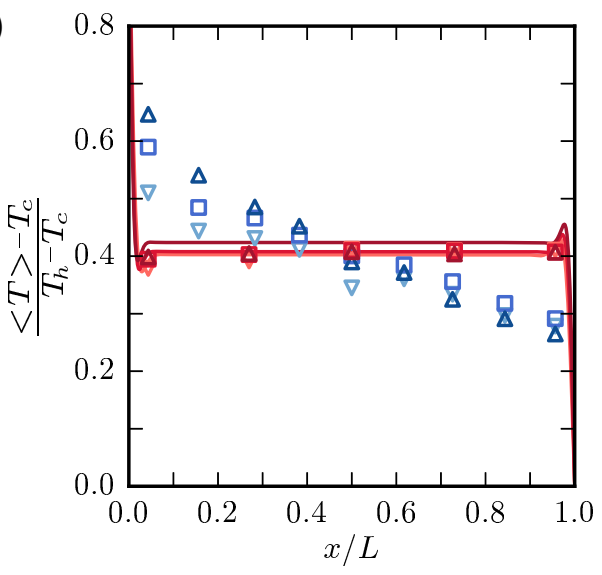

(b)

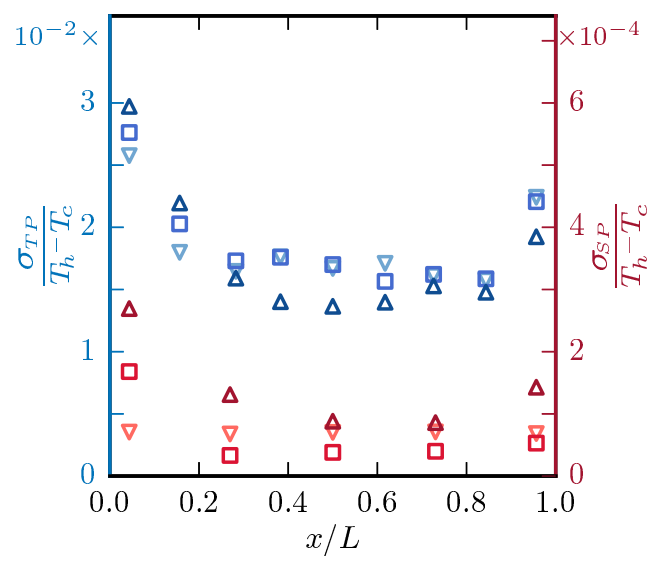

Figure 2.9: (a) Normalised mean temperature profile at the mid-height (the overshoots close to the walls in the numerical data appear because the thin layer of warmed up (cooled down) fluids moving upward (downward) are still colder (hotter) than the bulk where there is a stable stratification), (b) Normalised standard deviation of the temperature fluctuations. Red lines (numerical results in (a)) and symbols (experimental data) present single-phase, blue symbols present two-phase with $\alpha=$ $0.9 \%$, for various Rayleigh numbers: $R a_{H}=5.2 \times 10^{9}$ (downwards triangles), $R a_{H}=$ $1.6 \times 10^{10}$ (squares), and $R a_{H}=2.2 \times 10^{10}$ (upward triangles)). 


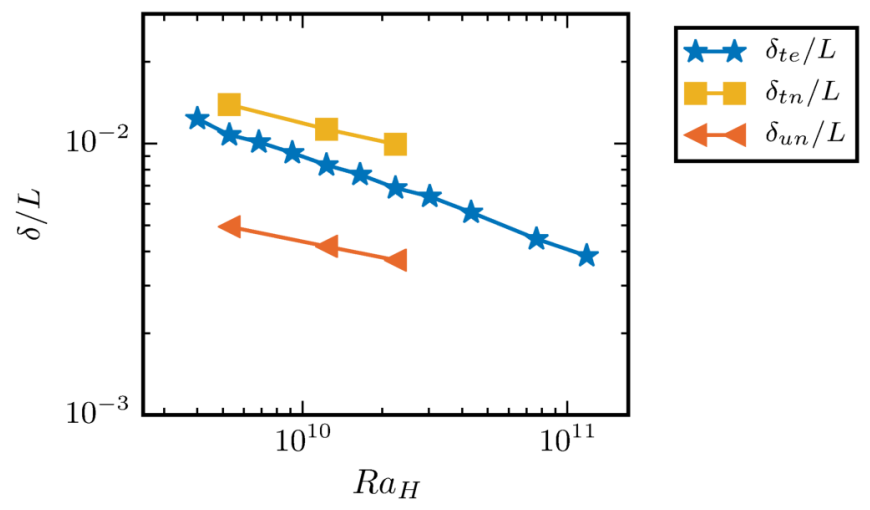

Figure 2.10: Normalised boundary layer thickness in the single phase as a function of $R a_{H}$. Here $\delta_{u_{n}}$ and $\delta_{t n}$ are numerically obtained thickness of the kinetic and thermal boundary layer, respectively. Thickness of the thermal boundary layer obtained from the experiments is given as $\delta_{t e}$.

the setup for the single- and two-phase cases. In the single-phase case the measured temperature fluctuations are limited to frequencies lower than $10^{-1} \mathrm{~Hz}$. At around $10^{-2} \mathrm{~Hz}$ we observe a peak, beyond which there is a very steep decrease of the spectrum (the same frequency can be observed in the figure 2.5 a)). As well known [72] this peak corresponds to the large scale circulation frequency $\left(f_{L S} \approx V_{f f} / 4 H\right)$, which can be estimated from the free fall velocity $V_{f f}=\sqrt{g \beta \Delta T H}$ which is $\sim 6 \mathrm{~cm} / \mathrm{s}$ for lowest $R a_{H}$ and $\sim 11 \mathrm{~cm} / \mathrm{s}$ for the highest $R a_{H}$. In both single-phase and two-phase cases, a higher level of thermal power is seen for higher $R a_{H}$ numbers. The same trend is seen for all the measurement positions at mid-height. If we now compare the single-phase and two-phase spectra, we can see that with the bubble injection, the thermal power of the fluctuations is increased by nearly three orders of magnitude. The bubbly flow also shows fluctuations at a range of time scales, with a gradual decay of thermal power from $f \simeq 0.1 \mathrm{~Hz}-3 \mathrm{~Hz}$. The observation that substantial power of the temperature fluctuations resides at smaller time scales, as compared to the single-phase where the power mainly resides at the largest time scales, further confirms that the bubble-induced liquid fluctuations are the dominant contribution to the total heat transfer.

The thermal power spectra plots in figure 2.11 (a) show a $R a_{H}$ dependence for both single- and two-phase cases. While upon normalising with the scale of temperature fluctuations $T_{r m s}^{2}$ in the single phase we do not observe complete overlap of the spectra 
possibly due to noise present at higher frequencies, in bubbly flow we observe a nearly perfect collapse of the three Rayleigh numbers (see figure 2.11(b)). This suggests a universal behavior for bubbly flow. Interestingly, this is similar to the velocity fluctuations spectra observed for bubbly flows [29, 30, 49, 73], where a normalisation with the scale of velocity fluctuations $u_{r m s}^{2}$ demonstrates universality. Furthermore, the same behaviour is seen at all measurement positions and all Rayleigh numbers (note that in figure 2.11 (b), we have shown the measurements at the centre only). We also observe a clear slope of -1.4 at the scales $f \simeq 0.1 \mathrm{~Hz}-3 \mathrm{~Hz}$. It remains unclear why this exact slope is present, and how it can be attributed to bubble-induced turbulence. Events occurring at shorter time scales, such as at frequencies where the -3 slope is present in velocity spectra for bubble-induced turbulence, typically starting at $1 / t_{\text {pseudo }} \sim 35 \mathrm{~Hz}[29]$, would be undetectable here due to the limiting response time of the thermistor used. 
(a)

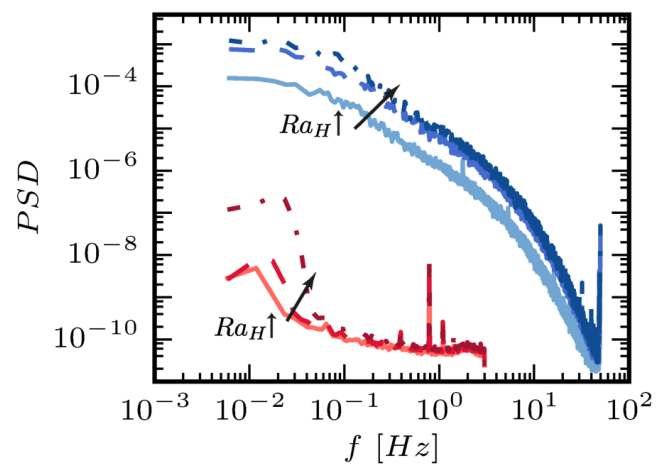

(b)

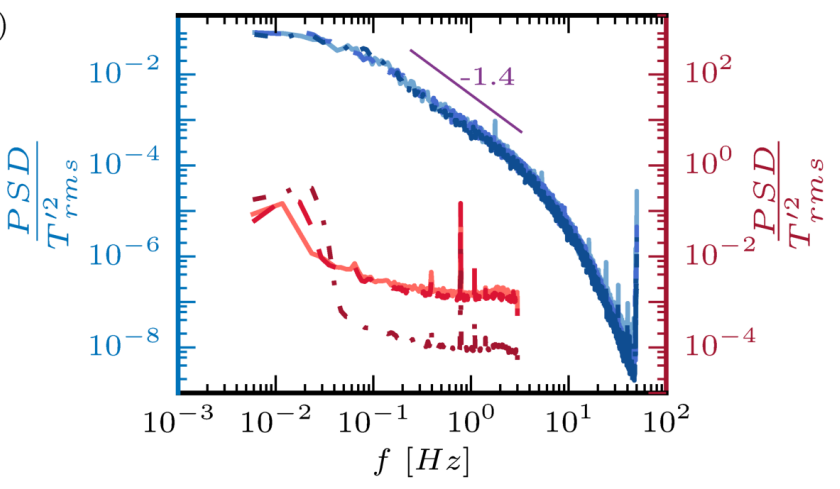

Figure 2.11: Raw (a) and normalised (b) power spectra of the temperature fluctuations at the center of the setup for single-phase (red lines) and two-phase $\alpha=0.9 \%$ (blue lines); solid line: $R a_{H}=5.2 \times 10^{9}$; dashed line: $R a_{H}=1.6 \times 10^{10}$; dash-dotted line: $R a_{H}=2.2 \times 10^{10}$. 


\subsection{Conclusions}

An experimental study on heat transport in homogeneous bubbly flow has been conducted. The experiments are performed in a rectangular bubble column heated from one side and cooled from the other (see figure 3.1). Two parameters are varied: the gas volume fraction and the Rayleigh number. The gas volume fraction ranges from $0 \%$ to $5 \%$, and the bubble diameters are around $2.5 \mathrm{~mm}$. The Rayleigh number is in the range $4.0 \times 10^{9}-1.2 \times 10^{11}$.

First, we focus on characterization of the global heat transfer for single-phase and two-phase cases. We find that two completely different mechanisms govern the heat transport in these two cases. In the single-phase case, the vertical natural convection is driven solely by the imposed difference between the mean wall temperatures. In this configuration the temperature acts as an active scalar driving the flow. The Nusselt number increases with increasing Rayleigh number, and as expected effectively scales as: $\overline{N u} \sim R a_{H}^{0.33}$ (see figure $3.5(\mathrm{a})$ ). However, in the case of homogeneous bubbly flow the heat transfer comes from two different contributions: natural convection driven by the horizontal temperature gradient and the bubble induced diffusion, where the latter dominates. This is substantiated by our observations that the Nusselt number in bubbly flow is nearly independent of the Rayleigh number and depends solely on the gas volume fraction, evolving as: $\overline{N u} \propto \alpha^{0.45}$ (see figure 3.6). We thus find nearly the same scaling as in the case of the mixing of a passive tracer in a homogeneous bubbly flow for a low gas volume fraction [65], which implies that the bubble-induced mixing is indeed limiting the efficiency of the heat transfer.

We further performed local temperature measurements at the mid-height of the setup for the gas volume fraction of $\alpha=0 \%$ and $\alpha=0.9 \%$, and for Rayleigh numbers $5.2 \times 10^{9}, 1.6 \times 10^{10}$ and $2.2 \times 10^{10}$. For single-phase flow, we observe that the mean temperature remains constant in the bulk at mid-height. However, in the two-phase flow case, this is completely obstructed by the mixing induced by bubbles. Injection of bubbles induces up to 200 times stronger temperature fluctuations (see figure 2.9 (b)). These fluctuations over a wide spectrum of frequencies (see figure 2.11) are thus the signature of the heat transport enhancement due to bubble injection. A clear slope of -1.4 at the scales $f \simeq 0.1 \mathrm{~Hz}-3 \mathrm{~Hz}$ was also observed.

To conclude, we observe up to 20 times heat transfer enhancement due to bubble injection (see figure 3.5 (b)). This demonstrates that the diffusion induced by bubbles is a highly effective mechanism for heat transfer enhancement. Nevertheless, several questions remain unanswered. One question of great practical importance is: at what Rayleigh number will the contribution of natural convection to the total heat 


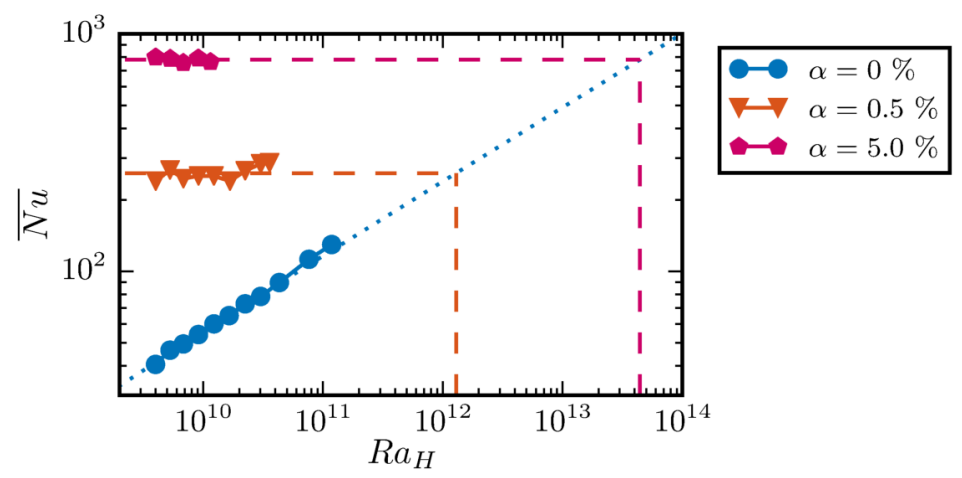

Figure 2.12: Extrapolation of the Nusselt number to high Rayleigh numbers for the two-phase (dashed lines - lowest and highest studied $\alpha$ ), and the single phase case (dotted line). A crossover between the extrapolated single- and two-phase cases occurs at $R a_{H} \approx 1.2 \times 10^{12}$ for $\alpha=0.5 \%$, and at $R a_{H} \approx 4 \times 10^{13}$ for $\alpha=5 \%$. However, as we approach these $R a_{H}$, we expect the Rayleigh-independent trends of Nusselt number to change, namely to increase with increasing $R a_{H}$.

transfer become comparable or even greater than the contribution of bubble-induced turbulence? If we extrapolate the data to higher Rayleigh numbers, we can obtain the maximum expected value of $R a_{H}$ at which the two contributions are comparable (see dashed lines in figure 2.12). This occurs at $R a_{H} \approx 1.2 \times 10^{12}$ for $\alpha=0.5 \%$ and at $R a_{H} \approx 4 \times 10^{13}$ for $\alpha=5 \%$. As we approach these $R a_{H}$, we expect the Rayleigh-independent behavior of Nusselt number to change. Presumably, when $R a_{H}$ is sufficiently large, the Nusselt number will increase with $R a_{H}$ even for the two-phase cases. Based on our current knowledge, it is difficult to predict at what $R a_{H}$ this trend will change. This calls for future investigations spanning a wider range of control parameters. 


\section{Chapter 3}

\section{Heat transport in inhomogeneous bubbly flows}

Based on: Biljana Gvozdić, On-Yu Dung, Elise Alméras, Dennis P. M. van Gils, Detlef Lohse, Sander G. Huisman, Chao Sun, 'Experimental investigation of heat transport in inhomogeneous bubbly flows' Chemical Engineering Science, 2018. 


\subsection{Introduction}

In this chapter we experimentally study the effect of inhomogeneous injection of millimetric bubbles on heat transfer in a rectangular bubbly column. We focus on understanding the influence of changing gas volume fraction on the liquid velocity and the global heat flux.

As noted previously in $\S 1$ and $\S 2$, injection of bubbles in a continuous liquid phase is widely used to enhance mixing without any additional mechanical parts. As a result, bubbly flows enhance heat and mass transfer and can therefore be found in various industrial processes such as synthesis of fuels and basic chemicals, emulsification, coating, fermentation, etc. In particular, to understand the effect of bubbles on heat transport, a variety of flow configurations have been used in previous works. These studies can be broadly classified based on $(i)$ the nature of forcing of the liquid, i.e. natural convection (liquid is purely driven by buoyancy) $[54,55]$ or forced convection (liquid is driven by both buoyancy and an imposed pressure gradient or shear) [50-53]; and $(i i)$ based on the size of the injected bubbles, i.e. sub-millimetric bubbles [54-56] to millimetric bubbles $[32,33]$.

Owing to the high complexity of the physical mechanism behind the bubble induced heat transfer enhancement, a systematic approach has to be taken when studying this phenomenon. Starting from a relatively simple case: bubbly flow in water combined with natural convection, Kitagawa et al. (2013) [56] studied the effect of bubble size on the heat transfer. They found that micro-bubbles (mean bubble diameter $d_{b u b}=0.04 \mathrm{~mm}$ ) which form large bubble swarms close to the wall with significant wall normal motion, induce higher heat transfer enhancement as compared to sub-millimeter-bubbles $\left(d_{b u b}=0.5 \mathrm{~mm}\right)$, which have weak wakes and low bubble number density.

In $\S 2$ we studied heat transfer combined with natural convection with injection of millimetric bubbles in water which due to their strong wake enhance the heat transport even more. Those experiments were performed in a rectangular bubble column heated from one side and cooled from the other in order to understand the influence of homogeneously injected millimetric bubbles on the overall heat transport. The primary advantage with such a setup is that the dynamics of homogeneous bubbly flows has been adequately characterised and studied in the past [28-31] and the flow without bubbles resembles the classical vertical natural convection system $[58,59,64,67-70]$. The strength of the thermal driving of the fluid in such a system is characterised by the Rayleigh number which is the dimensionless temperature 
difference:

$$
R a_{H}=\frac{g \beta\left(\overline{T_{h}}-\overline{T_{c}}\right) H^{3}}{\nu \kappa} ;
$$

and the dimensionless heat transfer rate, the Nusselt number:

$$
\overline{N u}=\frac{Q / A}{\chi\left(\overline{T_{h}}-\overline{T_{c}}\right) / L},
$$

where $Q$ is the measured power supplied to the heaters, $\overline{T_{h}}$ and $\overline{T_{c}}$ are the mean temperatures (over space and time) of the hot wall and cold wall, respectively, $L$ is the length of the setup, $A$ is the surface area of the sidewall, $\beta$ is the thermal expansion coefficient, $g$ the gravitational acceleration, $\kappa$ the thermal diffusivity, and $\chi$ the thermal conductivity of water. In $\S 2$ we found that homogeneous injection of bubbles in vertical natural convection can lead to a 20 times enhancement of the heat transfer compared to the corresponding flow with no bubbles. It was found that for $R a_{H}=4.0 \times 10^{9}-2.2 \times 10^{10}$ and a gas volume fraction of $\alpha=0.5 \%-5 \%$ the Nusselt number remained nearly constant for increasing $R a_{H}$. Furthermore, in $\S 2$ we found good agreement for the scaling of an effective diffusivity $D$ with the gas volume fraction $\alpha$ with the results of mixing of a passive scalar in a homogeneous bubbly flow [65], i.e. roughly $D \propto \alpha^{1 / 2}$, which implies that the bubble-induced mixing is controlling the heat transfer.

With a goal to further enhance bubble induced heat transport in vertical natural convection, in this study we explore the influence of inhomogeneous bubble injection on the overall heat transfer. Previous studies have shown that inhomogeneous gas injection induces mean liquid circulations (large-scale coherent rolls) in bubbles columns $[74,75]$. It is also known from classical Rayleigh-Bénard convection that aiding formation of the coherent structures can enhance heat transfer [3, 4]. In this work, we take advantage of both these phenomena and use the large-scale circulation generated by inhomogeneous bubble injection in a vertical natural convection setup to further enhance heat transport as compared to the case of homogeneous injection of bubbles. In this chapter we use the same experimental setup as in $\S 2$, while we inject the bubbles through one half of the injection section, either close to the hot wall or close to the cold wall (see Figure 3.1). We characterise the global heat transfer while varying two parameters: the gas volume fraction $\alpha=0.4 \%-5.1 \%$, and the Rayleigh number $R a_{H}=4 \times 10^{9}-2.2 \times 10^{10}$. We compare findings on global heat transfer for the cases of homogeneous bubble injection, injection close to the hot wall, and injection close to the cold wall. We further demonstrate the difference in the dynamics between lower gas volume fraction case $(\alpha=0.4 \%)$ and higher gas volume 
fraction case ( $\alpha=3.9 \%$ ) by performing velocity profile measurements along the length of the setup at mid-height.

\subsection{Experimental setup and instrumentation}

\subsubsection{Experimental setup}

In figure 3.1, we show a schematic of the experimental setup. The apparatus consists of a rectangular bubble column, where the two main sidewalls of the setup $\left(600 \times 230 \mathrm{~mm}^{2}\right)$ are made of $1 \mathrm{~cm}$ thick glass and the two (heated resp. cooled) sidewalls $\left(600 \times 60 \mathrm{~mm}^{2}\right)$ of $1.3 \mathrm{~cm}$ thick brass. Heating is provided via Joule heaters placed on the brass sidewall, while cooling of the opposite brass wall is performed using a circulating water bath. The temperature of these walls is monitored using thermistors. Millimetric bubbles are injected through 90 out of the total 180 capillaries at the bottom of the setup, either close to the hot wall or close to the cold wall.

The global gas volume fraction is modulated between $0.4 \%$ to $5.1 \%$ by varying the inlet gas flow rate. Global gas volume fraction was estimated as an average elevation of the liquid at the top of the setup, which is measured by processing images captured using a Nikon D850 camera. We find that different flow regimes develop with increasing inlet gas flow rate. In order to visualise the preferential concentration of the bubbles in figure 3.2 we show the normalised standard deviation of each pixel in the picture frame converted to grayscale over around 1500 frames. For low global gas volume fractions (around $0.4 \%$ ) we visually observe that the bubbles rise without migrating to the opposite side (see Figure 3.2(a)), while the bubble stream bends due to liquid recirculation caused by the pressure gradient between the two halves of the setup, as it was previously observed by Roig et al. (1998) [76]. For a global gas volume fraction of approximately $1 \%$, the bubbles start migrating to the opposite side (see Figure 3.2(b)), inducing a weak bubble circulation loop on the opposite half of the setup. This recirculation loop does not interfere with the main bubble stream. At an even higher gas volume fraction of around $2.3 \%$, a significant part of the bubble stream passes to the other half of the setup, and strongly interacts with the main bubble stream (see Figure 3.2(d)). The migrating bubbles form an unstable loop, which gets partially trapped by the main bubble stream and carried to the top of the setup. With increasing gas flow rate, the amount of bubbles passing from the injection side to the opposite half of the setup increases, as does the instability of the main bubble stream. These regimes have significant influence on the heat transfer, which will be addressed later in section 3.3.1. 


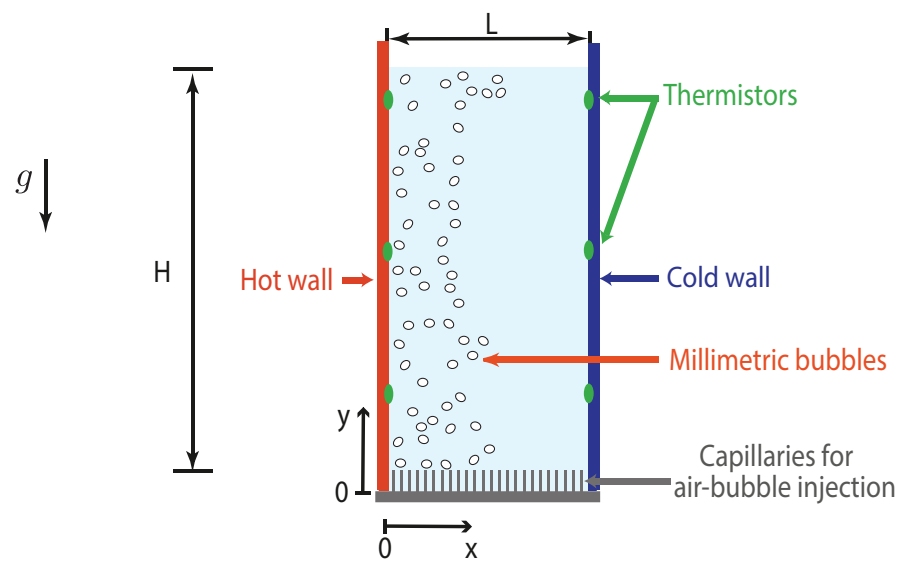

Figure 3.1: Rectangular bubbly column heated from one sidewall and cooled from the other $(H=500 \mathrm{~mm}, L=230 \mathrm{~mm})$. Bubbles are injected either close to the hot wall or close to the cold wall, through 90 capillaries (out of 180 in total) placed at the bottom of the setup (inner diameter $0.21 \mathrm{~mm}$ ).
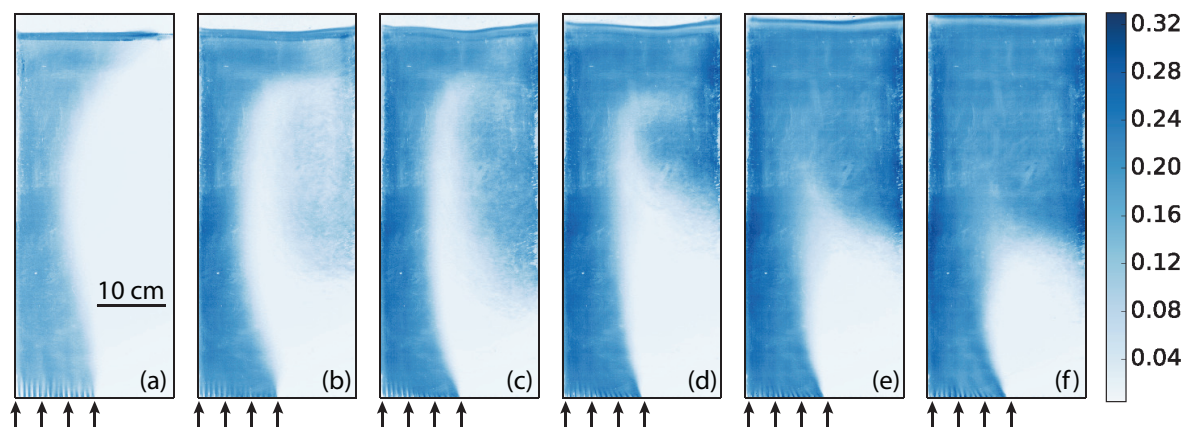

Figure 3.2: Visualisation of preferential concentration of bubbles for each gas volume fraction: (a) $\alpha=0.4 \%$, (b) $\alpha=0.9 \%$, (c) $\alpha=1.4 \%$, (d) $\alpha=2.3 \%$, (e) $\alpha=3.9 \%$, (f) $\alpha=5.1 \%$; arrows mark the gas injection. Colour corresponds to $\sigma /\left\langle\sigma_{b g}\right\rangle$, that is the standard deviation of each pixel intensity $\sigma$ normalised by $\left\langle\sigma_{b g}\right\rangle$ the mean of the standard deviation of pixel intensity for a background image taken without the bubble injection. 


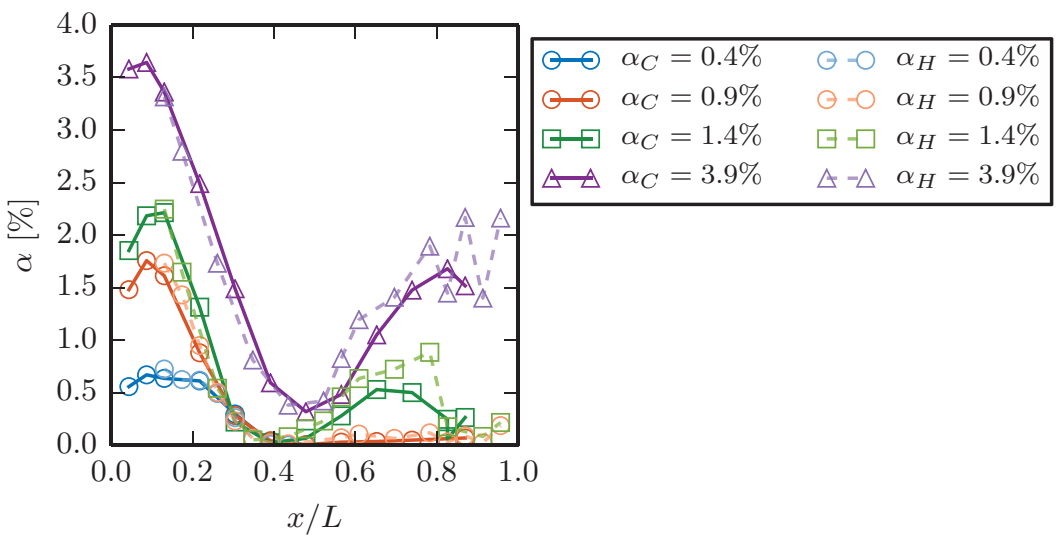

Figure 3.3: Gas volume fraction profiles at the mid-height for injection close to the hot wall $\alpha_{H}$ and injection close to the cold wall $\alpha_{C}$ (cold wall profiles are mirrored around $x / L=0.5$ for the comparison).

\subsubsection{Instrumentation for the gas phase characterisation}

In order to characterise the gas phase, we first perform a scan of the local gas volume fraction using a single optical fibre probe (for working principle see [77]). We perform measurements only at half-width of the column because the capilaries for bubble injection are arranged in 6 rows and 30 columns, and the width of the column is only $6 \mathrm{~cm}$. In figure 3.3 , we plot the local gas volume fraction measured at half-height $y / H=0.5$, versus the normalised length for both hot-wall and cold-wall injection. We find that the profiles of the gas volume fraction do not differ significantly for the cases where the bubbles are injected close to the hot wall or close to the cold wall.

The bubble diameter and bubble velocity were measured at half height using an in-house dual optical probe, which consists of two optical fibres placed one above the another. The bubble velocity is given as $V_{b u b}=\delta / \Delta t$, where $\delta=4 \mathrm{~mm}$ is the vertical distance between the fibre tips and $\Delta t$ is the time interval between which one bubble successively pierces each fibre. The diameter is estimated from the time during which the leading probe is in the gas phase. For the calculation of the diameter we used the following equation $d_{e q}=3 / 2\langle y\rangle \chi^{2 / 3}$ from [78], where $\chi$ is the aspect ratio of the bubble, and $\langle y\rangle$ is the mean measured cord length. To ensure precise measurements of the bubble diameter and velocity, we perform measurements only in the injection 

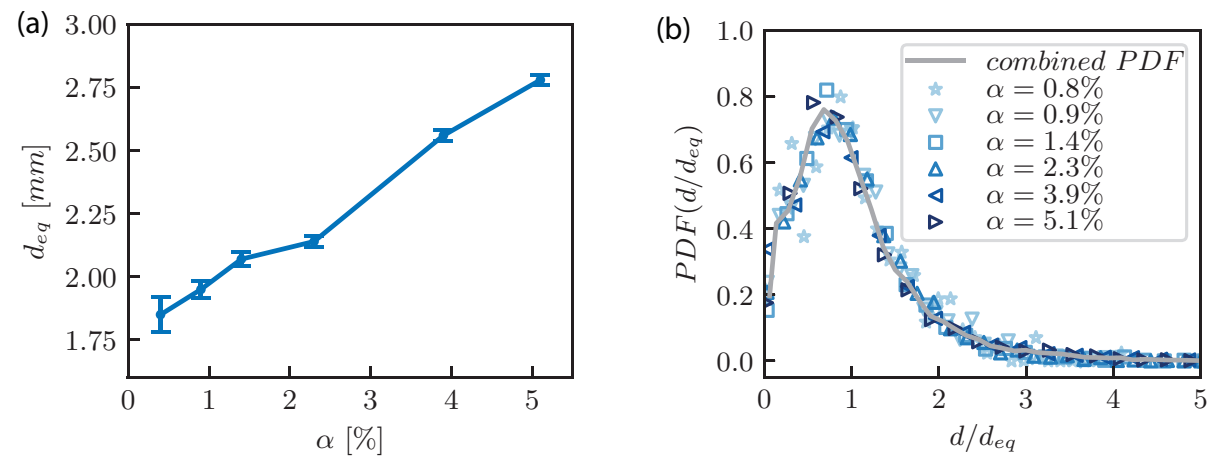

Figure 3.4: (a) Mean bubble diameter $d_{e q}$ for different gas volume fractions $\alpha$, the error-bar presents the standard error of the mean bubble diameter. (b) Probability density function (PDF) of the normalised bubble diameter. The symbols present the PDF for each gas volume fraction, while the line presents a PDF calculated using data points for all studied gas volume fractions.

stream. On the opposite side of the injection stream, bubbles move downwards which makes their accurate detection with a downward facing probe impossible. Bubble diameter measurements indicate an expected increasing trend with increasing gas volume fraction (see Figure 3.4 (a)), while the distribution of the normalised bubble diameter remains nearly the same for all the gas volume fractions with a standard deviation of 0.7 (see Figure 3.4 (b)). The bubble velocity is in the range $V_{b u b}=$ $0.5 \pm 0.02 \mathrm{~m} / \mathrm{s}$ for the given gas volume fraction span. The bubble rising velocity in the injection leg of the setup is nearly constant as it can be expressed as $V_{b u b}=U+V_{r}$, and the mean rising liquid velocity $U$ increases (see Section 3.3.2) while the relative velocity $V_{r}$ decreases with increasing gas volume fraction [29], thus compensating each other.

\subsubsection{Instrumentation for the liquid phase velocity measurements}

The vertical and the horizontal component of the liquid phase velocity are measured by means of Laser Doppler Anemometry (LDA) in backscatter mode. The flow is seeded with polyamid seeding particles (diameter $5 \mu \mathrm{m}$, density $1050 \mathrm{~kg} / \mathrm{m}^{3}$ ). The LDA system used consists of DopplerPower DPSS (Diode Pumped Solid State) laser and a Dantec burst spectrum analyser (BSA). It has been shown previously that 


\begin{tabular}{c||r|r|r|r|r|r|r|r|}
$R a_{H} \times 10^{-9}$ & 4.0 & 5.3 & 6.8 & 9.1 & 12.3 & 16.5 & 22.4 & 30.2 \\
\hline$\Delta T[K]$ & 2 & 2.6 & 3.3 & 4.3 & 5.6 & 7.2 & 9.3 & 11.3
\end{tabular}

Table 3.1: Operating values of $\Delta T$ at different $R a_{H}$

the LDA in backscatter mode measures predominantly the liquid velocity [79-81]. Therefore, no post-processing was performed on the data. Measurements of 30 minutes were performed for each measurement point with a data rate of $\mathcal{O}(100) \mathrm{Hz}$.

\subsubsection{Instrumentation for the heat flux measurements}

In order to characterise the global heat transport, namely to obtain $\overline{N u}$ and $R a_{H}$, we measured the hot and cold wall temperatures (the control parameters), and the heat input to the system (the response parameters). Accordingly, resistances of the thermistors placed on the hot and cold walls and the heat power input were read out every 4.2 seconds using a digital multimeter (Keysight 34970A). Operating temperatures for each Rayleigh number are given in table 3.1. The heat losses were estimated to be in the range of $3 \%$ to $7 \%$ by calculating convective heat transport rate from all outer surfaces of the setup if they are at $25{ }^{\circ} \mathrm{C}$ and by measuring the power needed to maintain the temperature of the bulk constant $\left(T_{\text {bulk }}=25^{\circ} \mathrm{C}\right)$ over 4 hours. More details on the temperature control of the setup and measurements of the global heat flux are provided in $\S 2$. The experimental data was acquired after a steady state was achieved in which the mean wall temperatures fluctuated less that $\pm 0.5 \mathrm{~K}$. Time averaging of the instantaneous supplied heating power was then performed over a period of 3 hours.

\subsection{Results}

\subsubsection{Global heat transfer enhancement}

We now analyse the heat transport in the presence of an inhomogeneous bubble swarm for gas volume fraction $\alpha$ ranging from $0.4 \%$ to $5.1 \%$ and the Rayleigh number ranging from $4 \times 10^{9}$ to $2.2 \times 10^{10}$. Experiments performed in $\S 2$ showed that in the single-phase case Nusselt increases with $R a_{H}$ as $\overline{N u} \propto R a_{H}{ }^{0.33}$, while in the case of homogeneous bubble injection $\overline{N u}$ remains nearly constant with increasing $R a_{H}$. In figure 3.5, along with the results previously obtained for the cases of single-phase 


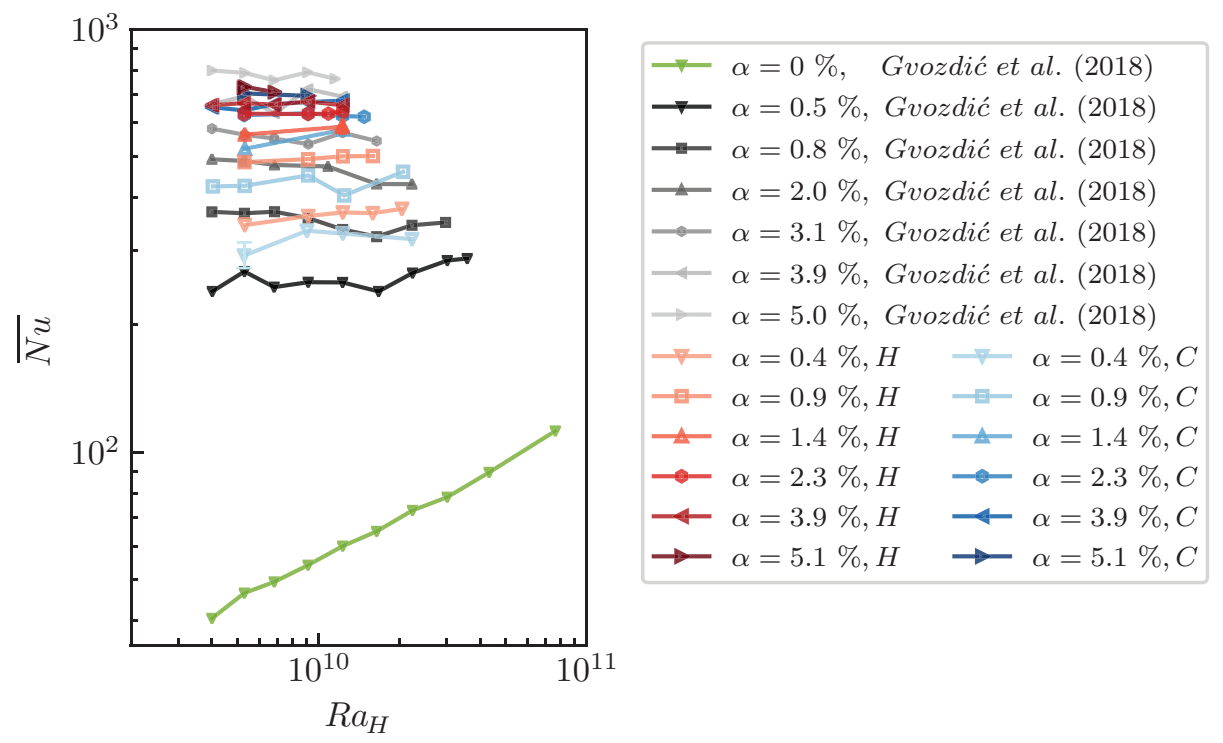

Figure 3.5: Dependence of the Nusselt number $\overline{N u}$ on the Rayleigh number $R a_{H}$ for different gas volume fractions. Green data presents the single-phase case from [82], black data the homogeneously injected bubbles from [82], red data the injection of bubbles close to the hot wall $(\mathrm{H})$ and blue data injection close to the cold wall $(\mathrm{C})$. 

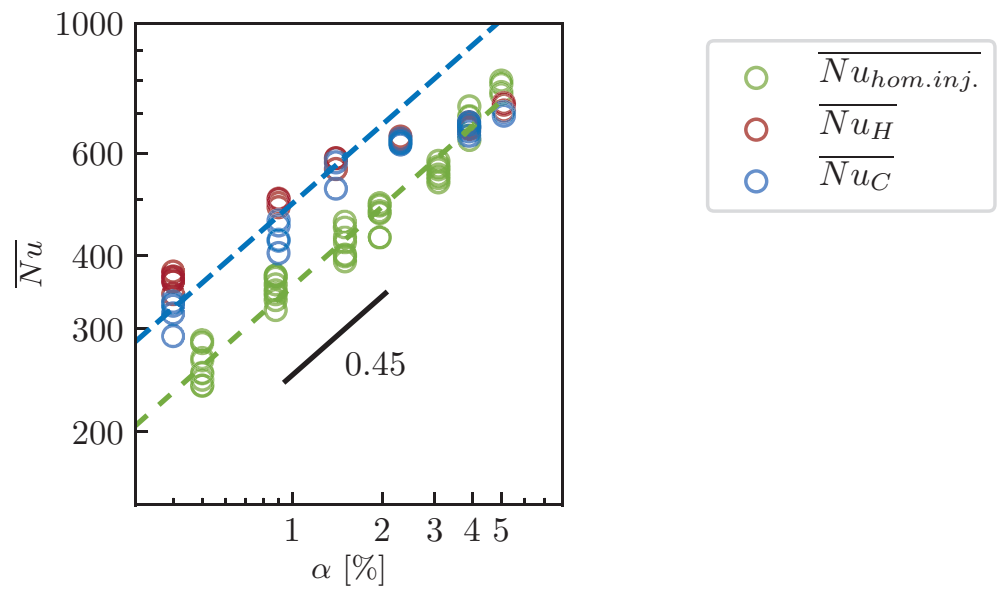

Figure 3.6: Nusselt number $\overline{N u}$ as a function of the gas volume fraction $\alpha$, subscripts: $C$ - injection close to the cold wall; $H$ - injection close to the hot wall, hom. inj. - homogeneous bubble injection. Hollow symbols show all the experimental measurements, and lines present the $\overline{N u} \propto \alpha^{0.45}$ scaling. The crossover from strong enhancement by the inhomogeneous bubble injection for low $\alpha$ towards no enhancement for high $\alpha$ is clearly seen.

flow and homogeneous bubble injection, we plot the Nusselt number versus $R a_{H}$ for inhomogeneous injection. Similarly to the results for the homogeneous bubble injection, we find that $\overline{N u}$ remains independent of $R a_{H}$ and is an order of magnitude higher when compared to the single-phase case even if the bubbles are injected only through one half of the bubble injection section.

Although Nusselt is not a function of Rayleigh in both cases, the heat transport enhancement mechanisms in case of inhomogeneous injection is different than the one present in case of homogeneously injected bubbles where $\overline{N u} \propto \alpha^{0.45 \pm 0.025}$. While in the case of a homogeneous bubble injection the mixing mechanism limiting the heat transport is bubble induced turbulence (BIT), the large-scale circulation of the liquid phase induced by inhomogeneous bubble injection leads to the occurrence of a shear layer between the fluid region injected with bubbles and its opposite side. Therefore, in the case of inhomogeneous bubble injection there are additional contributions to the mixing: the shear-induced turbulence (SIT) and mixing by large-scale liquid circulation. Given the difference in the fundamental mixing mechanisms for homogeneous injection and inhomogeneous injections, one can expect 
a difference in the scaling of the Nusselt number with $\alpha$. Indeed, for gas volume fractions $\alpha \geq 1.4 \% \overline{N u}$ does not follow the same trend with gas volume fraction as in the case of homogeneous injection, it seems to be less affected by changing $\alpha$ (see Figure 3.6). However, for low gas volume fractions the scaling exponent of $\overline{N u}$ with $\alpha$ for inhomogeneous injection agrees well with homogeneous injection, though with an increased prefactor. If we calculate the exact scaling exponent for inhomogeneous injection for gas volume fraction $\alpha \leq 1.4 \%$, for hot wall injection we get $0.37 \pm 0.03$, for cold wall it is $0.41 \pm 0.08$. These exponents are comparable to the one for homogeneous injection. It should be however taken into account that better precision of the exact scaling exponent would be obtained if the number of data points at low gas volume fractions would be greater, since in the present work only 3 gas volume fractions are available. The small observed difference in the exact scaling exponent between hot wall injection and cold wall injection will be addressed later.

In order to understand the observed trend of Nusselt with increasing $\alpha$, we plot the ratio of Nusselt number for inhomogeneous injection to the corresponding Nusselt for the homogeneous injection for the same gas volume fraction in figure 3.7. The results indicate that the heat transfer enhancement (as compared to the homogeneous bubble injection) decreases with increasing gas volume fraction. Studies focused on characterisation of the mixing in similar inhomogeneous bubbly flow have shown that ( $i$ ) in case of $\alpha<3.5 \%$ the mixing is enhanced using inhomogeneous injection [74, 75], (ii) for $\alpha<3 \%$ in the case of inhomogeneous bubbly flow where the buoyancy driven flow generates shear-induced turbulence involving wide range of scales from the from the size of the column to bubble diameter, the mixing time evolves as $\alpha^{-0.5}$ [75]. Our results for low gas volume fraction agree well with these findings. On the other hand, at higher gas volume fractions the observed trend is changed. Possible cause of decreased heat transport enhancement at higher gas volume fractions is that the interacting mixing mechanisms might deteriorate one another, resulting in inhomogeneous bubble injection to be less effective that the homogeneous one for $\alpha>4 \%$.

We now compare the global heat transfer for injection close to the hot wall and injection close to the cold wall. From figures 3.5 and 3.6 we find that there is almost no distinction between hot wall injection and cold wall injection for the same gas volume fraction for higher $\alpha$. The difference is more prominent for low gas volume fractions as compared to high gas volume fractions; namely, up to a critical value of the gas volume fraction $\alpha<1.4 \%$ the Nusselt number for hot wall injection is slightly higher than the one for cold wall injection. One possible reason for the observed difference in the Nusselt number could be the different interaction between the rising 


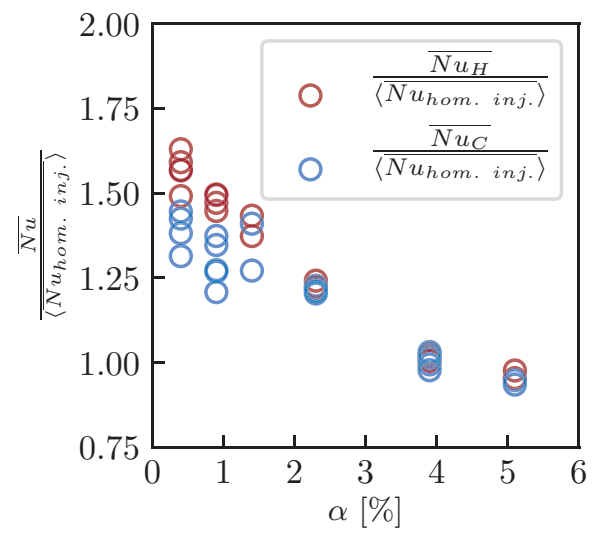

Figure 3.7: The ratio of Nusselt for the inhomogeneous bubble injection and Nusselt for homogeneous injection as a function of the gas volume fraction.

bubbles and the falling cold boundary layer or rising hot boundary layer, namely the co-current flow of bubbles with the thermal boundary layer might perturb the boundary layer more than the counter-current flow. However, we suspect that this is not the actual cause of the difference between hot wall injection and cold wall injection for two reasons: $(i)$ We do not see the difference between the different injection sides for higher gas volume fractions and $(i i)$ the Nusselt number does not depend on the Rayleigh number, meaning that it is very likely that the perturbation of the boundary layers by the bubbles rising next to the wall is very strong even for the lowest gas volume fractions so that the boundary layers do not react back on the bubbles.

On the other hand, the main distinction between the $\alpha=0.4 \%$ and $\alpha=0.9 \%$ cases and the cases with $\alpha \geq 1.4 \%$ is that at low gas volume fraction the boundary layer on the side opposite to the bubble injection is not mixed by bubbles because almost no bubbles migrate to the other half of the setup, while at high $\alpha$ both boundary layers are mixed by bubbles. Therefore the liquid (with almost no bubbles) flowing in the same direction as the cold boundary layer is more effective in transferring heat that the liquid flowing in the direction opposite to the movement of the hot boundary layer. Finally, the observed differences in heat transport if the bubbles are injected close to the hot wall or close to the cold wall at $\alpha \geq 1.4 \%$ are of the same order of magnitude as the variation of the Nusselt number for a constant gas volume fractions over the studied range of $R a_{H}$, but are reproducible by repeating the measurements. We also note that difference in the mixing mechanism close to the non-injection wall 
seems to be the cause of different exact scaling exponents of $\overline{N u}$ with $\alpha$ observed for $\alpha \leq 1.4 \%$ for hot and cold wall injection.

\subsubsection{Local liquid velocity measurements}

Liquid velocity measurements are performed by means of LDA with the goal of understanding the dynamics of the system and how it is affected by different bubble injection sides, heating, and different gas volume fractions, in order to relate it to our global heat transfer findings.

In the previous section we have seen that $\overline{N u}$ is slightly higher for hot wall injection when compared to cold wall injection for lower gas volume fractions. In order to examine this further we performed velocity measurements at half height of the setup in the direction normal to the heated and cooled walls for the case of lowest studied gas volume fraction $\alpha=0.4 \%$. In figures 3.8, we show the vertical and horizontal liquid velocity profiles for both hot-wall and cold-wall injections without the heating (cold side injection measurements are mirrored around $x / L=0.5$ ). The vertical velocity profile shows a high positive value at the injection side which is of the same order of magnitude as the bubble rising velocity, while the horizontal velocity is always negative indicating that the injected side is entraining the fluid from the opposite side. These findings are in agreement with the results of Roig et al. (1998) [76] who studied a turbulent bubbly mixing layer, which was produced by applying different inlet conditions of liquid velocity and gas volume fraction in two halves of a vertical square water channel. They found that even a very low difference between the gas volume fraction in the two halves of the setup induces strong acceleration of the fluid on the injection side of the mixing layer and a bending of the flow. Figure 3.8 (a) also shows the vertical velocity profiles for different injection sides with the heating $(\Delta T=5.6 \mathrm{~K})$. Results shown in figure 3.8 (a) indicate that heating and the side of injection do not have a significant influence on the mean velocity profiles. These findings do not comply with the ones for the global heat transfer possibly because the interaction of boundary layers with the co-current or counter-current bulk can only be captured by measuring velocity even closer to the heated and cooled wall, which is not possible due to strong reflections of the laser beam.

Since $\overline{N u}$ depends strongly on the gas volume fraction but not on $R a_{H}$ we now look into the influence of gas volume fraction on the measured velocity profiles. In figure 3.9, we show the vertical and horizontal velocity profiles at half height for gas volume fractions of $\alpha=0.4 \%$ and $\alpha=3.9 \%$. The horizontal velocity profiles are slightly higher in the centre of the setup for $\alpha=0.4 \%$. This most likely occurs due to the presence of the bubbles on the side opposite to the injection side for $\alpha=3.9 \%$, 

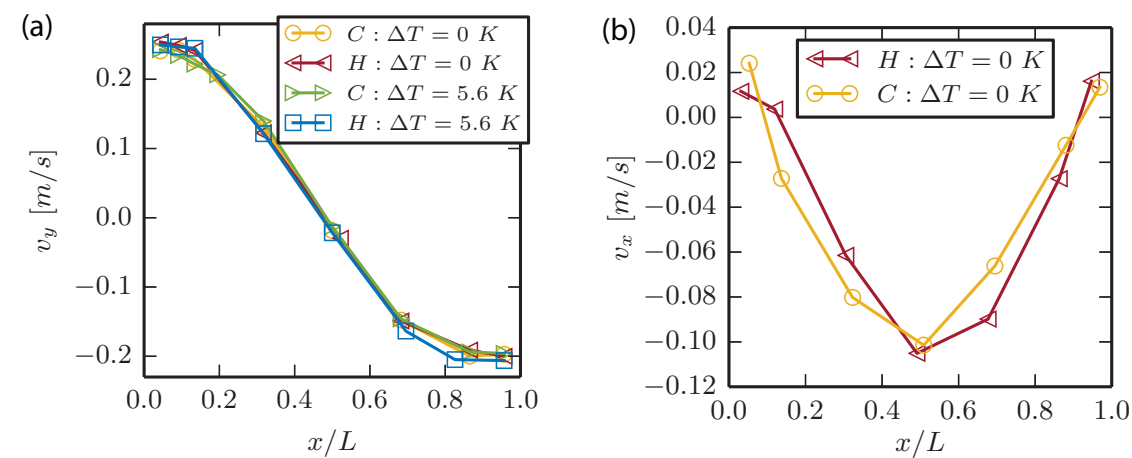

Figure 3.8: (a) Vertical velocity $\left(v_{y}\right)$ profiles for a gas volume fraction $\alpha=0.4 \%$, for different injection sides and different imposed wall temperature differences, (b) Horizontal velocity $\left(v_{x}\right)$ profiles for gas volume fraction $\alpha=0.4 \%$, for different injection sides without the heating.
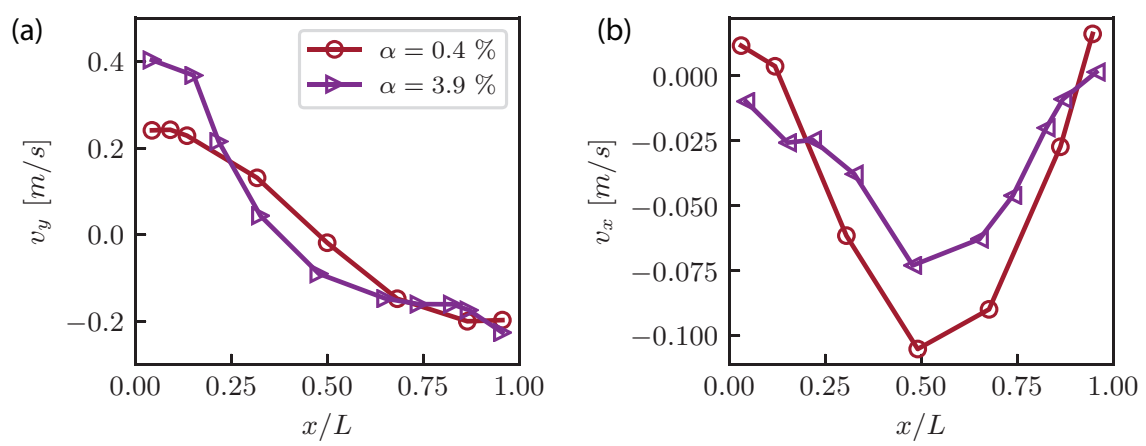

Figure 3.9: Vertical velocity $\left(v_{y}\right)$ and horizontal velocity $\left(v_{x}\right)$ profiles for different gas volume fractions without the heating. The gas injection is performed at $x / L \leq 0.5$. 
which leads to lower gradient of gas volume fraction at mid height for $\alpha=3.9 \%$ and lower driving for horizontal motion. Based on the profiles of the mean liquid velocity in the vertical direction a mean liquid rising velocity in the injection side of the setup $U$ can be estimated by averaging the velocity along the length of rising liquid layer. This way we find that the mean velocity for $\alpha=0.4 \%$ is $0.16 \mathrm{~m} / \mathrm{s}$ and for $\alpha=3.9 \%$ is $0.25 \mathrm{~m} / \mathrm{s}$. The mean velocity in the case $\alpha=0.4 \%$ is comparable to the one observed in previous studies on mixing in inhomogeneous bubbly flows (where $U=\mathcal{O}(10) \mathrm{cm})[74,75]$, which further justifies the direct comparison between the global heat transport results and findings from these studies.

\subsection{Conclusions}

An experimental study on heat transport in inhomogeneous bubbly flow has been conducted. The experiments were performed in a rectangular bubble column heated from one side and cooled from the other, where the millimetric bubbles were injected through one half of the injection section, either close to the cold wall or close to the hot wall (see figure 3.1). Two parameters were varied: the gas volume fraction (from $0.4 \%$ to $5.1 \%$ ) and the Rayleigh number (from $4 \times 10^{9}$ to $2.2 \times 10^{10}$ ).

By characterising the global heat transfer we find that in the case of bubbles injected only through one half of the injection section, just as for homogeneous bubble injection, the Nusselt number is nearly independent on the Rayleigh number and increases with increasing gas volume fraction (see Figure 3.5). However, the heat transfer enhancement is more prominent with inhomogeneously injected bubbles when compared to the same gas volume fraction and same range of $R a_{H}$ of homogeneous injection, provided $\alpha<4 \%$ (see Figure 3.6). This finding can be explained by the multiple mixing mechanisms present in the setup, once a gradient of gas volume fraction is imposed. Namely, besides the bubble induced turbulence (BIT), the large-scale circulation of the liquid phase induced by inhomogeneous bubble injection leads to the occurrence of a shear layer between the fluid region injected with bubbles and its opposite side. As previously observed by Alméras et al. (2016) [75] and Alméras et al. (2018) [74] for $\alpha<3.5 \%$, the different superimposed mixing mechanisms lead to enhancement of mixing, which results in up to 1.5 times larger heat transport as compared to homogeneous bubble injection (see Figure 3.7).

Although the measurements of the velocity in the bulk show comparable profiles for hot wall and cold wall injections (see Figure 3.8), the findings on global heat transfer indicate that the injection close to the hot wall induces stronger heat transfer enhancement for gas volume fraction lower than a critical value of $1.4 \%$ (see Figures 
3.5 and 3.6). At $\alpha \geq 1.4 \%$ we observe bubble-rich region near the non-injecting wall which promotes effective mixing near the thermal boundary layer at the wall. As a consequence the difference in the result on heat transport enhancement for the cases of hot wall and cold wall injection at $\alpha \geq 1.4 \%$ is diminished. For $\alpha<1.4 \%$ non-injection wall is not covered by bubbles, which means that in this range of $\alpha$ the co-current flow of the liquid directed from the hot wall to the cold wall aids large-scale circulation and the heat transport enhancement.

For $\alpha>4 \%$ the inhomogeneous injection causes lower heat transport enhancement than the homogeneous one. We visually observe that with increasing gas volume fraction the instability of the bubble stream increases as well as the contribution of the shear-induced turbulence (SIT). The velocity measurements show that the large-scale circulation gets stronger with increasing $\alpha$ as well (see Figure 3.9). Therefore the competition between BIT, SIT and the advection reduces the heat transport enhancement.

Lastly we comment on the generality of the obtained results on the heat transfer enhancement. When determining the generality of the results on the scaling of the Nusselt number with the gas volume fraction for lower studied gas volume fraction, one has to take into account the governing mixing mechanism in a inhomogeneous bubble column which depends on the aspect ratio (height over width) of the column and the size of the bubbles. If the bubble induced turbulence is the limiting mixing mechanism we expect the scaling of the Nusselt number to be the same, namely $N u \propto \alpha^{0.45}$. On the other hand, a significant change in the bubble size would affect the flow patterns as well. Experimentally it is challenging to generate bubbles of significantly different sizes (in this study it is varied only from $\sim 1.8 \mathrm{~mm}$ to $\sim 2.8$ $\mathrm{mm}$ ), and it is difficult to predict how would the scaling be affected by it. We expect that the evolution of Nusselt number with the Rayleigh number is also general. If the size of injected bubbles is comparable to the thickness of the thermal boundary layers (the thickness of the thermal boundary layer in the studied range of $R a_{H}$ in the single phase case is estimated to be of order of few millimeters (see § 2)) and if the bubbles are injected close to the wall so that they perturb these boundary layers we expect that $N u$ does not depend on $R a_{H}$. Unexplored effect of the changes in bubble sizes and the complexity of the interaction between different mixing mechanisms call for future investigations on this topic. 


\section{Chapter 4}

\section{Twente Mass and Heat Transfer}

Water Tunnel: Temperature controlled turbulent multiphase channel flow with heat and mass transfer

Based on: Biljana Gvozdić, On-Yu Dung, Dennis P. M. van Gils, Gert-Wim H. Bruggert, Elise Alméras, Detlef Lohse, Chao Sun, Sander G. Huisman, 'Twente Mass and Heat Transfer Water Tunnel: Temperature controlled turbulent multiphase channel flow with heat and mass transfer' In preparation. 


\subsection{Introduction}

In this chapter we present a new experimental setup for studying heat and mass transfer in turbulent bubbly flows. The new vertical water tunnel has been designed and constructed in-house and allows global temperature control, bubble injection and local heat/mass injection. This new facility offers the possibility to accurately study global and local statistics of heat and mass transfer in turbulent multiphase flows.

The wide range of applications of bubbly flows has lead to many studies on understanding the influence of bubble injection on heat and mass transfer in different configurations. While the focus of application-oriented studies is to formulate empirical correlations for the net heat and mass transfer coefficients, fundamental research focuses on measuring and characterising the local flow statistics which leads to physical insight behind the observed correlations. In particular, recent studies in turbulent bubbly flows have investigated a variety of aspects such as: (i) bubble size and velocity distributions [56, 78], (ii) global heat and mass transport measurements $[32,78,83]$, (iii) computational studies with ideal boundary conditions $[33,53]$, (iv) liquid velocity and temperature profile $[56,82,84]$, (v) homogeneous and inhomogeneous bubble injection [54, 82, 84], and (vi) natural and forced convection [50-55].

In systems of natural convection with bubble injection, mixing is provided by large scale circulations driven by density differences in the liquid and bubbles. Within such a system, studies have shown that bubble size has a major effect on the overall heat transfer [56]. However, there have been few studies on forced convective heat transfer in bubbly flows [50, 53, 85], where, in addition to buoyancy driven circulation, bubble wakes and their interplay, the mean liquid velocity provides an additional mixing mechanism. In systems of forced convection, experiments and numerical simulations have primarily focused on understanding the influence of bubble accumulation and deformability on the global mixing properties. Owing to the limitations in experimental setups [85], the highest flow Reynolds numbers reached in previous studies is only $O\left(10^{2}\right)$. However, industrial systems involving heat and mass transfer with forced convection, i.e. mean liquid velocity (for e.g. heat exchangers) reach much higher Reynolds numbers $O\left(10^{3}-10^{5}\right)$. Fundamental studies on the interaction between the turbulence in the carrier fluid, heat transfer and the dispersed bubbles at such high Reynolds numbers are currently lacking. Thus, the setup described in this chapter is built to tackle unresolved questions related to heat transfer in turbulent bubbly flow. The Twente Mass and Heat Transfer Water Tunnel will be used to: (i) quantitatively characterize the global heat transfer of a 
turbulent flow with and without gas bubble injection; (ii) correlate and understand the local heat flux with the local liquid velocity and temperature fluctuations in the bubbly turbulent flow; (iii) explore and understand the dependence of the heat transfer on the control parameters, such as the gas concentration, bubble size, and the Taylor-Reynolds number of the flow.

Another unexplored aspect of heat transport in bubbly flow is the influence of salt in the continuous phase which is highly relevant in certain industrial applications. For example, chlorate processes in chemical industry use brine (solution of $\mathrm{NaCl}$ ) as the continuous phase and the interaction of bubbles with turbulence and heat transfer in such systems is very different from bubbles in turbulence without salt. There are two possible mechanisms that might be causing the observed difference in bubbly flows with and without salt. Inclusion of salt changes the interfacial properties of the bubbles, i.e. from free-slip to no-slip. A small concentration of salt dissolved in a bubbly flow can significantly change the properties of the bubbles which may lead to drastic changes in the flow properties [86]. In order to study such flows and understand the influence of salt (in particular $\mathrm{NaCl}$ ) on the overall heat and mass transfer, we have built our setup specifically from corrosion-resistant stainless steel. In particular, we aim to: (i) understand the effect of the salt concentration on the surface properties of bubbles and the resulting change of coalescence and breakup of them; (ii) quantify the dependence of the global and local heat transport on salt concentration.

Apart from the possibility of heat transfer investigation mentioned above, mass transfer measurements can also be performed in the new vertical tunnel. The study of the transport of microparticles in turbulent bubbly flow may shed light on finding the optimal parameters for the mixing of particles in a flow with for example catalytic particles, thereby ultimately maximising the overall efficiency of the chemical reactions in a chemical reactor. Thus, we aim to find the transport mechanism of a scalar field (e.g. the concentration field of the catalytic microparticles) in a turbulent bubbly flow.

\subsection{System description}

The Twente Mass and Heat Transfer Water Tunnel (TMHT) is a recirculating vertical water tunnel for the study of heat and mass transfer in turbulent multiphase flows for both global and local quantities. We first list the main features:

- The tunnel has an internal volume of around 300 liters. 
- It is constructed out of marine-grade AISI316 stainless steel permitting the use of salt solutions in excess of $15 \%$ mass fraction.

- An $80 \mathrm{~m}^{3} / \mathrm{h}$ capacity propeller pump drives the flow upwards in the measurement section from around $0.05 \mathrm{~m} / \mathrm{s}$ up to $1 \mathrm{~m} / \mathrm{s}$.

- Up to $10 \mathrm{~kW}$ of heating power can be added into the flow by means of heater cartridges.

- A $12.5 \mathrm{~kW}$ chiller removes the added heat further downstream again and allows for global temperature control of the measurement liquid within $20 \mathrm{mK}$ long-term stability at statistically stationary conditions, see Figure $4.3 \mathrm{~b}$.

- There are three interchangeable measurement sections of each $1 \mathrm{~m}$ in length and of different cross sections, where the width $\times$ depth are either $0.3 \times 0.04 \mathrm{~m}^{2}$, $0.3 \times 0.06 \mathrm{~m}^{2}$ or $0.3 \times 0.08 \mathrm{~m}^{2}$.

- Using water at $21^{\circ} \mathrm{C}$ and a flow velocity range covering $0.05 \mathrm{~m} / \mathrm{s}$ to $1 \mathrm{~m} / \mathrm{s}$ in the measurement section results in a Reynolds number range of $\mathrm{Re}=1.5 \times 10^{4}$ to $3 \times 10^{5}$, where $\operatorname{Re}=U W / \nu$ with $U$ the mean flow velocity, $W$ the width of the measurement section and $\nu$ the dynamic viscosity of the liquid.

- Three of the four walls of each measurement section are made of glass (front, back and one side) in order to gain optical access to the flow allowing techniques such as high-speed imaging, laser-Doppler anemometry, particle image velocimetry, particle tracking velocimetry and laser-induced fluorescent imaging.

- In the case of heat transfer studies, the tunnel is intended to operate at statistically stationary conditions with the tunnel liquid temperature around the ambient lab temperature to ensure minimal heat flux through the walls.

- Millimetric bubbles can be injected into the flow by 140 exchangeable capillaries. The gas volume fraction inside the measurement section can be measured electronically and can go up to $7.5 \%$ depending on the flow conditions.

- An active turbulent grid consisting of agitator flaps that rapidly rotate inside the flow agitates the turbulence inside the measurement section to achieve high turbulent intensity levels.

- A computer-controlled two-axis traversing frame allows for positioning sensors inside of the measurement section in order to obtain local quantities, such as the local temperature by using thermistors with a few $\mathrm{mK}$ resolution, or the local gas volume fraction by using the optical fiber probe technique [77].

- The local heat flux inside the flow can be measured by simultaneously acquiring local velocity with laser-Doppler anemometry and local temperature with a thermistor. 
In the next sections we will describe the TMHT facility in more detail.
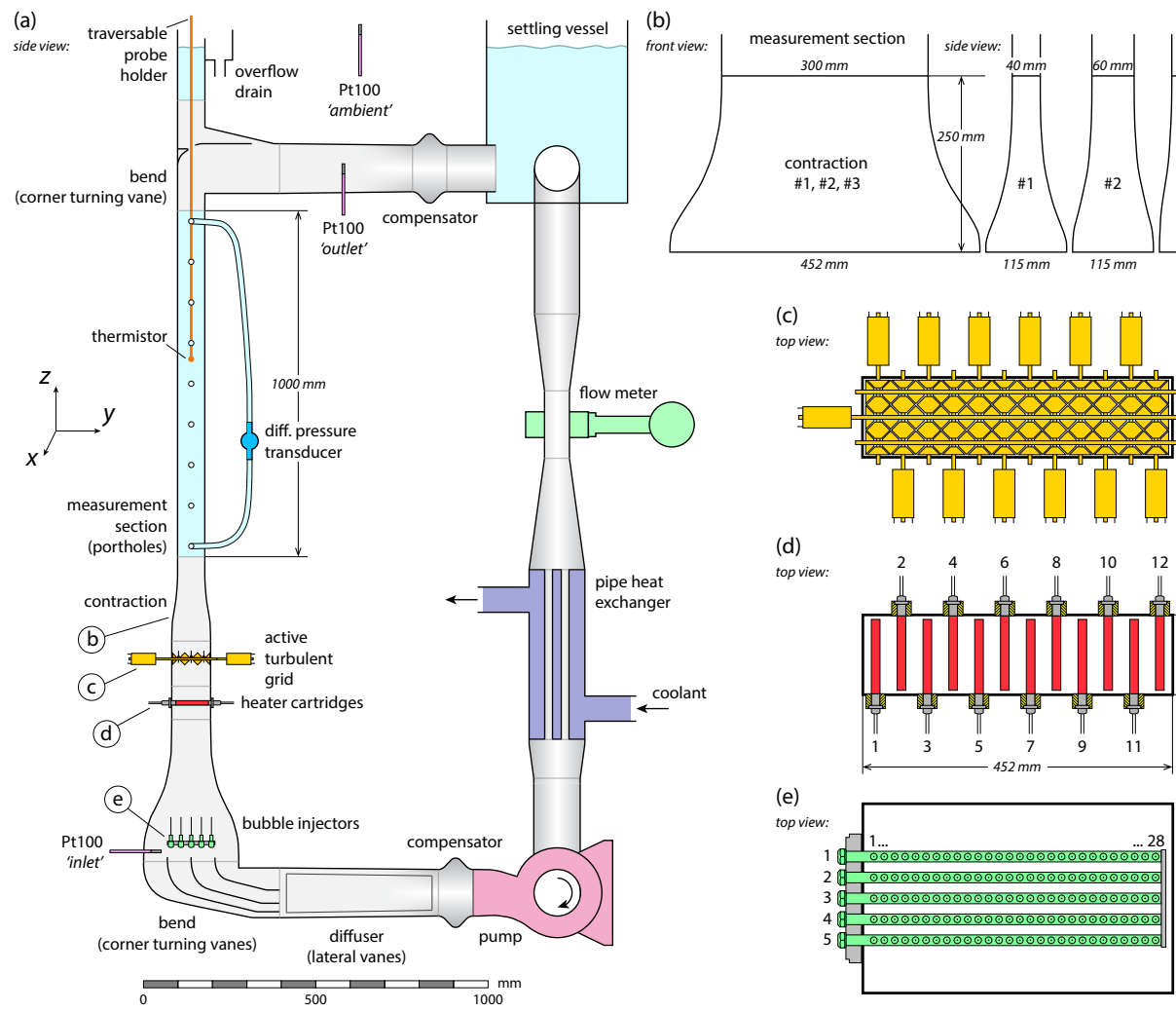

Figure 4.1: Schematic of the Twente Mass and Heat Transfer Water Tunnel (TMHT). $x, y$, and $z$ are the spanwise, wall-normal, and streamwise directions, respectively, where each of the measurement sections has dimensions $W$ (width), $D$ (depth), and $L$ (length) in the $x, y$, and $z$ directions. (a) A side view cross-section of the tunnel showing the major components. (b) The front and side profiles of the three exchangeable measurement sections and their respective contractions. (c) A top view of the active turbulent grid showing the fifteen independently rotating rods with agitator flaps attached to them, here all in their horizontal position for displaying purposes. (d) The twelve cylindrical heater cartridges in red and the thermal insulation in yellow. (e) Bubble injection provided by five rows of each twenty-eight exchangeable capillaries. The rows can be opened and closed independently from each other. See Sec. 4.2.1 for a walk-through description. 


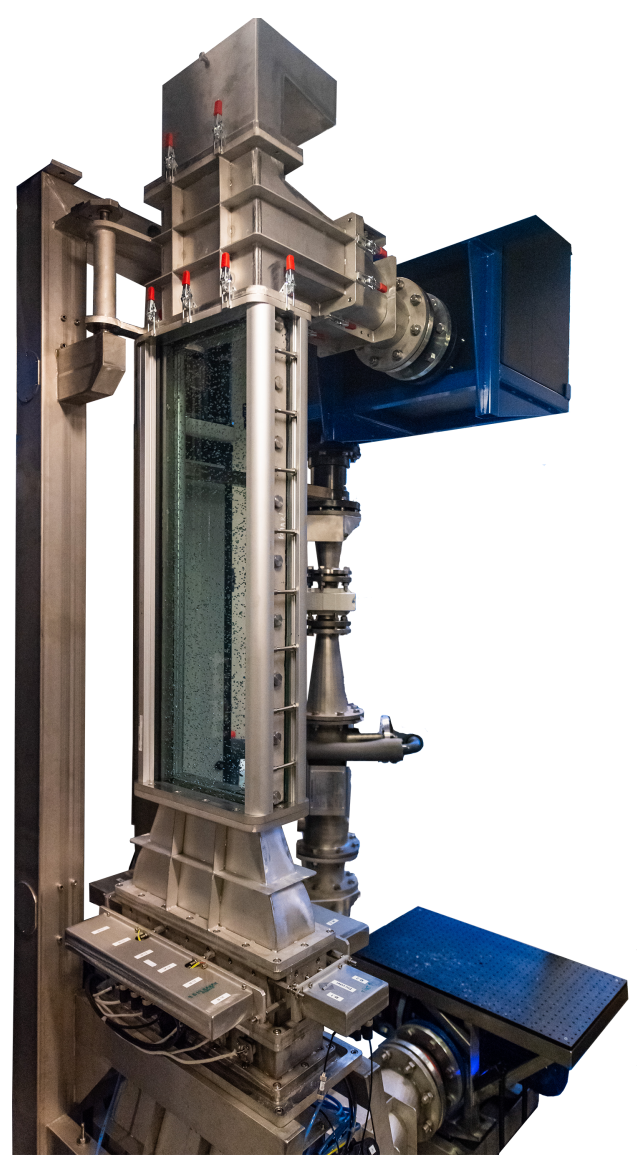

Figure 4.2: The Twente Mass and Heat Transfer Water Tunnel (TMHT) in the lab. In the front (from bottom to top): the heaters, active grid and the measurement section. In the back (from top to bottom): settling vessel, flow meter, the heat exchanger and the pump. 


\subsubsection{Overview}

Here follows a quick walk-through of all the major components of the tunnel, see Figure 4.1 for a schematic picture and Figure 4.2 for a photo. Starting from the pump, the flow is expanded from a circular cross-section to a larger rectangular area by the diffuser that has two laterally adjustable vanes inside to help steer the flow sideways. The flow then enters the bend and is guided by three corner-turning vanes to facilitate uniformity in the downstream flow velocity profile.

A Pt100 temperature probe measures the bulk 'inlet' liquid temperature and 140 exchangeable capillaries (detailed in Figure 4.1e) can inject bubbles into the flow near the bottom of this vertical tunnel section. Two modular sections follow that can be interchanged with each other. These are the section containing the heater cartridges (detailed in Figure 4.1d) and the section with the active turbulent grid (detailed in Figure 4.1c). A contraction placed downstream of these sections prevents the flow separation, it contracts the flow over its width ( $x$-direction) and depth ( $y$-direction).

There are three interchangeable measurement sections of different cross sections that can be installed next, where the width and depth are either $0.3 \times 0.04 \mathrm{~m}^{2}$, $0.3 \times 0.06 \mathrm{~m}^{2}$, or $0.3 \times 0.08 \mathrm{~m}^{2}$, each with a matching contraction of height $0.25 \mathrm{~m}$ (detailed in Figure 4.1b). Each measurement section is $1 \mathrm{~m}$ tall and their front, back and one of the sides are made of glass. The remaining sidewall is of stainless steel and has equidistant portholes for inserting probes or injecting dye and a wet/wet differential pressure transducer is attached to two of these portholes to monitor the gas volume fraction. The top part of the tunnel directly above the measurement section is open and this can be used to insert a long probe holder, with e.g. a thermistor attached to its end, down into the measurement section. The pole is attached to a computer-controlled two-axis traversing frame (not shown) allowing automated positioning over the $x$ and $z$-directions. The $y$-direction can be traversed manually by a positioning stage. Going over into the next bend we find another Pt100 temperature probe to register the bulk 'outlet' liquid temperature. Another Pt100 probe on the outside of the tunnel monitors the ambient air temperature of the lab. The flow then enters the settling vessel where bubbles can rise up to the surface or where salt can be mixed into the liquid. Going downwards from the vessel the flow is sped up by a funnel to pass through an electromagnetic flow rate meter. Lastly, all heat that was added by the heater cartridges can be removed again by the pipe heat exchanger which is fed with coolant from a chiller, after which the flow enters the pump again. 


\subsubsection{Flow control and adjustment}

The flow in the tunnel is driven by a custom close-coupled axial flow propeller pump (Herborner Pumpenfabrik, Uniblock P 125-201/0074) fully cast from marine-grade AISI316 stainless steel to allow the use of saline solution. The capacity is $80 \mathrm{~m}^{3} / \mathrm{h}$ at a maximum power of $0.75 \mathrm{~kW}$ and $1500 \mathrm{rpm}$. The three-phase electric motor of the pump is controlled by a digital frequency inverter (Herborner Pumpenfabrik, PED).

Directly after the pump is a rubber compensator to accommodate for thermal expansion of the tunnel. A diffuser with a circular inlet of $\varnothing 136 \mathrm{~mm}$ expands the flow to a rectangular outlet of $452 \times 146 \mathrm{~mm}^{2}$. Inside the diffuser are two adjustable lateral vanes to help spread the flow sideways. The next bend directs the flow upwards. Inside the bend are three adjustable corner turning vanes that guide the flow and help increase flow velocity uniformity after the bend.

An electromagnetic flow meter (ABB, ProcessMaster FEP311) with a bore of $\varnothing 65$ $\mathrm{mm}$ measures the volumetric flow rate over its nominal range of $2.4 \mathrm{~m}^{3} / \mathrm{h}$ to 120 $\mathrm{m}^{3} / \mathrm{h}$. According to the manual the measurement accuracy is better than $1 \%$ if the flow velocity through the meter is larger than $0.2 \mathrm{~m} / \mathrm{s}$, which is the reason for choosing this specific bore diameter. The flow is sped up by a funnel with an inclination angle of $8^{\circ}$ before entering the meter.

The flow rate reported by the flow meter is continuously read out by an Arduino M0 Pro microcontroller board over a 4-20 mA current loop. A tuned proportional-integral controller programmed into the Arduino feeds back to the propeller rotation rate of the tunnel pump over another 4-20 mA current loop to ensure a stable flow rate and velocity over time within $1 \%$ of the setpoint, see Figure 4.3e and Figure 4.3f.

\subsubsection{Temperature control and heat injection}

Heat can be injected into the flow by twelve cylindrical heater cartridges (Watlow, Firerod J5F-15004) placed $300 \mathrm{~mm}$ below the measurement section and sticking perpendicular to the flow direction through the front and back tunnel walls, see Figure 4.1d. Each heater cartridge has a diameter of $12.7 \mathrm{~mm}$ and a heated zone of $110 \mathrm{~mm}$ long as measured from its tip inside the tunnel, indicated by red. The end of the heated zone matches the start of the interior tunnel wall. Each heater is thermally insulated from the wall by a Teflon (PTFE) feed-through, indicated by yellow. A J-type thermocouple with an accuracy of $\pm 2.2 \mathrm{~K}$, for the absolute temperature, is embedded inside of each heater. Because the location of the thermocouple is not 
(a)

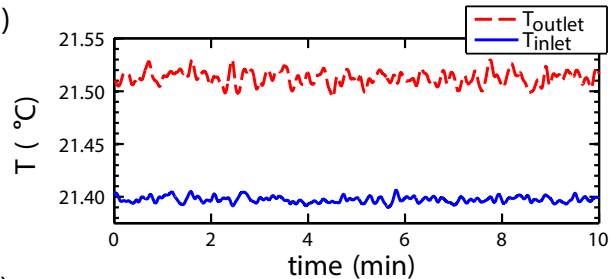

(c)

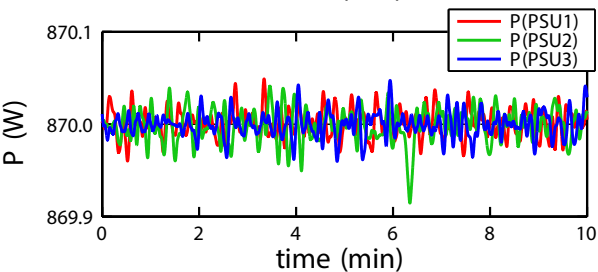

(e)

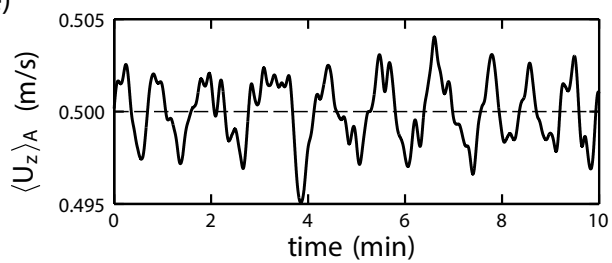

(b)

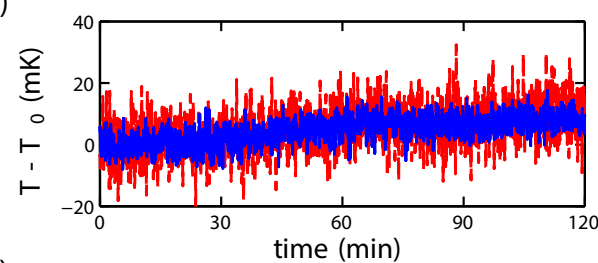

(d)

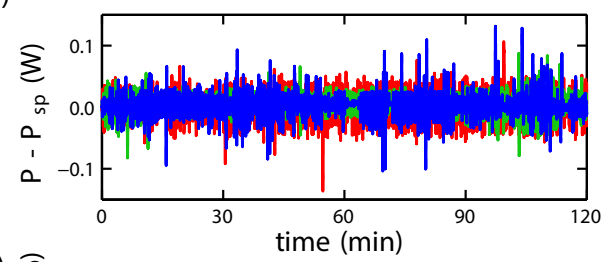

(f) $\stackrel{2}{\circ}$

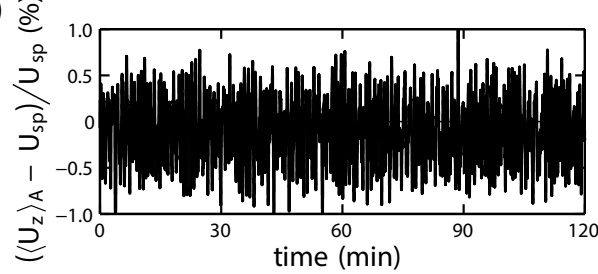

Figure 4.3: Typical timeseries of the main global tunnel quantities after having settled to statistically stationary conditions, demonstrating the short-term fluctuations in (a), (c) and (e) and the long-term stability in (b), (d) and (f). This specific case was at a set tunnel flow velocity of $\mathrm{U}_{s p}=0.5 \mathrm{~m} / \mathrm{s}$ using measurement section \#1 (subscript sp stand for setpoint), a chiller setpoint of $19{ }^{\circ} \mathrm{C}$ and a set heating power of $3 \times 870 \mathrm{~W}=2610 \mathrm{~W}$ divided over heaters 1 to 6 . Heaters 1 and 2 were connected in series to power supply PSU1, likewise 3 and 4 to PSU2 and 5 and 6 to PSU3. This caused the heaters to operate at an internal temperature of near $90{ }^{\circ} \mathrm{C}$. (a) Temperatures $\mathrm{T}$ of the tunnel inlet (solid blue) and outlet (dashed red). (b) The same data as the left panel, but with the starting temperature $\mathrm{T}_{0}$ subtracted. The temperature drift is below $20 \mathrm{mK}$ over 120 minutes. (c) Heating power $\mathrm{P}$ provided by power supplies PSU1 (red), PSU2 (green) and PSU3 (blue). (d) The same data as the left panel, but with the setpoint of the power $\mathrm{P}_{s p}$ subtracted. The power is stable within $0.15 \mathrm{~W}$ regardless of the setpoint. (e) Instantaneous streamwise flow velocity inside the measurement section $\left\langle\mathrm{U}_{z}\right\rangle_{A}$ averaged over its cross-sectional area $A$ (measured using the flow meter). The dashed line indicates the setpoint. (f) The same data as the left panel, but renormalized with the flow velocity setpoint $\mathrm{U}_{s p}$. The flow velocity is stable within $1 \%$ of the setpoint without drift over 120 minutes. 
guaranteed to be perfectly centred and a strong temperature gradient is to be expected in the interior of the heater cartridge when powered and placed in an advecting flow, the thermocouple temperature readings are only to be used as a rough indication of the heater temperature. Hence, they are solely being used for over-temperature protection. The heaters are rated for temperatures in excess of $250^{\circ} \mathrm{C}$, but will be limited by the over-temperature protection to a maximum of $95^{\circ} \mathrm{C}$ to prevent local boiling.

The heaters are operated by controlling the supply power. Each heater can provide $1160 \mathrm{~W}$ of heat at a maximum of $120 \mathrm{~V}$. They are powered by three independently programmable DC power supplies (Keysight, N8741A), each providing up to $3.3 \mathrm{~kW}$ at $300 \mathrm{~V}$ and $11 \mathrm{~A}$. Either a single heater is connected to a single power supply, or multiple heaters are connected in series to a single power supply, and any combination of this depending on the needs of the experiment. The programming accuracy of the power supplies is $150 \mathrm{mV}$ and $22 \mathrm{~mA}$, and the measurement accuracy is $300 \mathrm{mV}$ and $33 \mathrm{~mA}$. A tuned proportional-integral controller running on a computer regulates the power supply output voltage in order to tune the power output, resulting in an accuracy of the set power of $\pm 0.3 \mathrm{~W}$ with a settling time of below 10 seconds. The power is stable within $0.15 \mathrm{~W}$ regardless of the setpoint, see Figure $4.3 \mathrm{c}$ and Figure4.3d.

The bulk temperature of the liquid inside the tunnel is measured at two locations using two Pt100 temperature probes with a $1 / 10$ DIN accuracy corresponding to \pm 30 mK (Pico Technology, PT-104 data logger with SE012 probes). One probe labelled 'inlet' is upstream of the heaters at the location of the bubble injectors and protrudes $100 \mathrm{~mm}$ into the flow, see Figure 4.1a. The other probe labelled 'outlet' is downstream of the measurement section and before the settling vessel. A third Pt100 probe labelled 'ambient' measures the ambient lab air temperature.

Cooling of the tunnel liquid is taken care of by a pipe heat exchanger, manufactured on request by Geurts International, located just before the tunnel pump intake. Twenty-two marine-grade AISI316 stainless steel pipes of $500 \mathrm{~mm}$ long and with diameters of $22 \mathrm{~mm}$ through which the tunnel liquid is flowing, are embedded in an outer jacket through which cooling water is flowing. The pipe heat exchanger is designed to remove up to $10 \mathrm{~kW}$ of heat. The temperature of the cooling water is regulated by a $12.5 \mathrm{~kW}$ capacity air-cooled recirculating chiller (Thermo Scientific, ThermoFlex 15000 P5) with a listed temperature stability of $\pm 0.1 \mathrm{~K}$.

A typical example of settling times and temperature stability follows now. Starting with a quiescent water-filled tunnel at room temperature takes up to 2.5 hours to settle to a statistically stationary state, from the moment of setting the flow rate to 
$21.6 \mathrm{~m}^{3} / \mathrm{h}$ (equivalent to a velocity of $0.5 \mathrm{~m} / \mathrm{s}$ in the measurement section \#1), the global heat input to $2.6 \mathrm{~kW}$ and the setpoint of the chiller at $19{ }^{\circ} \mathrm{C}$. After this settling time, we report a long-term stability of the tunnel liquid temperature of $\pm 20 \mathrm{mK}$ for over 2 hours long, see Figure 4.3.

\subsubsection{Local temperature measurements}

High precision and local temperature measurements can be made with thermistors. We use thermistors from TE Connectivity (Measurement Specialties G22K7MCD419) with a glass bead of diameter $0.38 \mathrm{~mm}$ and a listed response time of $30 \mathrm{~ms}$ in liquids. All thermistors are calibrated against the 'inlet' Pt100 probe with a 1/10 DIN accuracy corresponding to $\pm 30 \mathrm{mK}$ (Pico Technology, PT-104 data logger with SE012 probe) inside of a large copper body placed in a temperature bath with a $5 \mathrm{mK}$ temperature stability (PolyScience, PD15R-30) resulting in a calibration accuracy of $\pm 30 \mathrm{mK}$ and a $5 \mathrm{mK}$ resolution.

Temperature timeseries can be acquired by using a dual-phase lock-in amplifier (Stanford Research, SR830) in combination with a balanced Wheatstone bridge of which one arm is a single thermistor. A digital acquisition card (National Instruments, PCI-6221) logs the amplifier's output voltage to a file on the computer. Multiple thermistors can be logged during a measurement by a digital multimeter (Keysight, 34972A) installed with a reed-relay multiplexer board (Keysight, 34902A) that will scan sequentially over all the thermistor resistance values with a listed scan rate of up to 250 channels per second.

\subsubsection{Traverse}

Accurately positioning thermistors, optical fibers or other probes inside of the measurement section and automatically scanning over multiple grid points is made possible by a custom-build two-axis traversing frame located above the tunnel. The traverse consists of two linear actuators (Parker, HMRB15SBD0-1800 and HMRB11SBD0-1000), powered by two servomotors (Parker, SMHA60451 and SMH60301) and digitally operated by two controllers (Parker, Compax3). The traverse can travel over the full width ( $x$-direction) and full height ( $z$-direction) of the measurement section. A probe holder is attached to the traverse carriage and descents into the measurement section from an opening in the top of the tunnel. The carriage can be positioned with an accuracy of $\pm 0.1 \mathrm{~mm}$. The third axis (depth, $y$-direction) can be traversed over manually by using the micro-stage that is in between the traverse carriage and the traverse pole. 


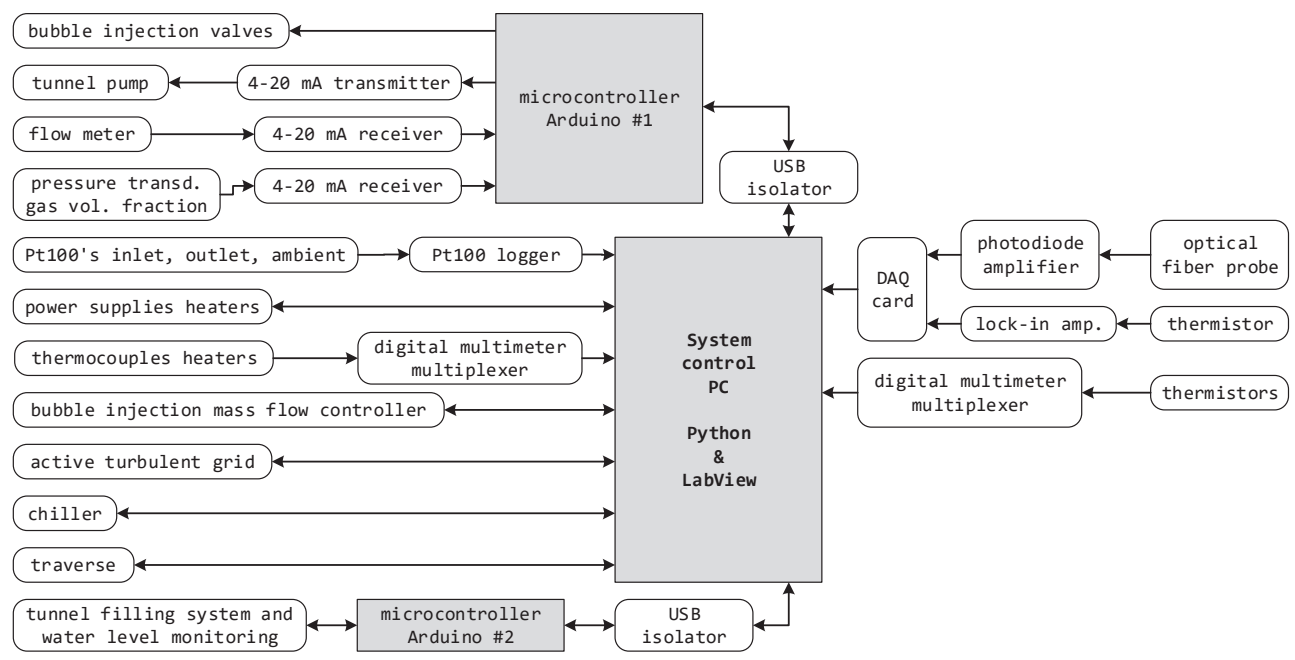

Figure 4.4: System control diagram. The tunnel filling system and water level monitoring running on Arduino \#2 are not discussed in this work and are mentioned for completeness.

\subsubsection{Bubble injection and gas volume fraction}

Bubbles can be injected into the flow by the pressurised air lines that are fed through the wall of the tunnel located underneath the heater cartridges. The lines are pressurised at 8 bars and connected to five rows of twenty-eight Luer lock fittings, see Figure 4.1a and Figure 4.1e. The standardised Luer lock allows for a wide variety of needles/capillaries to be installed and easily replaced (e.g. Nordson precision stainless steel dispensing tips), ranging from inner diameters of $0.2 \mathrm{~mm}$ to $2 \mathrm{~mm}$. The resulting size of the bubbles detaching from the capillaries may be influenced by the local velocity and shear of the surrounding liquid, surfactants, air flow rate, and the geometry of the tip of the capillaries. Each of the five rows can be opened or closed individually by computer controlled piston valves. A digital mass flow controller (Bronkhorst, F-111AC-50K-AAD-22-V) drives air through all five rows up to 44 litres per minute.

The global gas volume fraction over the full height of the measurement section is monitored by a wet/wet differential pressure transducer (Omega, PXM409170HDWUI). The pressure transducer is connected to two portholes, with a distance of $\Delta L=0.96 \mathrm{~m}$ in height apart, at the side of the measurement section. Each of these portholes has just a narrow channel of $1.0 \mathrm{~mm}$ in diameter that connects 
to the tunnel's internal volume. This ensures that no air will enter the lines from the portholes towards the pressure transducer and that they are always filled with liquid. The resulting difference in static pressure between these lines and the liquid column inside the measurement section translates into the relation $\alpha=\Delta P /\left(g \rho_{l} \Delta L\right)$, where $\alpha$ is the global gas volume fraction over the measurement section, $\Delta P$ is the measured pressure difference, $g$ the local acceleration of gravity, $\rho_{l}$ the density of the liquid and $\Delta L$ the distance in height between the portholes. We report a constant measurement accuracy in $\alpha$ of $\pm 0.2 \%$, given already in units of the gas volume fraction percentage. With the current iteration of the facility and injecting $36 \mathrm{l} / \mathrm{min}$ of air through the bubble injection capillaries, we can achieve a maximum of $\alpha=7.8 \pm 0.2 \%$ when the tunnel pump is switched off, and e.g. $\alpha=5.3 \pm 0.2 \%$ at a flow velocity of $0.5 \mathrm{~m} / \mathrm{s}$ inside measurement section $\# 1$.

The local gas volume fraction, bubble size and bubble velocity statistics can be obtained by the optical fiber probe technique. For details on this experimental technique and signal processing we refer to Cartellier [77] and van Gils et al. [47].

\subsubsection{Active turbulent grid}

The active turbulent grid consists of fifteen independently rotating rods with agitator flaps attached to them that stir up the liquid flowing past, see Figure 4.1a and Figure 4.1c. It resembles the grid described in paragraph $\S 3.3 .1$ of Poorte and Biesheuvel[87], albeit with modern DC-motors (Maxon, DCX32L GB KL 24V) and controllers (Beckhoff, EL7332) and with only 15 rods instead of 24 because of the smaller cross-sectional area of the tunnel. There are several forcing protocols that can be used to drive the rods independently at varying rotation speeds and direction for varying periods of time. The study over the different protocols by Poorte and Biesheuvel[87] revealed that the double-random asynchronous mode protocol is the most favourable, as this protocol does not lead to periodicities in the turbulent power spectrum directly downstream of the grid. Hence, this protocol (P0238) is the standard we use in our studies. In short, it varies the rotation speed of a single rod and the duration of that rotation by randomly choosing values from the intervals $\left[-\Omega_{m}, \Omega_{m}\right]$ and $[50,90] \mathrm{ms}$, respectively. A control parameter called 'grid speed factor' $G S F$ will rescale the value of $\Omega_{m}$, such that the amount of agitation can be tailored. For example, the nominal value of $\Omega_{m}$ at a grid speed factor of 0.5 corresponds to $18 \mathrm{~Hz}$. 


\subsubsection{System control}

The system control of the TMHT facility is controlled by two programmable multifunction microcontroller boards in conjunction with a PC, see Figure 4.4 for a simplified diagram. The boards used are two Arduino M0 Pro which are powered by a SAMD21 microcontroller unit from Atmel, featuring a 32-bit ARM Cortex M0 core.

One major source of electrical noise is carried by the lab facility electrical ground. Inductive spikes induced by e.g. motors or switching relays can travel over the ground leads and can interfere with the sensitive microcontrollers. To prevent ground loops, ground noise, or inductive spikes from reaching the sensitive microcontrollers, one has to float the microcontroller board with respect to the lab facility ground potential. We do this by powering the microcontrollers using a noise-suppressing power supply (Traco Power, TCL 120-112) whose output is left floating with respect to ground. That means that ground-referenced peripheral devices cannot be connected to the Arduino directly, lest we loose the floating ground reference. Hence, all USB connections from the microcontrollers to the PC are galvanically isolated by USB isolators (Olimex, USB-ISO). Also, all peripheral digital sensors and actuators are connected to the microcontrollers with opto-couplers in between.

All analog signals from and to the microcontrollers (i.e. set pump speed, flow meter and read pressure transducer) transmit over 4-20 mA current loops, which are inherently insensitive to electrical noise in contrast to using voltage as a data carrier. The 4-20 mA current transmitter and receivers used are, respectively MIKROE-1296 T Click and MIKROE-1387 R Click from MikroElektronika. The remaining peripheral devices (i.e. the Pt100 data logger, programmable power supplies, digital multimeter multiplexers, mass flow controller, active turbulent grid, chiller and traverse controllers) are directly connected to the PC.

The main control program is running in Python 3.6 on the $\mathrm{PC}$ and handles all device input/output communication including the microcontrollers, with the exception of the active turbulent grid which is running on LabView from National Instruments. The main program has a graphical user interface to provide control, monitoring, and data logging of the TMHT facility, whose global quantities are logged at a rate of $10 \mathrm{~Hz}$. The Python libraries that have been written to provide multithreaded communication with the specific laboratory devices including the Arduino microcontrollers are made available under the MIT open-source license and can be found at the GitHub repository [88]. 


\subsection{Measurements}

\subsubsection{Velocity profile measurements}

As a first step in demonstrating robustness and consistency of the setup, we measure the liquid velocity using two experimental techniques: laser Doppler anemometry (LDA) in backscatter mode and particle image velocimetry (PIV) in measurement section $\# 1$ (width $\times$ depth: $0.3 \times 0.04 \mathrm{~m}^{2}$ ). For LDA measurements the flow is seeded with polyamid seeding particles (diameter $5 \mu \mathrm{m}$, density $1050 \mathrm{~kg} / \mathrm{m}^{3}$ ). The LDA system used consists of DopplerPower DPSS (diode-pumped solid-state) laser and a Dantec burst spectrum analyser (BSA). For PIV measurements we seed the flow with fluorescent tracer particles (diameter $50 \mu \mathrm{m}$ ). We use a high speed laser (Litron LDY-303HE) with a cylindrical lens to generate a sheet of light passing through the centre of the glass side-wall of the measurement section $(y / D=0.5)$. A double-frame camera (PCO Imager sCMOS) at 20 fps was used to obtain the velocity field. All the velocity profiles obtained using PIV presented in this section are calculated by averaging the velocity over several heights, covering $\pm 5 \mathrm{~cm}$ around the noted height.

In figure 4.5 we plot the normalised mean profile of the streamwise and spanwise velocity obtained from PIV measurements for different mean flow rates, namely $0.3 \mathrm{~m} / \mathrm{s}, 0.5 \mathrm{~m} / \mathrm{s}, 0.8 \mathrm{~m} / \mathrm{s}$, and $1.0 \mathrm{~m} / \mathrm{s}$, for a constant active grid speed factor of 0.5 . We find that the variation of the mean horizontal and vertical velocity is negligible in the bulk of the setup, namely not more than $\pm 1.5 \%$ from the mean streamwise velocity. In figure $4.5 \mathrm{~b}$ we see that the spanwise velocity has a positive and negative peak, which is a signature of the contraction section placed downstream of the measurement section.

Next, we look at the velocity profiles for $\left\langle U_{z}\right\rangle_{A}=0.5 \mathrm{~m} / \mathrm{s}$ and $G S F=0.5$ at different heights, namely at $z / L=0.25, z / L=0.5$ and $z / L=0.75$. In figure 4.6 a we see that the streamwise velocity remains constant (within $\pm 2 \%$ ) along the width at different heights. By scanning the velocity at different heights we observe that the influence of the contraction on the spanwise velocity reduces as the height increases, although its amplitude is only of order of $1 \%$ of the streamwise component (see Figure $4.6 \mathrm{~b})$.

In figure 4.7 we plot the turbulence intensity measured using PIV at half-height for $\left\langle U_{z}\right\rangle_{A}=0.5 \mathrm{~m} / \mathrm{s}$ and study the influence of the active grid on the velocity statistics. By varying the grid speed factor (GSF) from 0 to 1 , it is easily observed that the active grid has a strong influence on the velocity fluctuations. For a grid speed factor (GSF) equal to zero, the active grid is switched off, and the rods are placed in such 

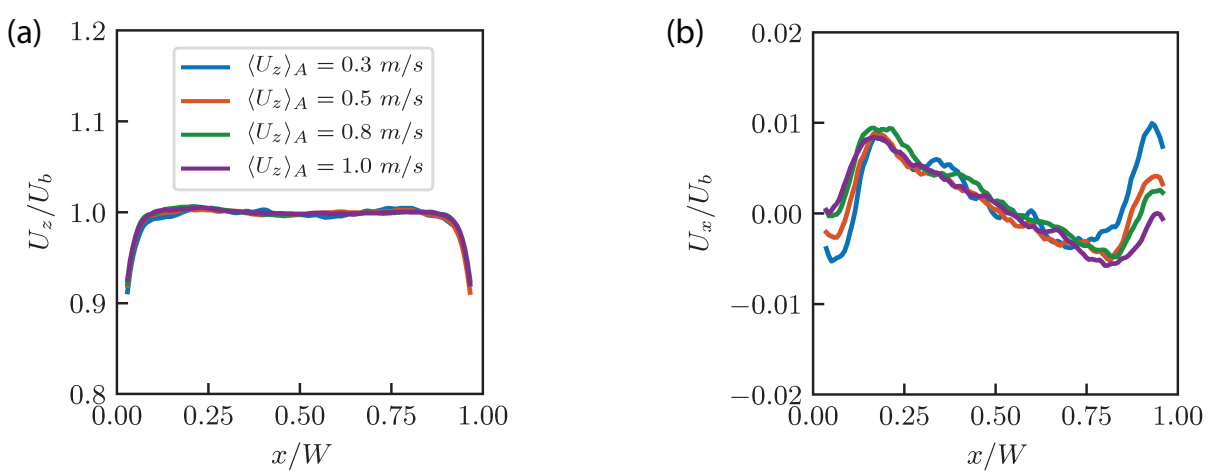

Figure 4.5: Normalised (a) streamwise $U_{z}$ and (b) spanwise $U_{x}$ velocity profile along the width of the setup at half-height obtained from PIV measurements for different mean flow rates $\left\langle U_{z}\right\rangle_{A}$ and constant speed of the active grid (the active grid is running at $G S F=0.5) . U_{b}$ is the streamwise velocity in the bulk, calculated by averaging the measured velocity over the width $x / W=0.25$ to $x / W=0.75$.
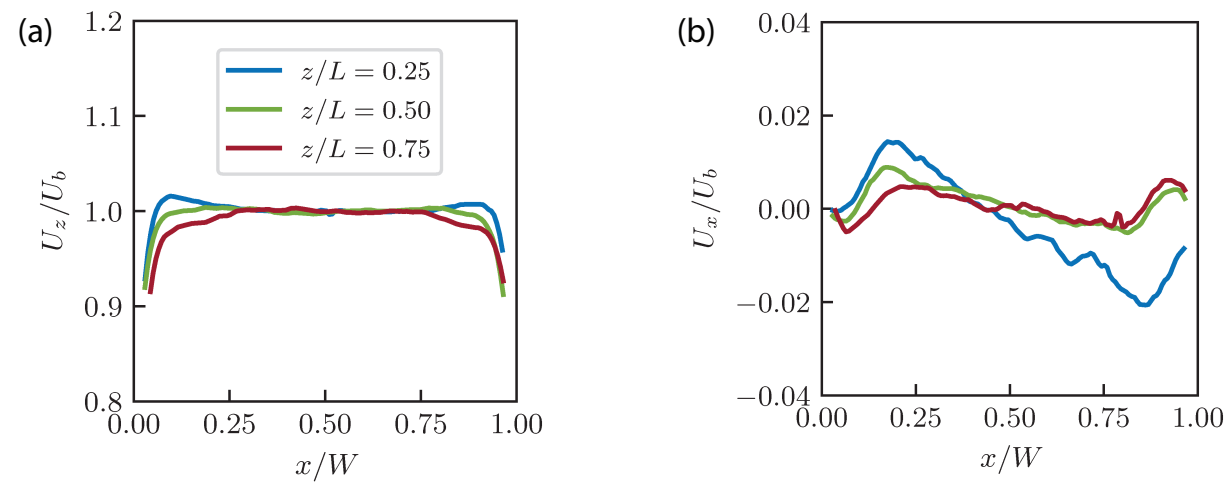

Figure 4.6: Normalised (a) streamwise $U_{z}$ and (b) spanwise $U_{x}$ velocity profile along the width of the setup obtained from PIV measurements at different heights for mean flow rate of $\left\langle U_{z}\right\rangle_{A}=0.5 \mathrm{~m} / \mathrm{s}$ and constant speed of the active grid $G S F=0.5 . U_{b}$ is the streamwise velocity in the bulk at each height, calculated by averaging the measured velocity over the width $x / W=0.25$ to $x / W=0.75$. 

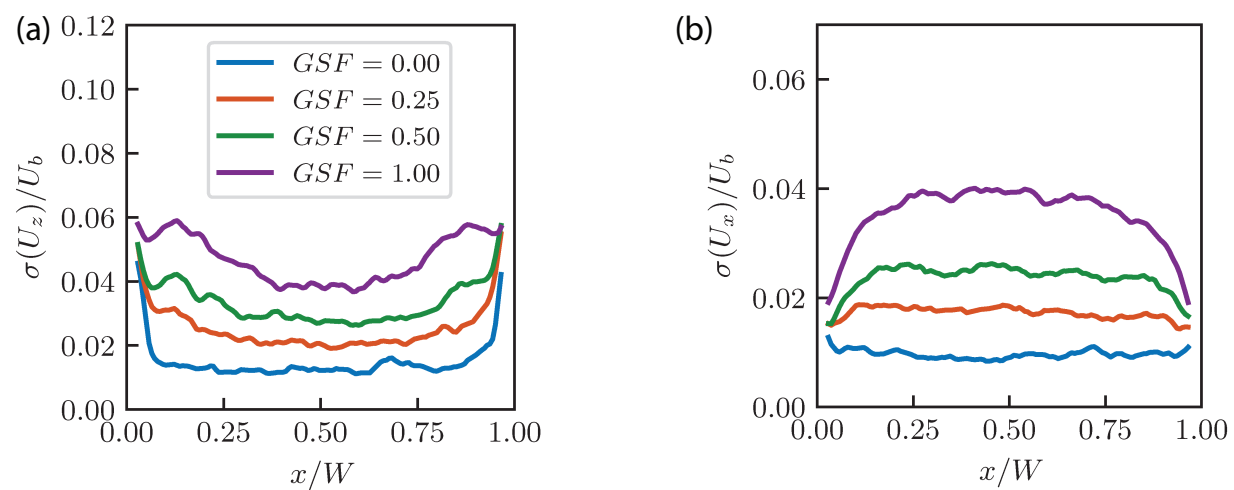

Figure 4.7: Turbulence intensity in (a) streamwise and (b) spanwise direction along the width of the measurement section at half-height obtained from PIV measurements for $\left\langle U_{z}\right\rangle_{A}=0.5 \mathrm{~m} / \mathrm{s}$ and varying speed of rotation of the active grid (varying the value of the grid speed factor $(G S F))$. $G S F=0$ corresponds to the measurement with the active grid switched off, while for $G S F=1$ rods are rotating at a maximum speed. $\sigma\left(U_{z}\right)$ is the standard deviation of the streamwise velocity, while $\sigma\left(U_{x}\right)$ is the standard deviation of the spanwise velocity.

a way that the flaps are open, forming a passive grid instead. In this case we observe the weakest velocity fluctuations. As the GSF increases the fluctuations increase up to 3 times, and for each of the cases the velocity fluctuations remain nearly constant along the width in the bulk. In Figure 4.8 we show the probability density function of the streamwise velocity obtained from LDA measurements for different GSF at the centre of the $\operatorname{setup}(x / W=0.5, y / D=0.5, z / L=0.5)$ at mean flow rate of $0.5 \mathrm{~m} / \mathrm{s}$. We observe that for all the settings of the active grid the distribution of the vertical velocity nearly follows Gaussian, with skewness of around 0.2 and kurtosis of around 3.25 for all cases.

Lastly, we examine the homogeneity in the wall-normal direction by measuring the vertical velocity along the depth of the setup at $z / L=0.5,\left\langle U_{z}\right\rangle_{A}=0.5 \mathrm{~m} / \mathrm{s}$ and $G S F=0.5$ using LDA. Results presented in Figure 4.9 demonstrate that the velocity is nearly constant in the wall-normal direction as well, with variations of only around $\pm 2 \%$ from $y / D=0.2$ to $y / D=0.8$. 


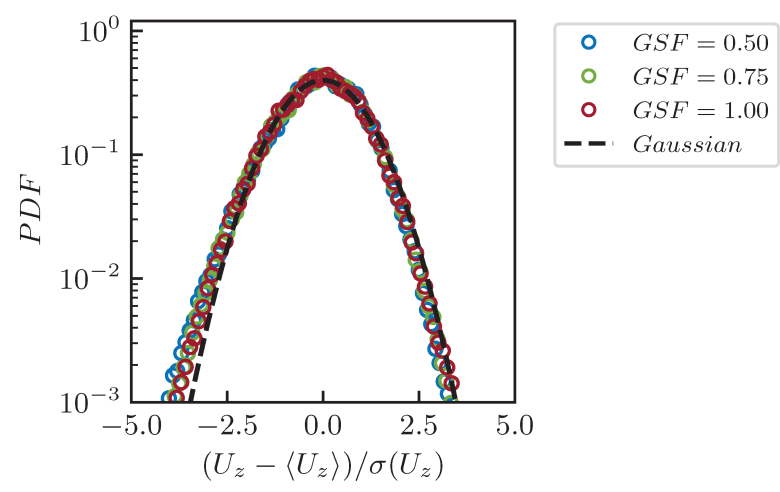

Figure 4.8: Probability density function of the streamwise velocity for $\left\langle U_{z}\right\rangle_{A}=$ $0.5 \mathrm{~m} / \mathrm{s}$ and different values of the grid speed factor, obtained at $x / W=0.5, y / D=$ $0.5, z / L=0.5$ using LDA. Gaussian with zero mean and unit variance is added for reference.

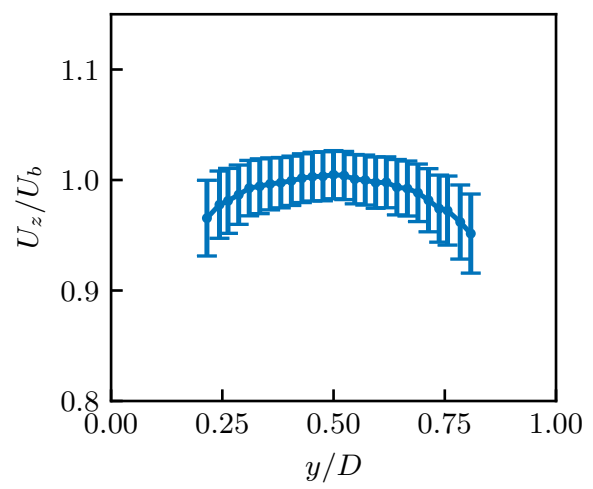

Figure 4.9: Scan of the vertical velocity along the depth of the setup at half-height performed using LDA for $\left\langle U_{z}\right\rangle_{A}=0.5 \mathrm{~m} / \mathrm{s}$ and $G S F=0.5$. The bars corresponds to \pm 1 standard deviation of the velocity. 


\subsubsection{Local temperature measurements}

Here we examine the influence of heating of one half of the heating section on the temperature profile in the measurement section of dimensions width $\times$ depth $0.3 \times 0.04 \mathrm{~m}^{2}$, with the mean liquid flow of $0.5 \mathrm{~m} / \mathrm{s}$ and the grid speed factor of 0.5 . In this specific configuration six heaters (out of total twelve) which are placed in the left half $(x / W \leq 0.5)$ of the heating section have been supplied by a constant power of $870 \mathrm{~W}$ each. The thermistor for the temperature measurements is inserted to the measurement section from the sidewall of the section and traversed over the width at half height. The measurements are logged at $2 \mathrm{~Hz}$ by a digital multimeter over 2 hours after statistically steady state is achieved. Figure 4.10 shows temperature profile obtained in such a way, where heating was introduced in the heating section $x / W \leq$ 0.5 . Here $\Delta T=T_{\text {inlet }}-T$ is the difference between temperature measured before the heaters $T_{\text {inlet }}$ and the temperature measured in the bulk in the measurement section $T$. We observe decrease in $\Delta T$ from $x / W=0$ to $x / W=1$ as a consequence of heating of only one half of the section.

After passing the heated section warm and cold volume of liquid mix resulting in different temperature signals in the measurement section at $x / W=0.25, x / W=0.5$ and $x / W=0.75$ (see Figure 4.11a)). This is also reflected on the probability density function shown in figure 4.11b). Namely, negative skewness is observed for the signal at $x / W=0.25$ due to non-heated liquid penetrating to the opposite side of the section. In the center, where the mixing between cold and warm part of the bulk is the most intense there is no skewness present, positive and negative fluctuations are equally represented. Again at $x / W=0.75$ warm liquid parcels penetrate the cold part of the bulk yielding a positively skewed PDF.

\subsubsection{Dispersion of a passive scalar in a turbulent bubbly flow}

The TMHT offers the possibility of studying the mixing of a passive scalar in a turbulent bubbly flow. The primary advantage of this setup over, for example, the Twente Water Tunnel [89] is that in this setup we can easily achieve gas volume fractions higher than 1\%. For the purpose of studying mixing of a low-diffusive dye induced by a swarm of high Reynolds number bubbles rising within a turbulent flow we inject a fluorescent dye (Fluorescein sodium) in the tunnel with the measurement section \#2 (dimensions width $\times$ depth $0.3 \times 0.06 \mathrm{~m}^{2}$ ). The dye injector (diameter $2 \mathrm{~mm}$ ) is placed in the middle of the cross-section $20 \mathrm{~cm}$ away from the bottom of the measurement section. The injection is performed over 60 seconds at a flow rate matching the mean liquid velocity in the tunnel $(\sim 30 \mathrm{~cm} / \mathrm{s})$. The images of the 


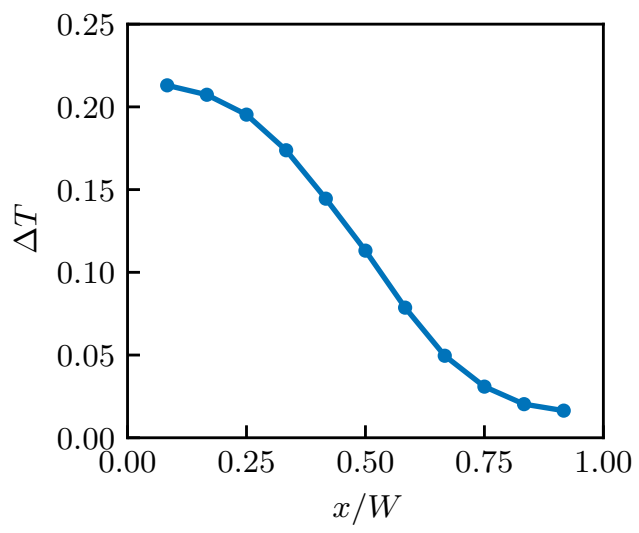

Figure 4.10: Temperature profile at half height in the case of heating of the left half $x / W=0$ to $x / W=0.5$ of the setup. Here $\Delta T=T_{\text {inlet }}-T$, where $T_{\text {inlet }}$ is the inlet temperature measured before the heaters, and $T$ is the temperature measured by a thermistor in the measurement section.

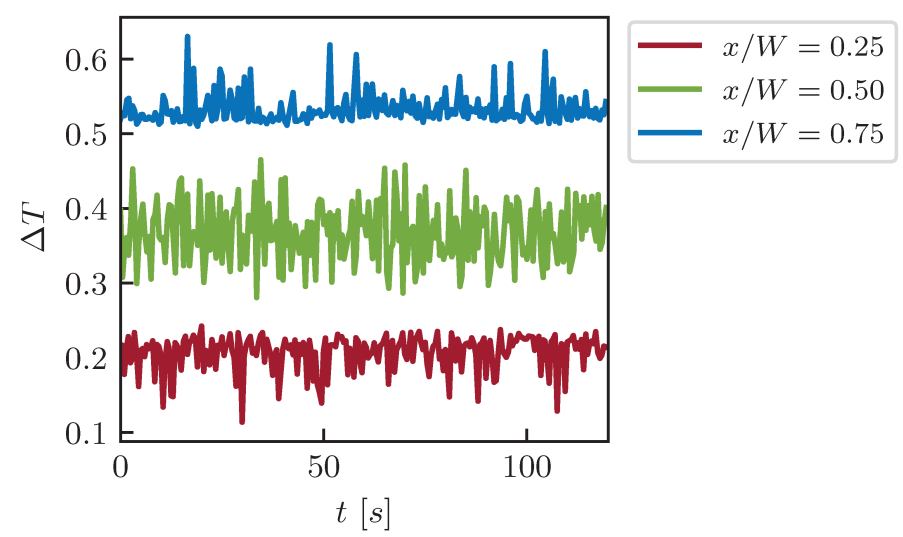

Figure 4.11: Temperature series measured at different locations: $x / W=0.25$ above the heated area, $x / W=0.50$ in the centre of the setup and $x / W=0.75$ above the non-heated area. Note that for the signals at $x / W=0.50$ and $x / W=0.75$ an offset of 0.25 and 0.50 is applied respectively for clarity. 


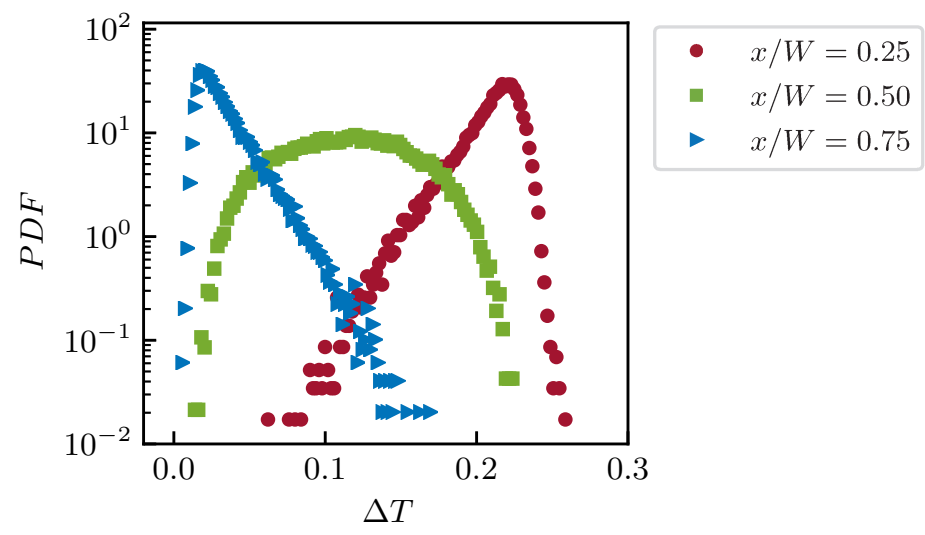

Figure 4.12: Probability density function of the temperature at different locations of the setup: $x / W=0.25$ above the heated area, $x / W=0.50$ in the centre of the setup and $x / W=0.75$ above the non-heated area.

flow are taken 10 second after the start of the injection, using two synchronized and vertically aligned cameras (Imager sCMOS, Lavision) with $105 \mathrm{~mm}$ macro lenses and optical band-pass filters (450-650 nm).

In figure $4.13 \mathrm{a}$, we show an instantaneous snapshot of the fluorescent dye being advected and diffused in the presence of a bubbly turbulent flow. Using a time-series of such snapshots, we measure the mean intensity profiles of the fluorescent light $I$ across the width of the setup at different heights; profiles for a few selected heights are shown in figure $4.13 \mathrm{~b}$. The profiles are symmetric due to the homogeneity of the flow in the horizontal direction. Additionally we find that the profiles are nearly Gaussian, suggesting that the spreading of the dye in the horizontal dimension is dominated by diffusion. The objective of future studies is to obtain the horizontal diffusion coefficient by measuring concentration of the dye by means of quantitative laser induced fluorescence. For further details on this experimental technique we refer to Alméras et al. [65]. 
(a)

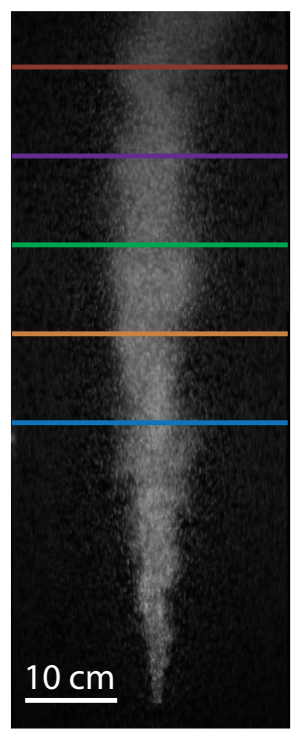

(b)
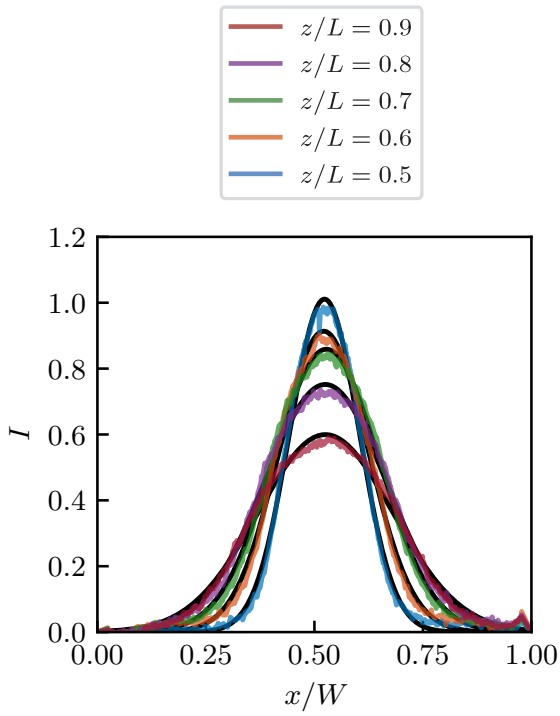

Figure 4.13: Dispersion of a fluorescent dye in a bubbly turbulent flow with $\left\langle U_{z}\right\rangle_{A}=$ $0.30 \mathrm{~m} / \mathrm{s}$. (a) Instantaneous snapshot of the flow taken an an arbitrary time showing the spatial distribution of the fluoresced light. (b) Time averaged light intensity profiles across the width of the setup at different heights (in colour) and corresponding Gaussian fits. 


\subsubsection{Salt}

As discussed in the section 4.1, the TMHT also allows the possibility to study the dynamics of bubbles injected in brine (salt solution). We perform preliminary tests by varying the mean liquid flow rate, gas flow rate, and the concentration of salt $(\mathrm{NaCl})$ in the brine solution with a constant grid speed factor $G S F=0.4$, while using the measurement section \#2. In figure 4.14, we show snapshots for the different cases. Images were taken using Photron SA1 camera with 1000 frames per second.

We visually observe a big difference in the flow regimes as we increase the salt concentration (by mass) of the solution from $c_{m}=0 \%$ to $c_{m}=12 \%$. The effect is more pronounced when the gas flow rate is higher, which may be due to presence of more smaller bubbles caused by the increase in surface tension by the addition of salt. This also leads to a change in the deformability of the bubbles and consequently in the dynamics of the system.

By means of image processing, we measure the bubble diameter for the cases of mean liquid velocity $0.15 \mathrm{~m} / \mathrm{s}$ and $0.25 \mathrm{~m} / \mathrm{s}$ and gas flow rate of $5 \mathrm{l} / \mathrm{min}$ for varying salt concentrations. In figures $4.15 \mathrm{a}$ and $4.15 \mathrm{~b}$, we show sample images from two different simple image processing algorithms for edge detection implemented using Matlab. For cases with low concentration of salt $\left(c_{m} \leq 1.3 \%\right)$ we identify contours of objects as well as boundaries of holes inside these objects (see Figure 4.15a). Criteria used to identify bubbles is that the area of the outermost object is 1.3 times greater than the area of the object completely enclosed by it. For the case of high salt concentration $c_{m}=12 \%$, where more spherical bubbles are present, bubbles are selected by identifying round objects under the condition that the bubbles are in focus (see Figure 4.15b). Each method detects at least 1300 bubbles for each of the examined cases. Average bubble diameters obtained this way are shown in figure $4.15 \mathrm{c}$. We find that a small increase of the concentration of salt from $c_{m}=0 \%$ to $c_{m}=1.3 \%$ significantly decreases the average bubble diameter. Further increase the salt concentration from $c_{m}=1.3 \%$ to $c_{m}=12 \%$ seems to have almost no influence on the average bubble diameter. For each examined salt concentration increase in mean liquid flow rate resulted in almost no change in average bubble diameter. Future studies in this setup will be dedicated to studying the effect of salt on the dynamics of the system and the coupling of heat transport with salt concentration. 


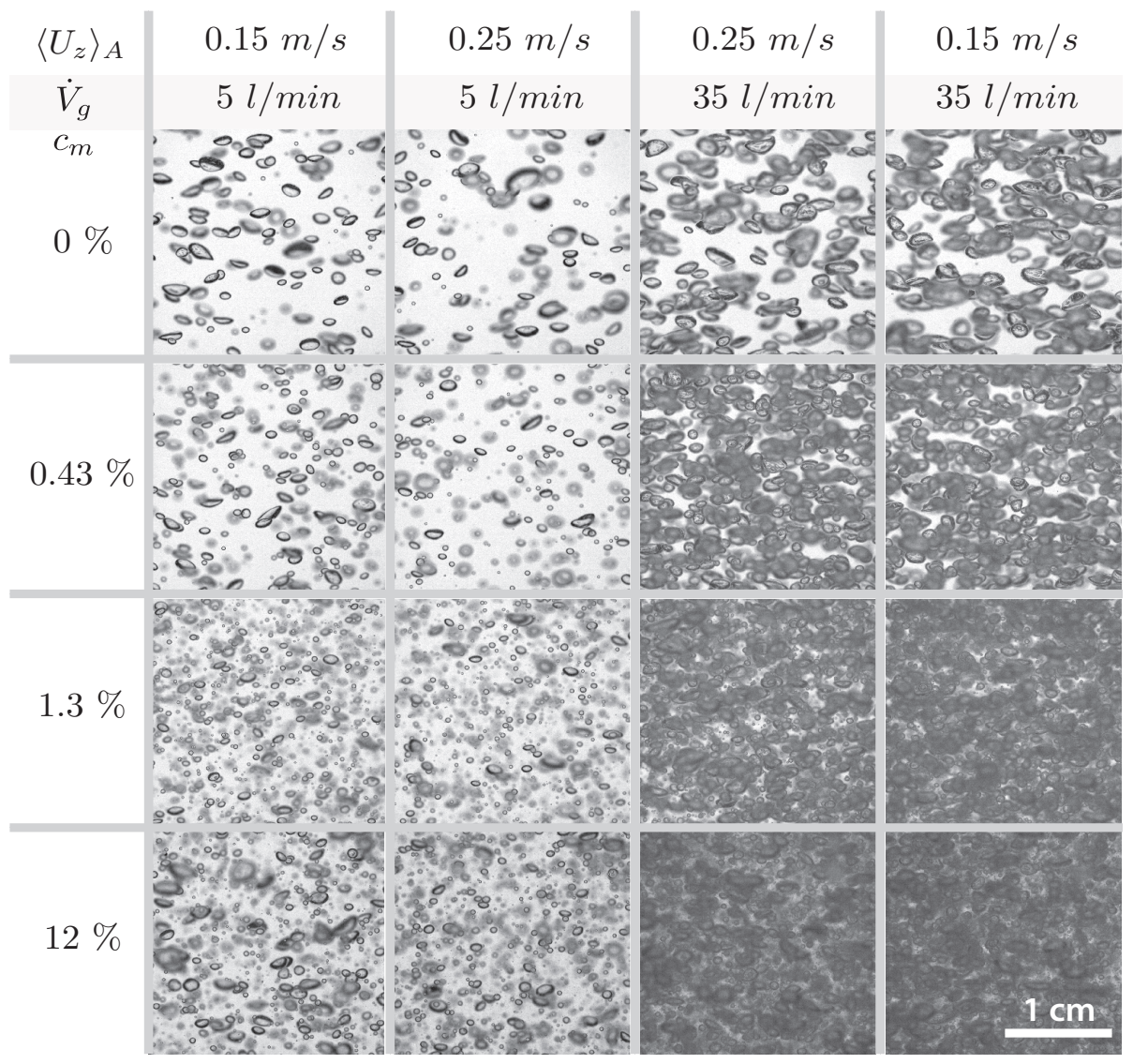

Figure 4.14: Snapshots of the flow in TMHT with the addition of salt. $\left\langle U_{z}\right\rangle_{A}$ is the mean liquid stream-wise velocity, $\dot{V}_{g}$ is the gas flow rate, $c_{m}$ is the mass fraction of salt in the solution. 
(a)

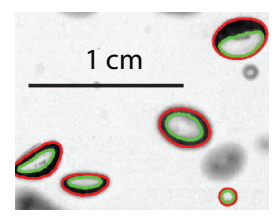

(b)

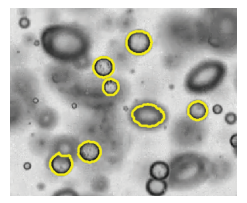

(c)

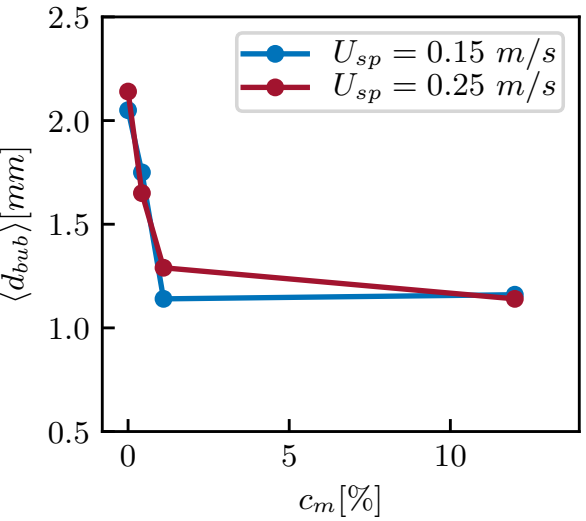

Figure 4.15: (a) Zoom of a snapshot for the case of mean liquid velocity $\left\langle U_{z}\right\rangle_{A}=$ $0.15 \mathrm{~m} / \mathrm{s}$, gas flow rate $\dot{V}=5 \mathrm{l} / \mathrm{min}$ and $c_{m}=0 \%$ showing bubbles identified as pairs of objects; (b) Zoom of a snapshot for the case of $\left\langle U_{z}\right\rangle_{A}=0.15 \mathrm{~m} / \mathrm{s}$, gas flow rate $\dot{V}=5 \mathrm{l} / \mathrm{min}$ and $c_{m}=12 \%$ showing bubbles identified as round objects; (c) Mean bubble diameter for $\left\langle U_{z}\right\rangle_{A}=0.15 \mathrm{~m} / \mathrm{s}$ and $\left\langle U_{z}\right\rangle_{A}=0.25 \mathrm{~m} / \mathrm{s}$ for varied salt concentration.

\subsection{Summary}

A new experimental facility the Twente Mass and Heat Transfer Water Tunnel (TMHT) has been built. This facility has global temperature control, bubble injection and local heat/mass injection and offers the possibility to study heat and mass transfer in turbulent multiphase flow. The tunnel is made of high-grade stainless steel permitting the use of salt solutions in excess of $15 \%$ mass fraction, besides water. The total tunnel volume is 300 liters. Three interchangeable measurement sections of $1 \mathrm{~m}$ height but of different cross sections $\left(0.3 \times 0.04 \mathrm{~m}^{2}, 0.3 \times 0.06 \mathrm{~m}^{2}, 0.3 \times 0.08\right.$ $\mathrm{m}^{2}$ ) span a Reynolds-number range from $1.5 \times 10^{4}$ to $3 \times 10^{5}$ in the case of water at room temperature. The glass vertical measurement sections allow for optical access to the flow, enabling techniques such as laser Doppler anemometry, particle image velocimetry, particle tracking velocimetry, and laser-induced fluorescent imaging. Thermistors mounted on a built-in traverse provide local temperature information at a few milli-Kelvin accuracy. Combined with simultaneous local velocity measurements the local heat flux in single phase and two phase turbulent flow can be studied.

We demonstrate long term and short term stability of the power of the heaters, of the inlet and outlet temperature of the tunnel and the mean flow rate. PIV and 
LDA measurements were performed for a variety of flow conditions to show that homogeneity of the flow is satisfying. Preliminary temperature measurements in single phase, and measurements with salt and dye injection in two phase flows were performed as well. 
Chapter 5

Summary and outlook 
Bubble injection in convective flows has proven to be a useful method of enhancing heat transfer. In order to understand the underlying physics behind bubble induced heat transfer enhancement, in this thesis we study the global and local flow statistics in a canonical vertical natural convection flow with bubble injection. Additionally, we have designed and built a new experimental facility Twente Mass and Heat Transfer Water Tunnel, which allows for global temperature control, bubble injection and local heat/mass injection. This setup will be used for studying of heat and mass transfer in turbulent multiphase flows.

In $\S 2$ we perform experiments in a rectangular bubble column heated from one side and cooled from the other with homogeneous bubble injection from the bottom. We independently control the Rayleigh number and the gas volume fraction and study the effect on the global heat transfer. The gas volume fraction ranges from $0 \%$ to $5 \%$, and the bubble diameters are around $2.5 \mathrm{~mm}$. The Rayleigh number is in the range $4.0 \times 10^{9}-1.2 \times 10^{11}$. We find that two completely different mechanisms govern the heat transport in flows with and without bubbles. In the single-phase case, the vertical natural convection is driven solely by the imposed difference between the mean wall temperatures. In this configuration the temperature acts as an active scalar driving the flow. The Nusselt number which quantifies the overall heat transport increases with increasing Rayleigh number, and as expected effectively scales as: $\overline{N u} \sim R a_{H}^{0.33}$. However, in the case of homogeneous bubbly flow the heat transfer comes from two different contributions: natural convection driven by the horizontal temperature gradient and the bubble induced diffusion, where the latter dominates. This is substantiated by our observations that the Nusselt number in bubbly flow is nearly independent of the Rayleigh number and depends solely on the gas volume fraction, scaling as: $\overline{N u} \propto \alpha^{0.45}$. We thus find nearly the same scaling as in the case of the mixing of a passive tracer in a homogeneous bubbly flow for a low gas volume fraction [65], which implies that the bubble-induced mixing is indeed limiting the efficiency of the heat transfer. For single-phase flow, the mean temperature remains constant in the bulk at mid-height which is completely obstructed by the mixing induced by bubbles in two-phase flow. Injection of bubbles induces up to 200 times stronger temperature fluctuations. These fluctuations cover a wide spectrum of frequencies and are thus the signature of the heat transport enhancement due to bubble injection. A clear slope of -1.4 at the scales $f \simeq 0.1 \mathrm{~Hz}-3 \mathrm{~Hz}$ was also observed.

In $\S 3$, we study the effect of inhomogeneous injection of bubbles on the overall heat transport. The experiments were performed in the same setup as in $\S 2$, with millimetric bubbles injected only through one half of the injection section, either 
close to the cold wall or close to the hot wall. Two parameters were varied: the gas volume fraction (from $0.4 \%$ to $5.1 \%$ ) and the Rayleigh number (from $4 \times 10^{9}$ to $2.2 \times 10^{10}$ ). By characterising the global heat transfer we find that in the case of bubbles injected only through one half of the injection section, just as for homogeneous bubble injection, the Nusselt number is nearly independent on the Rayleigh number and increases with increasing gas volume fraction. However, the heat transfer enhancement is more prominent with inhomogeneously injected bubbles when compared to the same gas volume fraction and same range of $R a_{H}$ of homogeneous injection, provided $\alpha<4 \%$. This finding can be explained by the multiple mixing mechanisms present in the setup, once a gradient of gas volume fraction is imposed. Namely, besides the bubble induced turbulence (BIT), the large-scale circulation of the liquid phase induced by inhomogeneous bubble injection leads to the occurrence of a shear layer between the fluid region injected with bubbles and its opposite side. The different superimposed mixing mechanisms lead to enhancement of mixing, which results in up to 1.5 times larger heat transport as compared to homogeneous bubble injection. For $\alpha>4 \%$, the inhomogeneous injection causes lower heat transport enhancement than the homogeneous one. We visually observe that with increasing gas volume fraction the instability of the bubble stream increases as well as the contribution of the shear-induced turbulence (SIT). The velocity measurements show that the large-scale circulation gets stronger with increasing $\alpha$ as well (see Figure 3.9). Therefore the competition between BIT, SIT and the advection reduces the heat transport enhancement.

Although the measurements of the velocity in the bulk show comparable profiles for hot wall and cold wall injections, the findings on global heat transfer indicate that the injection close to the hot wall induces stronger heat transfer enhancement for gas volume fraction lower than a critical value of $1.4 \%$. At $\alpha \geq 1.4 \%$ we observe bubble-rich region near the non-injecting wall which promotes effective mixing near the thermal boundary layer at the wall. As a consequence the difference in the result on heat transport enhancement for the cases of hot wall and cold wall injection at $\alpha \geq 1.4 \%$ is diminished. For $\alpha<1.4 \%$ the non-injection wall is not covered by bubbles, which means that in this range of $\alpha$ the co-current flow of the liquid directed from the hot wall to the cold wall aids large-scale circulation and the heat transport enhancement.

In $\S 2$ and $\S 3$, the heater capacities limited the range of $R a_{H}$ that was studied. In the studied range of $R a_{H}$ bubble-induced mixing contributed to global heat transfer much more than the natural convection. Future studies should focus on extending the range of studied $R a_{H}$ in order to make the contribution of the natural 
convection comparable to the contribution of the bubble induced turbulence to the global heat transfer. Numerical simulations of such a system will go a long way in complimenting experimental measurements and to disentangle the different influence of bubble injection on global heat transfer. In the experiments presented in $\S 2$ and $\S 3$, we have limited ourselves to a gas volume fraction of $5 \%$. However, many industrial processes have gas volume fractions as high as 30\%. Experimental techniques for measuring local quantities in such conditions need to be developed.

In order to accurately study heat and mass transfer in turbulent multiphase flow we built a unique experimental setup, the Twente Mass and Heat Transfer Water Tunnel, presented in $\S 4$. The new vertical water tunnel has global temperature control, bubble injection and local heat/mass injection. The total tunnel volume is 300 liters. Three interchangeable measurement sections of $1 \mathrm{~m}$ height but of different aspect ratios $\left(0.3 \times 0.04 \mathrm{~m}^{2}, 0.3 \times 0.06 \mathrm{~m}^{2}, 0.3 \times 0.08 \mathrm{~m}^{2}\right)$ span a Reynolds-number range from $1.5 \times 10^{4}$ to $3 \times 10^{5}$ in the case of water at room temperature. The glass vertical measurement sections allow for optical access to the flow, enabling techniques such as laser Doppler anemometry, particle image velocimetry, particle tracking velocimetry and laser-induced fluorescent imaging. Thermistors mounted on a built-in traverse provide local temperature information at a few milli-Kelvin accuracy. Combined with simultaneous local velocity measurements the local heat flux in single phase and two phase turbulent flow can be studied. A largely unexplored area of research is the fundamentals of heat transport in bubbly flows in the presence of salt. Heat transfer in salt solutions (e.g. brine) is highly relevant for certain industrial applications such as chlorate processes, heat exchangers etc. Taking this into account, we built the tunnel with high-grade stainless steel, making it suitable for studying previously unexplored heat transfer in salt solution in excess of $15 \%$ mass fraction. Future studies using this facility will focus on understanding the dependency of heat efficiency on control parameters such as gas volume fraction, bubble size, Taylor-Reynolds number and salt concentration. By quantifying the spatial distribution of the local heat flux due to bubble injection we will gain more insight into the fundamentals of heat transport in bubbly flows in the presence of grid generated turbulence. 


\section{Bibliography}

[1] L. R. Glicksman. Energy efficiency in the built environment. Physics Today, 61(7):35, 2008.

[2] F. P. Incropera. Liquid cooling of electronic devices by single-phase convection, volume 3. Wiley-Interscience, 1999.

[3] G. Ahlers, S. Grossmann, and D. Lohse. Heat transfer and large scale dynamics in turbulent Rayleigh-Bénard convection. Rev. Mod. Phys., 81:503, 2009.

[4] D. Lohse and K.-Q. Xia. Small-scale properties of turbulent Rayleigh-Bénard convection. Annu. Rev. Fluid Mech., 42:335-364, 2010.

[5] X.-D. Shang, X.-L. Qiu, P. Tong, and K.-Q. Xia. Measured local heat transport in turbulent rayleigh-bénard convection. Phys. Rev. Lett., 90(7):074501, 2003.

[6] E. van der Poel. Structures, boundary layers and plumes in turbulent Rayleigh-Bénard convection. PhD thesis, University of Twente, 2015.

[7] A. Bejan. Heat transfer. John Wiley \& Sons, 1993.

[8] K. L. Chong, S. Huang, M. Kaczorowski, and K.-Q. Xia. Condensation of coherent structures in turbulent flows. Phys. Rev. Lett., 115(26):264503, 2015.

[9] P.-E. Roche, B. Castaing, B. Chabaud, and B. Hébral. Observation of the $1 / 2$ power law in Rayleigh-Bénard convection. Phys. Rev. E, 63(4):045303, 2001.

[10] J.-C. Tisserand, M. Creyssels, Y. Gasteuil, H. Pabiou, M. Gibert, B. Castaing, and F. Chilla. Comparison between rough and smooth plates within the same Rayleigh-Bénard cell. Phys. Fluids, 23(1):015105, 2011.

[11] Y.-C. Xie and K.-Q. Xia. Turbulent thermal convection over rough plates with varying roughness geometries. arXiv preprint arXiv:1703.03137, 2017.

[12] X. Zhu, R. J. A. M. Stevens, R. Verzicco, and D. Lohse. Roughness-facilitated local $1 / 2$ scaling does not imply the onset of the ultimate regime of thermal convection. Phys. Rev. Lett., 119(15):154501, 2017.

[13] L. Léal, M. Miscevic, P. Lavieille, M. Amokrane, F. Pigache, F. Topin, B. Nogarède, and L. Tadrist. An overview of heat transfer enhancement methods 
and new perspectives: Focus on active methods using electroactive materials. Int. J. Heat Mass Transfer, 61:505-524, 2013.

[14] T. Alam and M.-H. Kim. A comprehensive review on single phase heat transfer enhancement techniques in heat exchanger applications. Ren. Sust. Energy Rev., 81:813-839, 2018.

[15] J. L. Fernández and R. Poulter. Radial mass flow in electrohydrodynamically-enhanced forced heat transfer in tubes. Int. J. Heat Mass Transfer, 30(10):2125-2136, 1987.

[16] S. Wangnipparnto, J. Tiansuwan, S. Jiracheewanun, T. Kiatsiriroat, and C.-C. Wang. Air side performance of thermosyphon heat exchanger in low reynolds number region: with and without electric field. Energy Conv. Manag., 43(14):1791-1800, 2002.

[17] Q. Li and Y. Xuan. Experimental investigation on heat transfer characteristics of magnetic fluid flow around a fine wire under the influence of an external magnetic field. Exp. Therm. Fluid Sci., 33(4):591-596, 2009.

[18] M. Lajvardi, J. Moghimi-Rad, I. Hadi, A. Gavili, T. D. Isfahani, F. Zabihi, and J. Sabbaghzadeh. Experimental investigation for enhanced ferrofluid heat transfer under magnetic field effect. J. Magnetism Magnetic Mat., 322(21):3508-3513, 2010.

[19] T. Nishimura and S. Matsune. Vortices and wall shear stresses in asymmetric and symmetric channels with sinusoidal wavy walls for pulsatile flow at low reynolds numbers. Int. J. Heat Fluid Flow, 19(6):583-593, 1998.

[20] B. N. Prasad, A. Kumar, and K. D. P. Singh. Optimization of thermo hydraulic performance in three sides artificially roughened solar air heaters. Sol. Energy, 111:313-319, 2015.

[21] R. Karwa, B. K. Maheshwari, and N. Karwa. Experimental study of heat transfer enhancement in an asymmetrically heated rectangular duct with perforated baffles. Int. Comm. Heat Mass Transfer, 32(1-2):275-284, 2005.

[22] A. Layek. Performance evaluation of solar air heater having chamfered rib groove roughness on absorber plate. In AIP Conference Proceedings, volume 1298, pages 282-287. AIP, 2010.

[23] A. Tabish, R. P. Saini, and J. S. Saini. Effect of circularity of perforation holes in v-shaped blockages on heat transfer and friction characteristics of rectangular solar air heater duct. Energy Conv. Manag., 86:952-963, 2014.

[24] P. Promvonge and S. Eiamsa-ard. Heat transfer behaviors in a tube with combined conical-ring and twisted-tape insert. Int. Commun. Heat Mass Transfer, 34(7):849-859, 2007. 
[25] S. Gunes, V. Ozceyhan, and O. Buyukalaca. The experimental investigation of heat transfer and pressure drop in a tube with coiled wire inserts placed separately from the tube wall. Applied Thermal Eng., 30(13):1719-1725, 2010.

[26] V. Kongkaitpaiboon, K. Nanan, and S. Eiamsa-Ard. Experimental investigation of heat transfer and turbulent flow friction in a tube fitted with perforated conical-rings. Int.Commun. Heat Mass Transfer, 37(5):560-567, 2010.

[27] P. Promvonge, C. Khanoknaiyakarn, S. Kwankaomeng, and C. Thianpong. Thermal behavior in solar air heater channel fitted with combined rib and delta-winglet. Int. Commun. Heat Mass Transfer, 38(6):749-756, 2011.

[28] F. Risso and K. Ellingsen. Velocity fluctuations in a homogeneous dilute dispersion of high-Reynolds-number rising bubbles. J. Fluid Mech., 453:395-410, 2002.

[29] G. Riboux, F. Risso, and D. Legendre. Experimental characterization of the agitation generated by bubbles rising at high Reynolds number. J. Fluid Mech., 643:509-539, 2010.

[30] I. Roghair, J. Martinez Mercado, M. van Sint Annaland, H. Kuipers, C. Sun, and D. Lohse. Energy spectra and bubble velocity distributions in pseudo-turbulence: Numerical simulations vs. experiments. Int. J. Multiphase Flow, 37(9):1093-1098, 2011.

[31] J. Mercado Martínez, D. Chehata Gómez, D. van Gils, C. Sun, and D. Lohse. On bubble clustering and energy spectra in pseudo-turbulence. J. Fluid Mech., 650:287-306, 2010.

[32] A. T. Tokuhiro and P. S. Lykoudis. Natural convection heat transfer from a vertical plate - i. Enhancement with gas injection. Int. J. Heat Mass Transfer, 37(6):997-1003, 1994.

[33] N. G. Deen and J. A. M. Kuipers. Direct numerical simulation of wall-to liquid heat transfer in dispersed gas-liquid two-phase flow using a volume of fluid approach. Chem. Eng. Sci., 102:268-282, 2013.

[34] P. Bhuvankar and S. Dabiri. Impact of a single bubble rising near a wall on the wall-to-liquid heat flux. Int. J. Heat Mass Transfer, 116:445-457, 2018.

[35] S. Dizaji and S. Jafarmadar. Heat transfer enhancement due to air bubble injection into a horizontal double pipe heat exchanger. Int. J. Automotive Eng., 4(4):902-910, 2014.

[36] D Panahi. Evaluation of Nusselt number and effectiveness for a vertical shell-coiled tube heat exchanger with air bubble injection into shell side. Exp. Heat Transfer, 30(3):179-191, 2017. 
[37] W.-D. Deckwer. On the mechanism of heat transfer in bubble column reactors. Chem. Eng. Sci., 35(6):1341-1346, 1980.

[38] N. Kantarci, F. Borak, and K. O. Ulgen. Bubble column reactors. Process biochemistry, 40(7):2263-2283, 2005.

[39] P. Oresta, R. Verzicco, D. Lohse, and A. Prosperetti. Heat transfer mechanisms in bubbly Rayleigh-Bénard convection. Phys. Rev. E, 80(2):026304, 2009.

[40] J.-Q. Zhong, D. Funfschilling, and G. Ahlers. Enhanced heat transport by turbulent two-phase Rayleigh-Bénard convection. Phys. Rev. Lett., 102(12):124501, 2009.

[41] L. E. Schmidt, P. Oresta, F. Toschi, R. Verzicco, D. Lohse, and A. Prosperetti. Modification of turbulence in Rayleigh-Bénard convection by phase change. New J. Phys., 13(2):025002, 2011.

[42] R. Lakkaraju, R. Stevens, P. Oresta, R. Verzicco, D. Lohse, and A. Prosperetti. Heat transport in bubbling turbulent convection. Proc. Nat. Acad. Sci., 110(23):9237-9242, 2013.

[43] D. Narezo Guzman, Y. Xie, S. Chen, D. F. Rivas, C. Sun, D. Lohse, and G. Ahlers. Heat-flux enhancement by vapour-bubble nucleation in Rayleigh-Bénard turbulence. J. Fluid Mech., 787:331-366, 2016.

[44] D. Narezo Guzman, T. Fraczek, C. Reetz, C. Sun, D. Lohse, and G. Ahlers. Vapour-bubble nucleation and dynamics in turbulent Rayleigh-Bénard convection. J. Fluid Mech., 795:60-95, 2016.

[45] J. Rensen, S. Luther, and D. Lohse. The effect of bubbles on developed turbulence. J. Fluid Mech., 538:153-187, 2005.

[46] T. H. Van Den Berg, S. Luther, I. M Mazzitelli, J. M. Rensen, F. Toschi, and D. Lohse. Turbulent bubbly flow. J. Turb., (7):N14, 2006.

[47] D. P. M. van Gils, D. Narezo Guzman, C. Sun, and D. Lohse. The importance of bubble deformability for strong drag reduction in bubbly turbulent Taylor-Couette flow. J. Fluid Mech., 722:317-347, 2013.

[48] V. Spandan, R. Ostilla-Mónico, R. Verzicco, and D. Lohse. Drag reduction in numerical two-phase Taylor-Couette turbulence using an Euler-Lagrange approach. J. Fluid Mech., 798:411-435, 2016.

[49] V. N. Prakash, J. Martínez Mercado, L. van Wijngaarden, E. Mancilla, Y. Tagawa, D. Lohse, and C. Sun. Energy spectra in turbulent bubbly flows. $J$. Fluid Mech., 791:174-190, 2016.

[50] K. Sekoguchi, M. Nakazatomi, and O. Tanaka. Forced convective heat transfer in vertical air-water bubble flow. Bulletin of JSME, 23(184):1625-1631, 1980. 
[51] Y. Sato, M. Sadatomi, and K. Sekoguchi. Momentum and heat transfer in two-phase bubble flow-i. Theory. Int. J. Multiphase Flow, 7(2):167-177, 1981.

[52] Y. Sato, M. Sadatomi, and K. Sekoguchi. Momentum and heat transfer in two-phase bubble flow-ii. A comparison between experimental data and theoretical calculations. Int. J. Multiphase Flow, 7(2):179-190, 1981.

[53] S. Dabiri and G. Tryggvason. Heat transfer in turbulent bubbly flow in vertical channels. Chem. Eng. Sci., 122:106-113, 2015.

[54] A. Kitagawa, K. Kosuge, K. Uchida, and Y. Hagiwara. Heat transfer enhancement for laminar natural convection along a vertical plate due to sub-millimeter-bubble injection. Exp. Fluids, 45(3):473-484, 2008.

[55] A. Kitagawa, K. Uchida, and Y. Hagiwara. Effects of bubble size on heat transfer enhancement by sub-millimeter bubbles for laminar natural convection along a vertical plate. Int. J. Heat Fluid Flow, 30(4):778-788, 2009.

[56] A. Kitagawa and Y. Murai. Natural convection heat transfer from a vertical heated plate in water with microbubble injection. Chem. Eng. Sci., 99:215-224, 2013.

[57] A. Bejan. Convection heat transfer. John Wiley \& Sons, 2004.

[58] C. S. Ng, A. Ooi, D. Lohse, and D. Chung. Vertical natural convection: application of the unifying theory of thermal convection. J. Fluid Mech., 764:349-361, 2015.

[59] C. S. Ng, A. Ooi, D. Lohse, and D. Chung. Changes in the boundary-layer structure at the edge of the ultimate regime in vertical natural convection. $J$. Fluid Mech., 825:550-572, 2017.

[60] E. P. van der Poel, R. Ostilla-Mónico, J. Donners, and R. Verzicco. A pencil distributed finite difference code for strongly turbulent wall-bounded flows. Computers \& Fluids, 116:10-16, 2015.

[61] X. Zhu, E. Phillips, V. Spandan, J. Donners, G. Ruetsch, J. Romero, R. Ostilla-Mónico, Y. Yang, D. Lohse, R. Verzicco, M. Fatica, and R. A. J. M. Stevens. AFiD-GPU: a versatile Navier-Stokes solver for wall-bounded turbulent flows on GPU clusters. arXiv:1705.01423, 2017.

[62] E. Alméras, V. Mathai, D. Lohse, and C. Sun. Experimental investigation of the turbulence induced by a bubble swarm rising within incident turbulence. $J$. Fluid Mech., 825:1091-1112, 2017.

[63] E. Alméras. Étude des propriétés de transport et de mélange dans les écoulements à bulles. PhD thesis, Université de Toulouse, 2014.

[64] A. Belmonte, A. Tilgner, and A. Libchaber. Temperature and velocity boundary layers in turbulent convection. Phys. Rev. E, 50(1):269, 1994. 
[65] E. Alméras, F. Risso, V. Roig, S. Cazin, C. Plais, and F. Augier. Mixing by bubble-induced turbulence. J. Fluid Mech., 776:458-474, 2015.

[66] A. Loisy. Direct numerical simulation of bubbly flows: coupling with scalar transport and turbulence. $\mathrm{PhD}$ thesis, Université de Lyon, 2016.

[67] J. W. Elder. Turbulent free convection in a vertical slot. J. Fluid Mech., 23(1):99-111, 1965.

[68] N. C. Markatos and K. A. Pericleous. Laminar and turbulent natural convection in an enclosed cavity. Int. J. Heat Mass Transfer, 27(5):755-772, 1984.

[69] S. Kimura and A. Bejan. The boundary layer natural convection regime in a rectangular cavity with uniform heat flux from the side. J. Heat Transfer, 106(1):98-103, 1984.

[70] O. Shishkina and S. Horn. Thermal convection in inclined cylindrical containers. J. Fluid Mech., 790:R3, 2016.

[71] E. Bouche, S. Cazin, V. Roig, and F. Risso. Mixing in a swarm of bubbles rising in a confined cell measured by mean of PLIF with two different dyes. Exp. Fluids, 54(6):1552, 2013.

[72] B. Castaing, G. Gunaratne, F. Heslot, L. Kadanoff, A. Libchaber, S. Thomae, X.-Z. Wu, S. Zaleski, and G. Zanetti. Scaling of hard thermal turbulence in Rayleigh-Bénard convection. J. Fluid Mech., 204:1-30, 1989.

[73] M. Lance and J. Bataille. Turbulence in the liquid phase of a uniform bubbly air-water flow. J. Fluid Mech., 222:95-118, 1991.

[74] E. Alméras, C. Plais, V. Roig, F. Risso, and F. Augier. Mixing mechanisms in a low-sheared inhomogeneous bubble column. Chem. Eng. Sci., 186:52-61, 2018.

[75] E. Alméras, C. Plais, F. Euzenat, F. Risso, V. Roig, and F. Augier. Scalar mixing in bubbly flows: Experimental investigation and diffusivity modelling. Chem. Eng. Sci., 140:114-122, 2016.

[76] V. Roig, C. Suzanne, and L Masbernat. Experimental investigation of a turbulent bubbly mixing layer. Int. J. Multiphase Flow, 24(1):35-54, 1998.

[77] A. Cartellier. Optical probes for local void fraction measurements: characterization of performance. Rev. Sci. Instr., 61(2):874-886, 1990.

[78] D. Colombet, D. Legendre, F. Risso, A. Cockx, and P. Guiraud. Dynamics and mass transfer of rising bubbles in a homogenous swarm at large gas volume fraction. J. Fluid Mech., 763:254-285, 2015.

[79] R. F. Mudde, J. S. Groen, and H. E. A. Van Den Akker. Liquid velocity field in a bubble column: LDA experiments. Chem. Eng. Sci., 52(21-22):4217-4224, 1997. 
[80] J. S. Groen, R. F. Mudde, and H. E. A. Van Den Akker. On the application of LDA to bubbly flow in the wobbling regime. Exp. Fluids, 27(5):435-449, 1999.

[81] C. Vial, R. Laine, S. Poncin, N. Midoux, and G. Wild. Influence of gas distribution and regime transitions on liquid velocity and turbulence in a 3-D bubble column. Chem. Eng. Sci., 56(3):1085-1093, 2001.

[82] B. Gvozdić, E. Alméras, V. Mathai, X. Zhu, D. PM van Gils, R. Verzicco, S. G Huisman, C. Sun, and D. Lohse. Experimental investigation of heat transport in homogeneous bubbly flow. J. Fluid Mech., 845:226-244, 2018.

[83] H. Ayed, J. Chahed, and V. Roig. Hydrodynamics and mass transfer in a turbulent buoyant bubbly shear layer. AIChE journal, 53(11):2742-2753, 2007.

[84] B. Gvozdić, O.-Y. Dung, E. Alméras, D. PM van Gils, D. Lohse, S. G Huisman, and C. Sun. Experimental investigation of heat transport in inhomogeneous bubbly flow. Chem. Eng. Sci., 2018.

[85] A. Kitagawa, K. Kimura, and Y. Hagiwara. Experimental investigation of water laminar mixed-convection flow with sub-millimeter bubbles in a vertical channel. Exp. Fluids, 48(3):509-519, 2010.

[86] P. T. Nguyen, M. .A Hampton, A. V. Nguyen, and G. R. Birkett. The influence of gas velocity, salt type and concentration on transition concentration for bubble coalescence inhibition and gas holdup. Chem. Eng. Research Design, 90(1):33-39, 2012.

[87] R.E.G Poorte and A. Biesheuvel. Experiments on the motion of gas bubbles in turbulence generated by an active grid. J. Fluid Mech., 461:127, 2002.

[88] D. P. M. van Gils, University of Twente. Python library for (multithreaded) communication with laboratory instruments. https://github. com/Dennis-van-Gils, 2018.

[89] R.E.G. Poorte. On the motion of bubbles in active grid generated turbulent flows. $\mathrm{PhD}$ thesis, 91998. 


\section{Samenvatting}

Het is gebleken dat het injecteren van bubbels in convectiestromingen een goede methode is om warmteoverdracht te verbeteren. Om de achterliggende fysica te begrijpen waarom het toevoegen van bubbels de warmteoverdracht verbetert, bekijken we in deze thesis de globale en lokale statistieken als we bubbels injecteren in een verticale vrije convectiestroom. Daarnaast hebben we een nieuwe experimentele faciliteit ontworpen en gebouwd, de Twente Mass and Heat Transfer Water Tunnel, waarmee we controle hebben over de temperatuur van het gehele systeem, over het injecteren van de bubbels en over de lokale injectie van warmte/massa. Deze opstelling zal gebruikt worden voor het bestuderen van warmte- en massaoverdracht in turbulente meer-fasestromingen.

In $\S 2$ beschrijven we experimenten gedaan in een rechthoekige bubbel-kolom die wordt verwarmd aan de ene kant en gekoeld aan de andere kant met een homogene injectie van bubbels vanaf de onderkant. Onafhankelijk van elkaar beïnvloeden we het getal van Rayleigh en de volumefractie van gas en bestuderen we de invloed op de totale warmteoverdracht. De volumefractie van gas varieert van $0 \%$ tot $5 \%$, waarbij de bubbeldiameters rond de $2.5 \mathrm{~mm}$ zijn. Het getal van Rayleigh reikt van $4.0 \times 10^{9}-1.2 \times 10^{11}$. We zien dat twee totaal verschillende mechanismen de warmteoverdracht bepalen bij stromingen met en zonder bubbels. In het geval zonder bubbels is de verticale vrije convectie alleen gedreven door het verschil in temperatuur tussen de twee muren. In dit geval is de temperatuur de actieve scalaire die de stroom drijft. Het getal van Nusselt, dat de totale warmteoverdracht kwantificeert, neemt toe met toenemend getal van Rayleigh, en zoals verwacht schaalt het effectief met: $\overline{N u} \sim R a_{H}^{0.33}$. Daarentegen zijn er in het geval met een homogene stroom bubbels twee verschillende contributies voor de warmteoverdracht: vrije convectie gedreven door de horizontale temperatuurverschillen en diffusie door de aanwezigheid van de bubbels, waarbij het laatste dominant is. Dit onderbouwt onze observaties dat het getal van Nusselt in een stroming met bubbels bijna onafhankelijk is van het getal van Rayleigh en alleen afhankelijk is van de volumefractie van gas, schalend als $\overline{N u} \propto \alpha^{0.45}$. We vinden dus bijna dezelfde schaling als in het geval van het mengen van passieve tracers in een homogene stroom van bubbels met een lage volumefractie van gas [65], wat impliceert dat het mengen veroorzaakt door de bubbels 
inderdaad is wat het rendement van warmteoverdracht limiteert. In stromingen zonder bubbels is de gemiddelde temperatuur in het midden van de vloeistofkolom halverwege de hoogte constant, wat belemmerd wordt door het mengen dankzij de bubbels in stromingen met bubbels. Het injecteren van bubbels veroorzaakt tot wel 200 keer sterkere fluctuaties in temperatuur. Deze fluctuaties komen voor over een breed frequentiespectrum en zijn daarom kenmerkend voor de verbetering in warmteoverdracht dankzij het injecteren van bubbels. Een duidelijke trend was van -1.4 was ook zichtbaar rond $f \simeq 0.1 \mathrm{~Hz}-3 \mathrm{~Hz}$.

In $\S 3$ bestuderen we het effect van een inhomogene injectie van bubbels op de warmteoverdracht. De experimenten zijn gedaan op dezelfde opstelling als in §2, waarbij de millimeter grote bubbels worden geïnjecteerd door de helft van de spuiten bij de warme muur of de helft bij de koude muur. Twee parameters worden gevarieerd: de volumefractie van gas (van $0.4 \%$ tot $5.1 \%$ ) en het getal van Rayleigh (van $4 \times 10^{9}$ tot $\left.2.2 \times 10^{10}\right)$. Door het karakteriseren van de totale warmteoverdracht vinden we dat in het geval dat de bubbels maar door de helft van de spuiten wordt geïnjecteerd, net als bij homogene injectie, het getal van Nusselt bijna onafhankelijk is van het getal van Rayleigh en het toeneemt met toenemend volumefractie van gas. De toename van de warmteoverdracht is niettemin groter bij een inhomogene injectie van bubbels dan bij dezelfde volumefractie van gas en hetzelfde bereik van $R a_{H}$ bij een homogene injectie, gegeven dat $\alpha<4 \%$. Deze vondst kan worden uitgelegd door de verschillende mechanismen van mengen aanwezig in het systeem zodra er een gradiënt van volumefractie van gas is. Er is namelijk naast de turbulentie gedreven door de bubbels (BIT) een rotatie van vloeistof op grotere schaal, veroorzaakt door de inhomogene injectie van bubbels, die lijdt tot een schuiflaag tussen de regio met bubbels en de andere kant. De combinatie van verschillende mengmechanismen leidt tot een verbeterde menging, die resulteert in wel 1.5 keer beter warmtetransport vergeleken met de homogeen geïnjecteerde bubbels. Als $\alpha>4 \%$, dan geeft de inhomogene injectie slechter warmtetransport dan bij homogene injectie. We kunnen zien dat bij een hogere volumefractie van gas de stroom van bubbels instabieler is en de bijdrage van de schuiflaag gedreven turbulentie (SIT) groter is. De gemeten snelheden laten zien dat ook de rotatie op grote schaal sterker wordt als alpha groter wordt (zie Figuur 3.9). Dus de competitie tussen BIT, SIT en de advectie verlagen de toename in warmtetransport.

Ondanks dat de metingen van de snelheid in het middendeel vergelijkbare profielen hebben voor zowel injecties bij de warme als koude muur, vinden we dat de toename van de totale warmteoverdracht met injectie bij de warme muur beter is onder de kritische waarde van $1.4 \%$ voor de volumefractie van gas. Als $\alpha \geq 1.4 \%$ zien we een 
regio met veel bubbels bij de muur waar de bubbels niet geïnjecteerd zijn, waardoor er effectiever gemengd wordt bij de thermische grenslaag bij de muur. Het gevolg hiervan is dat het verschil in warmtetransport tussen injectie van bubbels bij de warme en koude muur verdwijnt als $\alpha \geq 1.4 \%$. Als $\alpha<1.4 \%$ dan zijn er geen bubbels bij de muur waar geen bubbels worden geïnjecteerd, wat betekent dat met deze alpha de meestroom van de vloeistof van de warme muur naar de koude muur bijdraagt aan de rotatie op grote schaal en de verbetering van het warmtetransport.

In $\S 2$ en $\S 3$ is het bereik van de bestudeerde $R a_{H}$ beperkt door het verwarmingsvermogen. In het bestudeerde bereik van $R a_{H}$ droeg het mengen door bubbels veel meer bij aan de totale warmteoverdracht dan vrije convectie. Numerieke simulaties van zo'n systeem kunnen veel toevoegen aan experimentele metingen en het onderscheiden van de verschillende invloeden van het injecteren van bubbels op de totale warmteoverdracht. In de experimenten gepresenteerd in $\S 2$ en $\S 3$ was de hoogste volumefractie van gas $5 \%$. Echter, de volumefractie van gas in veel industriële processen is maar liefst 30\%. Experimentele technieken voor het meten van de lokale hoeveelheden in zulke omstandigheden moeten ontwikkeld worden.

Om warmte- en massaoverdracht nauwkeurig te kunnen besturen in turbulente meer-fasestromingen hebben we een unieke experimentele opstelling gebouwd, de Twente Mass and Heat Transfer Water Tunnel, gepresenteerd in $\S 4$. De nieuwe verticale watertunnel heeft controle over de temperatuur van het hele systeem, het injecteren van bubbels en lokale injectie van warmte/ massa. Het totale volume van de tunnel is 300 liter. Drie vervangbare meetsecties van $1 \mathrm{~m}$ hoog, maar met andere afmetingen $\left(0.3 \times 0.04 \mathrm{~m}^{2}, 0.3 \times 0.06 \mathrm{~m}^{2}, 0.3 \times 0.08 \mathrm{~m}^{2}\right)$, waarmee het bereik in het getal van Reynolds van $1.5 \times 10^{4}$ tot $3 \times 10^{5}$ is, in het geval van water op kamertemperatuur. De glazen verticale meetsecties geven optisch toegang tot de stroming, waardoor technieken zoals laser Doppler anemometry, particly image velocimetry, particle tracking velocimetry en laser-induced fluorescent imaging mogelijk zijn. Thermistors gemonteerd op een ingebouwde traverse meten de lokale temperatuur met een paar milli-Kelvin nauwkeurig. In combinatie met lokaal gemeten snelheden op hetzelfde moment kan de lokale warmtestroom bestudeerd worden, zowel met als zonder bubbels in turbulente stromingen. Een groot onbekend onderzoeksgebied is fundamentele kennis over warmtetransport in stromingen met bubbels en zout. Warmtetransport in zoutoplossingen (zoals pekel) is zeer relevant voor bepaalde industriële toepassingen zoals chloraat processen, warmtewisselaars enzovoort. Hiermee rekening houdend is de tunnel met hoogwaardig roestvrij staal gemaakt, waarmee er metingen gedaan kunnen worden aan warmtetransport met zoutoplossingen met massafracties van boven de $15 \%$. Toekomstige onderzoeken met deze opstelling zullen zich richten op 
het begrijpen hoe warmteoverdracht afhangt van parameters zoals de volumefractie van gas, bubbelgrootte, het getal van Taylor-Reynolds en de zoutconcentratie. Door de verdeling van lokale warmtestromingen te kwantificeren door het injecteren van bubbels, zullen we meer inzicht krijgen in fundamentele werkingen van warmtetransport in stromingen met bubbels in het bijzijn van rooster gegenereerde turbulentie. 


\section{Acknowledgments}

Physics of Fluids Group is unique. I doubt that anywhere else in the world one can find so many bright, open and helpful people at a single place. I have spent a great deal of my time in the lab, which was always so enjoyable in labs so well equipped, smartly designed and governed. I cherish my time spent in PoF as very valuable, I have gained experience that will benefit me greatly in the future. Detlef, thank you for providing me the opportunity to work in such a unique environment that $\mathrm{PoF}$ is. I admire your ability to handle many different projects at once, while being critical and helpful in giving research directions. Chao, thank you for your patience and guidance over the course of my Ph.D. While discussing ideas and results, and working on papers with you I learnt a great deal. Sander, you have been my daily supervisor in the final part of my Ph.D. I enjoyed discussing all the issues I encountered in my work with you. I admire your eye for details.

The results presented in this thesis would not have been possible if there was not support and collaboration of many other people. I use this opportunity to thank all of them, with a hope not to forget anyone.

One of the first people to welcome me in PoF was Varghese. Varghese, thank you for your help with starting up the project, all the discussions, your guidance in the lab at the start of my Ph.D, and in general for your support.

Elise, firstly, thank you for teaching me a lot about experimental techniques and in general about bubbly flows. Secondly, after every discussion with you I felt inspired to battle with problems that arise. Working with you in the lab was always so easy and fun. Your encouragement always made me go through a tough day. I love working with you and having you as a friend.

Peter, you joined the TWT lab crew in second half of my Ph.D. It was really nice to work with you, I could always count on you which I appreciate a lot. I wish you all the best for the continuation of your $\mathrm{Ph} . \mathrm{D}$ and your academic career.

All the experimental turbulence guys, Sander, Roeland, Ruben, Rodrigo, Dennis B., Pim, Jelle, thanks for all the help with the experiments.

Maintaining experimental setups would be impossible without the crucial contribution of PoF's amazing technicians. Gert-Wim, Martin, Bas and Dennis van Gils, thank you for all the help with building and maintaining the experimental setups. 
Gert-Wim, your passion towards your work is truly admirable. I appreciate all the great effort you put into the design of the new water tunnel. Martin, thank you for giving a hand in the lab whenever it was needed. Bas, thanks for all the computer and electronics related help. Dennis, I learned a great deal from you. Starting from how to control an experimental setup using Python to how to build a setup and how to keep the lab a safe place to work. I am very grateful for all the hard work you put into the design and control of the new water tunnel.

Keeping PoF organised and operating is possible because of Joanita. Joanita, thanks for all the help with various administrative task. I appreciate your efficiency.

I am grateful to all the PoF people for all the fun time spent outside of Meander too. Lunches, dinners, drinks, outings, conferences, travels, all kinds of activities brought good mood to me at all times. Thank you all for that, you are keeping PoF a happy loving nerdy community! Keep it up!

Climbing crew, Adeline, Remi, Paul, Maxime, Dennis, Rodrigo, Carola, Ricardo, Corentin, Jessica, Maaike and all the folks that occasionally joined in the Cube, thanks for all the fun! My 'Frenchies', Elise, Paul, Adeline, Remi, Maxime, Anais, I would never be able to speak 'fluent franglish' without you. I loved spending time with all of you, it made my days in Enschede memorable. Thank you for introducing me to good tea, French cuisine, French wine, board games, slacklining and most importantly climbing.

Ivan(e), I always enjoyed our chats. Thanks for tuning down your accent so I can easily follow what you are saying. I am so happy I had you to support my enthusiasm for karting. Bojane, Nina, Nevene and Jovana, you are my Serbia in the Netherlands, thanks for all your support and understanding. Poorvi, our discussions always leave me with new things to think about. Thanks for inspiring me to better myself. Shantanu, Ruben and Arjan, I enjoyed sharing our ME212 cubicle with you. Diana, I enjoy our chats whenever you visit Enschede. I am sure that the two last years of Ph.D you will spend here will be a happy time. Loreto and Leo, thanks for all the great time, thanks for all the fun and all the dinners. I was also always happy to spend time with Pelu and Blanca, they are amazing dogs. Roi and Dennis B., you guys were around from the beginning. It was simply nice travelling, chilling and chatting with you. Thanks for being there. Mazi, I will always be happy to make your small choices for you. Carola, words fail to describe my gratitude for having you in my life. Thank you for your unselfish care. Vamsi, thanks for being a great support to me in the last four years. Having you next to me all this time made my each day complete. 
Lastly, I thank all my family and friends in Serbia for their support at all times. Ujo, Ujna, Rade, Milane, Baba thanks for just being there. Thanks to my parents, Mika and Miloš, for their unconditional love, and to my sisters Marijana and Gorica and to Gorica's family, for always being there for me. 
